\title{
III. Personal und Organisation
}

\section{Erweiterung des Führungspersonals: Kader aus Antifa-Lagern und Parteischulen}

Von Anfang an waren Führungskader in der DBD äußerst knapp. Die SED zeigte sich während und nach der Gründung der DBD kaum bereit, qualifiziertes Personal abzugeben. Bereitwillig verzichtete sie nur auf jene, die in ihren Augen minder qualifiziert erschienen. Viele DBD-Funktionäre sahen sich einem generellen Dünkel der Genossen ausgesetzt, die ihre Bündnispartner nicht besonders hoch schätzten. Doch sollte der Aufbau eines neuen Verbündeten der SED gelingen, so mußten die Engpässe besonders in den Führungsebenen der DBD beseitigt werden. Bei der Suche nach geeigneten Kandidaten trat die DBD in Konkurrenz zur SED; denn Kader, die man als zuverlässig einschätzte, die politisch erfahren und organisatorisch begabt waren sowie die erforderliche landwirtschaftliche Fachkompetenz mitbrachten, gehörten nicht zur Stammitgliedschaft der KPD. Dieser Funktionärstyp war auch in der SED sehr gefragt ${ }^{1}$. Nur so durfte sie hoffen, ihre agrarpolitischen Konzepte - sofern es denn welche waren - durchzusetzen und den anhaltenden Einfluß traditionell-bürgerlicher Fachleute etwa in der DWK, in landwirtschaftlichen Forschungsinstitutionen oder im landwirtschaftlichen Fachschulwesen zurückzudrängen und entsprechende „Säuberungen“ personell aufzufangen.

In der DBD wie anderswo sind zumindest zwei Typen von Antifa-Absolventen aus sowjetischer Kriegsgefangenschaft zu unterscheiden: diejenigen, die eine Schule minderer Bedeutung häufig in kurzer Zeit durchlaufen hatten und deren politische Zuverlässigkeit und Einsetzbarkeit sich daher für die SED kaum erhöhte, und diejenigen, die tatsächlich eine systematische Kaderschulung erhalten hatten. Am meisten versprachen sich insbesondere sowjetische Stellen von jenen, die selbst als Aktivleiter und Lehrer jahrelang in Antifa-Lagern gewirkt hatten, teils nach ihrer offiziellen Entlassung aus der Kriegsgefangenschaft freiwillig in der Sowjetunion geblieben waren. Die Antifa-Schulen bereiteten nicht zielgerichtet auf eine Verwendung in Deutschland vor ${ }^{2}$. In exakten Zahlen läßt sich der zuerst angesprochene Personenkreis nicht fassen. Begründeten Schätzungen zufolge kamen ca. 12000 Antifa-geschulte deutsche Kriegsgefangene nach 1945 in das Gebiet der SBZ bzw. der DDR ${ }^{3}$. Wie verhielt sich die SED zu diesen potentiellen Kadern? Der Einsatz von Antifa-Schülern unterschied sich 1948 entsprechend der geänderten politischen Lage sichtlich von der Praxis 1945. In der unmittelbaren

SAPMO NY 4036/745, Bl. 115-126, Brief an ZK der KPdSU, Gen. Suslow, 29. 10. 1948.

2 Morré, Kulissen, S. 197.

3 Foitzik, „Säuberungen“, S. 414 f. Weitere Zahlen bei Foitzik, Struktur, S. 196; lt. Morré, Kulissen, S. 198, wurden 1942-46 3800 Deutsche unter der Leitung des Instituts 99 geschult, 1945/46 nur knapp 300. 
Nachkriegszeit verstärkten besonders bewährte und langjährig geschulte Kommunisten, die in die Besatzungszone kamen, den kommunistischen Einfluß in Schlüsselpositionen der Verwaltung, Wirtschaft und Politik ${ }^{4} .1946$ profitierte der Sicherheitsapparat der SMAD von den Repatriierten, während SED und Propagandaverwaltung der SMAD vergeblich um Kader nachsuchten ${ }^{5} .1948$ wurde die weitere Stalinisierung der SED durch ideologische Kontrolle und organisatorische Straffung vorangetrieben. In dieses Konzept fügten sich für die SED solche Antifa-Schüler, deren politische Haltung noch nicht erwiesen war, nicht reibungslos ein. Die Skepsis gegenüber Personen ohne "antifaschistische" Vergangenheit war hoch. Daher versuchte man schon bei der Ankunft der Kriegsheimkehrer im Durchgangslager Frankfurt/Oder, die Spreu vom Weizen zu trennen; die Personalpolitische Abteilung des Zentralsekretariates erfaßte nur ehemalige Antifaschisten systematisch. Das Zentralsekretariat hielt eine Betreuung durch die Kreisvorstände für unzweckmäßig, da deren personalpolitische Abteilungen zu dieser Zeit dazu nicht in der Lage waren. Sowjetische Stellen hätten ein solches Vorgehen bevorzugt, wie es nachweislich ab 1950 praktiziert wurde ${ }^{6}$, hielten 1948 aber personenbezogene Informationen aus der Lagerzeit zurück. Ende 1948 belief sich die Zahl der so registrierten ehemaligen „Aktivisten“ auf ca. 2300. Die Lücke in der Kaderbiographie erschwerte den Einsatz in zentralen Funktionen ${ }^{7}$.

Die Mechanismen der Einweisung von Antifa-Schülern in die jeweiligen Aufgabenbereiche zeigen, daß sowohl die DBD als Partei wie der Bereich Landwirtschaft nur nachrangig berücksichtigt wurden. Sicherlich hätten zu viele, meist ortsfremde Antifa-Schüler in einer Partei, die in den Dörfern erst um Anerkennung ringen mußte, kein Vertrauen bei der potentiellen Mitgliederschaft erweckt. In den Ländern Mecklenburg und Sachsen fällt auf, daß Antifa-Absolventen vorrangig in industrielle und gewerbliche Tätigkeiten delegiert, landwirtschaftliche Einsatzorte hingegen vernachlässigt wurden. Falls jemand durch seine familiäre Herkunft oder berufliches Wissen für eine Verwendung in der Landwirtschaft in Frage kam, so schickte man ihn vorzugsweise in MAS oder Organisationen der VdgB, denn um deren Funktionstüchtigkeit stand es nicht zum Besten. Viele Heimkehrer verstärkten die 1948 im Ausbau befindliche Volkspolizei ${ }^{8}$.

4 Vgl. Keiderling (Hg.), "Gruppe Ulbricht“. Zum Spannungsverhältnis zwischen AntifaKadern und in Deutschland Verbliebenen siehe Erler, Moskau-Kader, S. $257 \mathrm{ff}$.

5 Morré, Kulissen, S. 188-190.

6 Vgl. die Berichte sächsischer Kreisleitungen, SStAD BPA SED LL A/1605a, LV SED Kaderabteilung-Parteifunktionäre, Auszüge aus Berichten der Kreise über Antifa-Schüler aus Lagern 2040, 2041 und 9999, 6. 1. 1950.

7 SAPMO NY 4036/745, Bl. 115-126, Brief an ZK der KPdSU, Gen. Suslow, 29. 10. 1948. Demnach erfüllten die Kader nicht die in sie gesetzten Erwartungen. Das Schreiben zielte darauf ab, die Beurteilungen der Geschulten aus ihrer Lagerzeit von sowjetischen Stellen zu erhalten. Diese wurden der SED auch später vorenthalten, wie verschiedentlich aus MfS-Akten hervorgeht; sowjetische Stellen beantworteten jedoch Nachfragen, wie z.B. im Fall Schnitzler, BStU MfS AP 6122/63, Hans Paul von Schnitzler, Bl. 25-28, HA V/3 Bericht 26. 9. 1958.

8 Foitzik, Struktur, S. 196. SStAD BPA SED LL A/1605a, Liste: Antifalager 2040, Juli 1949, nur eine Person - Sohn eines Einzelbauern - mit Perspektive DBD angeführt. MLHA BPA Schwerin IV2/5/156, Bl. 12, Schreiben Abt. Personalpolitik des ZS an SED LV, 7. 4. 1948. 
Nur wenige waren für die DBD vorgesehen. Diese erlangten dort jedoch häufig die wichtigeren Positionen. 1950 hatten mindestens 22 Antifa-Zentralschulabsolventen leitende Funktionen in der DBD inne9. Allein drei 1948 entlassene Heimkehrer besetzten Sekretariatsposten im mecklenburgischen Landesverband: Heinz Heinrich, Karl Grambow und Hans Olbrich. Weiter waren unter den Mecklenburger Funktionären auch Erich Schiborr, Georg Böhm und Fritz Krtschil Antifa-Schüler ${ }^{10}$. Offensichtlich begünstigte das besonders enge Verhältnis zur SMA Mecklenburg bei der Parteigründung den Einbau auffällig vieler Antifa-Leute. Auch in den anderen Landessekretariaten trifft man sie an, so Helmut Merke, Wilhelm Schröder und Edgar Strümpfel11. Antifa-Schüler nahmen häufig solche Positionen ein, die ideologisches Vorwissen erforderten und auf denen sie solches auch vermitteln sollten, wie z.B. in den Parteischulen (Hans Rietz, Georg Böhm, Alois Melz) und in den Abteilungen Schulung und Werbung (Karl Grambow). Insgesamt galten in den Augen der sowjetischen Kommandanturen, die bei Personalfragen anfangs erheblich mitbestimmten, die Männer aus der Antifa grundsätzlich als verläßliche Kader, in deren Wirken man große Hoffnungen setzte. Die für den erfolgreichen Parteiaufbau so wichtigen Kreissekretariate führten entweder langjährige KPD-Mitglieder oder Antifa-Kader. Letzteren vertraute man ebenso wie KPD-Veteranen, in jedem Fall zog man sie ehemaligen Sozialdemokraten oder Mitgliedern ohne einschlägige Vergangenheit vor.

Im folgenden sollen jene DBD-Führungsfunktionäre herausgegriffen werden, die überwiegend selbst als Lehrer in Antifa-Schulen deutsche Kriegsgefangene unterrichtet, in jedem Fall aber eine längere Schulung absolviert hatten. Dies trennte sie deutlich von jenen Mitgliedern der Parteispitze, die zwar altgediente Genossen waren, deren ideologisches Wissen sich aber nicht auf dem von Moskau vorgegebenen neuesten Stand bewegte und die nicht jede taktische Wendung unmittelbar nachvollzogen.

Zu den Antifa-Absolventen in Spitzenfunktionen gehörten u.a. Berthold Rose, Hans von Schnitzler, Hans Rietz, Hans Reichelt und Erwin Körber. Manche Antifa-Schüler in der DBD waren sich schon während der Lagerzeit begegnet. Acht

MLHA BPA Schwerin IV2/5/156, Bl. 15, Schreiben ZK Abt. Justiz an Abt. Justiz des SED LV, 21. 4. 1948. Zur Verteilung auf die Einsatzorte siehe MLHA BPA Schwerin IV/L/2/5/ 172, Listen der Antifa-Schüler zentral und kreismäßig, und ihr Einsatz 1947-1952.

9 Wernet-Tietz, Bauernverband, S. 123; Robel, Kriegsgefangene, S. 308.

10 MLHA BPA Schwerin IV/L/2/5/172, Listen der Antifa-Schüler; in Neubrandenburg war Erich Schiborr Kreissekretär der DBD (Bl. 168), in Parchim Otto Filter (Bl. 170), im Kreis Schwerin wurde Karl Grambow, der im Dez. 1948 aus der SU gekommen war, nach SEDMitgliedschaft als Landessekretär für die Abt. Schulung und Werbung der DBD eingesetzt (Bl. 215); Böhm (Aufstellung der Zentral-Antifa-Schüler des Kreises Rostock, Bl. 261), kehrte im Dez. 1949 aus der SU zurück, trat am 20.1.1950 in die SED und danach in die DBD ein. Böhm (*26.3. 1923) kam ursprünglich aus der ČSR, war Sohn eines Arztes, Oberschüler und gelernter Bauer. Mit 19 Jahren war er der NSDAP beigetreten. Er leitete ab 1951 die Parteischule in Bad Kleinen und war von 1955-1960 Hauptabteilungsleiter für Schulung und Aufklärung beim PV. Als solcher gehörte er dem Sekretariat an. Bis 1972 wirkte er in den Bezirken Neubrandenburg, Magdeburg und Halle; Barth u.a. (Hg.), DDR, S. 260, Buch, Namen (1973), S. 26.

11 Weitere Namen bei Reichelt, Blockflöte, S. 34. 
von 75 Mitgliedern des Parteivorstandes von 1960 wurden als ehemalige AntifaSchüler des sowjetischen Zentrallagers 2040 geführt $^{12}$. Berthold Rose und Hans von Schnitzler kannten sich aus dem Militärdienst und waren seit ihrer sowjetischen Kriegsgefangenschaft eng befreundet ${ }^{13}$.

Berthold Rose ${ }^{14}$ wurde Generalsekretär der DBD bis 1960. 1904 in Berlin als Sohn eines Postboten geboren, absolvierte er nach der Volksschule zwei Semester lang eine landwirtschaftliche Ausbildung an einer Lehranstalt und war bis 1924 Lehrling. Von 1925 bis 1940 ging er wechselnden Tätigkeiten in Berlin als Wirtschaftsgehilfe, Arbeiter, Angestellter und auch als Postbote nach. Er war also nicht entsprechend seiner Ausbildung im landwirtschaftlichen Umfeld berufstätig geworden. Offenbar gehörte Rose vor 1933 keiner Partei an, belegt ist lediglich eine Funktionärstätigkeit in der syndikalistischen „Freien Vereinigung Deutscher Gewerkschaften " ab 1925 und in der RGO im Berliner Wedding. Nach seiner Gefangennahme 1945 verbrachte er zwei Jahre an der Zentralschule 2041, davon ein Jahr freiwillig als Schulassistent. Wie Schnitzler geriet offenbar auch er während seiner Antifa-Zeit in politische Bedrängnis. Ihm drohte der Ausschluß aus dem AntifaAktiv ${ }^{15}$.

Nach seiner Entlassung aus der Kriegsgefangenschaft wurde Rose in Berlin ein einwandfreies theoretisches Wissen, ausgeprägtes Selbstbewußtsein und ein untadeliger Lebenswandel attestiert ${ }^{16}$. In den Zentrallagern 2040 und 2041 hatte er die Bekanntschaft späterer Funktionäre der SED gemacht, wie er bei Gesprächen mit ZK-Abteilungen einfließen ließ. Auch Lothar Bolz, den späteren Vorsitzenden der NDPD, kannte er seither; dieser Umstand stiftete ein gutes Verhältnis zwischen den beiden ${ }^{17}$. Am 1. Februar 1949 trat er in die DBD ein, leitete die Abteilung Schulung und Werbung und gehörte dem Sekretariat des Parteivorstandes an. Offensichtlich hatte man es jedoch versäumt, Gerüchte auszuräumen, die an seiner politischen Zuverlässigkeit Zweifel anmeldeten. Vor dem Hintergrund seines rasanten Aufstiegs und wachsender Rivalitäten innerhalb des Sekretariates fiel der Verdacht einer angeblichen SA-Mitgliedschaft jedenfalls auf fruchtbaren Boden ${ }^{18}$.

12 Neben den oben genannten Rose, Schnitzler, Rietz, Reichelt und Körber auch Leonhard Helmschrott, Heinz Heinrich und Alois Melz, der langjährige Leiter der Zentralen Parteischule der DBD „Thomas Müntzer“ in Borkheide; ACDP VI-052-0017, Mitglieder des PV 1960, vorbereitende Aufstellung zum VI. PT 1960.

13 BStU MfS AP 661/92, Goldenbaum, Bl. 42f., Bericht über Treffen mit IM „Bernd“ (=Helmschrott), 19.2. 1958; dagegen herrschte zwischen dem stellvertretenden Chefredakteur des „Bauern-Echo“ Huster, und Rose, die sich ebenfalls aus der Kriegsgefangenschaft kannten, eine tiefe Abneigung. Vgl. SAPMO DY 30 IV 2/15/53, Bericht AG BO über Arbeitsweise im Apparat des PV der DBD, 12. 9. 1955.

14 Nachfolgende biographische Angaben aus BStU MfS AIM 1363/53, Personalakte Rose, Bl. 6-10, Abschrift Personalfragebogen, 21.8. 1950, Charakteristik und Personenbeschreibung [1950].

15 BStU MfS AP 661/92, Goldenbaum, Bl. 62-72, HA V/3 Bericht eines Informators über Vorkommnisse innerhalb des PV der DBD, 24. 11. 1958, hier Bl. 62-64; Barth u.a. (Hg.), DDR, S. 1652.

16 BStU MfS AIM 1363/53, Personalakte Rose, Bl. 8, Charakteristik [1950].

17 SAPMO DY 30 IV 2/15/53, Bericht AG BO über Arbeitsweise im Apparat des PV der DBD, 12.9. 1955.

18 BStU MfS AP 661/92, Goldenbaum, Bl. 62-72, HA V/3 Bericht eines Informators über 
Altgediente KPD-Genossen ohne Antifa-Schulung, namentlich Goldenbaum und Scholz, rückten gegen Rose, der zwar Antifa-Lehrer, aber KPD-Neuling ohne Stallgeruch war, zusammen ${ }^{19}$.

1951 wurde er Generalsekretär und kam damit auf jenen Posten, den bislang Paul Scholz als Hauptgeschäftsführer innegehabt hatte. Nach einem heftigen Streit im inneren Parteizirkel hatte man das Amt eines Generalsekretärs eingeführt ${ }^{20}$, nachdem Scholz im Herbst 1950 Goldenbaum als Landwirtschaftsminister der DDR nachgefolgt war. Rose war bis 1960 eine der profiliertesten Führungsfiguren der DBD. Er pflegte ein besonders enges Verhältnis zur SED, das auch darin Ausdruck fand, daß er sich von Oktober 1950, also in etwa zeitgleich mit seinem Aufstieg zum Generalsekretär, bis Oktober 1953 als Geheiminformator für die Staatssicherheit verpflichtete. Rose hielt engen Kontakt zur SKK ${ }^{21}$.

Auch Hans Paul von Schnitzler, geboren 1908, war während der Zeit seiner sowjetischen Gefangenschaft als Lehrer und Aktivleiter in verschiedenen Lagern beschäftigt ${ }^{22}$, nachdem er selbst eine Schulung durchlaufen hatte ${ }^{23}$. Unmittelbar nach seiner Entlassung als Brigadier in Frankfurt/Oder stieß er Mitte August 1949 zunächst als stellvertretender Chefredakteur des „Bauern-Echo“ zur DBD und gehörte 1949 dem Parteivorstand an. Auch seine spätere zweite Frau, Lieselotte Franke, eine landwirtschaftliche Hilfslehrerin, arbeitete in der Zeitungsredaktion $^{24}$.

Ab April 1950 war Schnitzler Sekretär des Sekretariats des Parteivorstandes. Von 1951 bis 1955 leitete er als Nachfolger von Rose die Hauptabteilung Schulung und Werbung bzw. Aufklärung. Danach vertrat er die DBD im Büro des Nationalrats der Nationalen Front ${ }^{25} .1963$ schied er aus dem Nationalrat aus, legte sein Volkskammermandat nieder und nahm eine Tätigkeit in der Akademie der Landwirtschaftswissenschaften auf ${ }^{26}$. Hans von Schnitzler stammte aus einer Kölner

Vorkommnisse innerhalb des PV der DBD, 24. 11. 1958, hier Bl. 62-64. Der Bericht enthält eine Episode, wonach Rose in Kontakt mit SA-Leuten versuchte, vom Kreisleiter der NSDAP zu erwirken, daß auch seine Frau arbeiten durfte. Rose wurde in der DBD verschiedentlich verdächtigt, sich während des Nationalsozialismus nicht immer „antifaschistisch" verhalten zu haben.

19 Vgl. die kryptischen Hinweise bei Reichelt, Blockflöte, S. 34.

20 ACDP VI, unverz. Handakten Rose, Protokoll Sekretariat, 29. 11. 1950; Beschluß dann im PV, ACDP VI-052-0144, Protokoll PV, 1. 2. 1951.

21 BStU MfS AIM 1363/53, Personalakte Rose.

22 Folgende biographische Angaben nach BStU MfS AP 6122/63, Schnitzler, Bl. 1-5, Lebenslauf 28. 8. 1950, Bl. 11, von Scholz verfaßte Charakteristik 19. 1. 1950 [Abschrift], Bl. 32-37, Lebenslauf undatiert [Abschrift]. ACDP VI-052-0017, vorbereitende Aufstellung für Besetzung PV nach dem PT von 1960.

23 Reichelt, Blockflöte, S. 34, allerdings ohne Beleg.

24 BStU MfS AP 6122/63, Schnitzler, Bl. 3, Lebenslauf, 28. 8. 1950, Bl. 15, Bericht 19. 11. 1951; ACDP VI-052-0143, z. B. Protokoll der PV-Sitzung, 11. 7. 1949.

25 BStU MfS AP 6122/63, Schnitzler, Bl. 18, Einschätzung durch Fritz Otto, Mitglied des Büro des Nationalrates, 18. 8. 1958.

26 Ebd., Bl. 58, Ablagevermerk der HA V/3 anläßlich des Ausscheidens aus dem Nationalrat der Nationalen Front. Lt. Protokoll des VII. PT 1963, S. 291, wurde er als Nachfolgekandidat für den PV gewählt. Zu diesem Zeitpunkt arbeitete er als wissenschaftlicher Redakteur beim Institut für landwirtschaftliche Information und Dokumentation Berlin. 
Patrizierfamilie, die um 1912 geadelt worden war $^{27}$. Hans und sein zehn Jahre jüngerer Bruder Karl Eduard, bekannt als Chefkommentator des DDR-Fernsehens und als solcher einer der düstersten Propagandaagitatoren der $\mathrm{DDR}^{28}$, brachen mit dieser Familientradition und schlossen sich in jungen Jahren sozialistischkommunistischen Kreisen an. Nach dem Abitur studierte Hans Schnitzler zwei Jahre bis 1928 in Bonn, danach in Göttingen Rechtswissenschaften und entsprach damit dem väterlichen Wunsch, der eine Beamtenlaufbahn vorsah. Über die Lektüre naturwissenschaftlicher Werke, besonders solcher über den biologischen Determinismus, fand er - Scholz zufolge - den Weg zu materialistischer Literatur ${ }^{29}$ und damit auch zum Kommunismus. Diese Lektüre und die „Abneigung gegen die eigene Klasse" führten 1931 noch vor dem Kontakt mit der Arbeiterbewegung zum Bruch mit der Familie ${ }^{30}$. Nach gescheitertem juristischen Referendarexamen begab er sich von 1930 bis 1932 als Lehrling zu einer internationalen Berliner Transportfirma. Ein Intermezzo als Inhaber der Firma „Filmspedition“, wozu ihm nach dem Tod des Vaters 1934 eine Erbschaft verholfen hatte, endete im Ruin. Ab 1937 arbeitete er wieder im kaufmännischen Metier ${ }^{31}$.

Unmittelbar nach seinem KPD-Beitritt 1932 wurde er in derem illegalen Nachrichtendienst eingesetzt. Im Oktober 1933 verhaftete ihn die Gestapo ${ }^{32}$. Der Umstand, daß er bald wieder freikam, machte seine Genossen stutzig. Sie vermuteten eine Intervention seines Onkels, der eine bedeutende Funktion bei den IG Farben Werken innehatte und später im Nürnberger IG Farben Prozeß verurteilt wurde ${ }^{33}$. Trotz Einsatzes für die kommunistische Sache und ständigem Bemühen, seine politische Überzeugung zu beweisen, verfolgte ihn nachweislich bis 1952 der Verdacht, aufgrund seiner großbürgerlichen Herkunft doch mit „kapitalistischen" und „kriegsverbrecherischen“ Kreisen Verbindungen zu pflegen ${ }^{34}$.

27 Schnitzlers Mutter lebte seinen Angaben von 1950 zufolge von einer Pension in Westdeutschland, wo sie für die Nationale Front arbeitete. BStU MfS AP 6122/63, Schnitzler, Bl. 32-37, Lebenslauf undatiert [Abschrift], hier Bl. 32. Vgl. Schnitzler, Schlösser, S. 17, 22.

28 Vgl. Karl Eduard von Schnitzlers autobiographische Ausführungen in ders., Schlösser.

29 BStU MfS AP 6122/63, Schnitzler, Bl. 11, von Scholz verfaßte Charakteristik 19. 1. 1950 [Abschrift].

30 Ebd., Bl. 32-37, Lebenslauf undatiert [Abschrift], hier Bl. 32f. Anders Schnitzler, Schlösser, S. 30, wonach Hans schon 5 Jahre vor Hitlers Machtübernahme für die Partei gearbeitet habe.

31 BStU MfS AP 6122/63, Schnitzler, Bl. 1-5, Lebenslauf 28. 8. 1950; ebd., Bl. 32-37, Lebenslauf undatiert [Abschrift].

32 Ebd., hier Bl. 33.

33 Ebd. Ebenso Schnitzler, Schlösser, S. $62 \mathrm{f}$.

34 BStU MfS AP 6122/63, Schnitzler, Bl. 13, SED-LL Sachsen, Abt. Staatl. Verwaltung an ZK-Abt. Staatl. Verwaltung, 16. 10.1950, mit der Verdächtigung, Schnitzler habe mit einer Flakbatterie das IG-Farben Werk in Auschwitz geschützt. Entlastung durch Aussage eines „Bruno“, 31. 10. 1950. Ebd., Bl. 25-28, Einschätzung und Bericht der HA V/3 des MfS, 26. 9. 1958, danach bezeugte Grete Wittkowski Schnitzlers antifaschistische Tätigkeit im Roten Studentenbund 1933. Sowjetische Stellen versicherten, daß Denunziationen, die bereits während seiner Kriegsgefangenschaft aufgetaucht waren, sich als haltlos erwiesen hatten. Seine Zuverlässigkeit unterstrichen sämtliche Einschätzungen aus DBD-Kreisen. Ebd., BI. 11, 19. 1. 1950, Beurteilung von Scholz; Bl. 16, 30. 10. 1954, Einschätzung von IM „Steffan“ (= Besler); Bl. 18, 18. 8. 1958, Einschätzung von Fritz Otto; Bl. 20, 27. 8. 
Nach seiner Verhaftung 1933 waren die Kontakte zur KPD abgerissen. So organisierte er selbständig antifaschistische Gruppen in Hanau, Berlin, Frankfurt und Saarbrücken. Aus der Wehrmachtszeit ab 1942 kannte er Berthold Rose, den er als Zeugen für seine Widerstandstätigkeit benannte. Kurz vor Kriegsende, im Mai 1945, nahm die Rote Armee den frisch beförderten Leutnant in der ČSR gefangen. Politische Differenzen und Konkurrenz unter den Lagerangehörigen führten offenbar dazu, daß er mit Rückendeckung sowjetischer Stellen als „Kriegsverbrecher, Naziaktivist, Direktor der IG-Farben, Gestapoagent und verkappter SS-Offizier" 35 denunziert wurde. Schnitzler wurde aus dem Antifa-Aktiv ausgeschlossen und bis Februar 1949 als Häftling und Zwangsarbeiter gefangengehalten letzteres gab er in den Akten natürlich nicht so wieder ${ }^{36}$. Seine kommunistische Gesinnung litt unter den schmerzlichen Erfahrungen anscheinend in keiner Weise, obwohl er an den Folgen einer Malariaerkrankung, die er sich höchstwahrscheinlich in den Lagern zugezogen hatte, zeit seines Lebens laborierte. Erst im Frühjahr 1949 wurde der Fall geprüft und seine Unschuld bestätigt. Nach längeren Lazarettaufenthalten entlassen, traf er Ende Juli 1949 in Frankfurt/Oder ein. Bereits vor der Denunziation hatte er sich als Informant der sowjetischen Geheimpolizei verpflichtet. Diesen Auftrag erfüllte er nach seiner Rehabilitierung bis 1952. Dann wurde er aus gesundheitlichen Gründen als Informator abgelegt ${ }^{37}$.

Deutlich jünger als Rose und Schnitzler war Hans Rietz ${ }^{38}$, der am 26. April 1914 in Cönnern bei Halle als unehelicher Sohn einer Putzmacherin zur Welt $\mathrm{kam}$. Die ersten Lebensjahre wuchs er in einem Kinderheim, dann bei Pflegeeltern auf, bis ihn seine inzwischen verheiratete Mutter zu sich nach Bitterfeld holte. Wegen wirtschaftlicher Not konnte Rietz die Mittelschule nicht abschließen. Er begann 1928 eine Schlosserlehre bei der IG Farben in Wolfen, wo er bis zu seinem Diensteintritt beim RAD 1934 arbeitete. Dort unterstand er genauer Beobachtung, da man ihn verdächtigte, an seine bisherige kommunistische Jugendarbeit anknüpfen zu wollen. Rietz war erst vierzehnjährig dem Metallarbeiterverband beigetreten und gehörte bis 1933 dem Kommunistischem Jugendverband und verschiedenen Agitationsbrigaden in Bitterfeld an. Er nahm als Soldat in einem Nachrichtenregiment am Polen-, Frankreich- und ab 1942 am Rußlandfeldzug teil. 1945 geriet Rietz in sowjetische Kriegsgefangenschaft, 1946 kam er in ein An-

1958 Beurteilung von GI „Bernd“ (= Helmschrott), der immerhin noch „Reste bürgerlicher Gewohnheiten" meldete.

35 Ebd., Bl. 32-37, Lebenslauf undatiert [Abschrift], hier Bl. $35 \mathrm{f}$.

36 Ebd., Bl. 36. Schnitzler schob die Verantwortung für seine Verhaftung deutschen Kriegsgefangenen im „sogenannten Antifaaktiv“ des Hauptlagers 7328/1 in Baku zu.

37 Ebd., Bl. 23, Aktenvermerk, undatiert.

38 Das folgende nach BStU MfS AP 14985/92, Personalakte Rietz, BI. 2 f., Lebenslauf, 4. 12. 1950 [Abschrift], Bl. 4-7, Personalfragebogen, 16. 12. 1950. Das MfS bereitete 1950 eine Verpflichtung von Hans Rietz zur Mitarbeit für das MfS vor, die dann aber offenbar ausblieb. Ebd., Bl. 9. Trotzdem wird er als "Gewährsmann“ oder als „KP Hans“ in den Akten geführt. In anderen IM-Vorgangsakten wird er öfter als IM bezeichnet. Unter Umständen wurde er zwar verpflichtet, mußte aber keine Verpflichtungserklärung unterzeichnen, wie dies gelegentlich mit sowjetischer Rückendeckung praktiziert wurde. Vgl. zu seiner Person auch die allgemeinen Abgaben in Barth u.a. (Hg.), DDR, S. 1634; Herbst u. a., DDR, Bd. 3, S. 277; Wernet-Tietz, Bauernverband, S. 224; Buch, Namen (1973), S. 232. 
tifa-Lager. Nach der Gebietsschule in Leningrad durchlief er 1948 auch die Zentralschule 2040 in Ogre, wo er anschließend freiwillig bis Juli 1949 als Aktivleiter blieb. Im Juli 1949 kehrte er in die SBZ zurück.

Er bekam eine Selle als Landesinstrukteur der Abteilung Schulung im SEDLandesverband Sachsen-Anhalt. Am 1. November 1949 trat er in Absprache mit seiner Partei in die DBD über und führte bis 1951 deren Zentralschule in Borkheide. 1951 wünschte er, diese Funktion aufzugeben. Da ihm Rose eine Perspektive beim Parteivorstand eröffnete, herrschte auch zwischen diesen beiden ebenso wie zwischen Rose und Schnitzler ein gutes Verhältnis. Diese Protektion zahlte sich für Rose bei parteiinternen Querelen gegen Goldenbaum und/oder Scholz später aus 39 .

Dem Jahrgang 1925, also einer jüngeren und anders politisch sozialisierten $\mathrm{Ge}-$ neration gehörte Hans Reichelt $\mathrm{an}^{40}$. Er kam im oberschlesischen Proskau als Sohn einer alleinstehenden Hausschneiderin zur Welt, die häufig beruflich unterwegs war. Hans wuchs daher ab seinem 9. Lebensjahr zeitweise in einem Waisenhaus auf. Ausgesprochen selbständig und bildungsbeflissen wechselte er in die Oberschule, gleichzeitig trat er in die Hitlerjugend ein, wo er in den Rang eines Jungscharführers aufstieg. 1943 bewarb er sich um Aufnahme in die NSDAP. Im gleichen Jahr berief man den 18jährigen Oberschüler zur Wehrmacht ein ${ }^{41}$. Kurz nach seiner Beförderung zum Leutnant Ende April geriet er am 9. Mai 1945 in der ČSR in sowjetische Kriegsgefangenschaft. In der Sowjetunion als Wald- und Straßenarbeiter eingesetzt, brachte er es bald zum Brigadier. Nach anfänglichem Zögern wuchs ab dem Frühjahr 1946 sein Interesse für die politischen Fragen, die in den Antifa-Lehrgängen im Kriegsgefangenenlager behandelt wurden. Ab Sommer 1947 besuchte er einen zweimonatigen Lehrgang, der ihn zum Jungaktivisten seines Bataillons qualifizierte. Im Sommer 1948 wurde er Führer eines Unteroffiziersbataillons. Von Februar bis Juni 1948 absolvierte er im Lager 7437 die Arbeitsschule und von Juni bis Dezember 1949 die Zentralschule des Lagers 2041. Reichelt wurde am 24. Dezember 1949 in Frankfurt/Oder aus sowjetischer Kriegsgefangenschaft entlassen ${ }^{42}$. Unmittelbar danach warben ihn Scholz und Scheffler für die DBD an ${ }^{43}$. Bis spätestens Sommer 1950 folgte Reichelt Scheffler in der Funktion des Hauptabteilungsleiters Organisation. Im Herbst 1950 unterschrieb er eine Verpflichtungserklärung beim MfS, nachdem Scholz ihn im August einem Geheimpolizisten vorgestellt hatte ${ }^{44}$. Reichelt war von 1950 bis 1989 Mit-

39 BStU MfS AP 14985/92, Personalakte Rietz, Bl. 113, Auskunftsbericht, 14. 3. 1962.

40 Das folgende nach BStU MfS AIM 127/54, Personalakte Reichelt, Bl. 4 f., Personalfragebogen, 21. 8. 1950 [Abschrift], Bl. 9, Lebenslauf [Abschrift von Abschrift, höchstwahrscheinlich 1950], Bl. 11, Charakteristik von Scholz [1950]. Vgl. auch die Angaben in Barth u. a. (Hg.), DDR, S. 1603; Wernet-Tietz, Bauernverband, S. 223, Herbst u. a., DDR, Bd. 3, S. 271.

41 BStU MfS AIM 127/54, Personalakte Reichelt, Bl. 9, Lebenslauf [1950].

42 SStAD BPA SED LL A/1605a, Liste des Kreises Leipzig Betr.: Antifa-Schüler/Schulen 2040 und 2041/Ankunft in Gronenfelde am 23. 12. 1949. [Falschdatierung des Geburtsdatums um einen Monat, übrige Angaben aber zutreffend].

43 ACDP VI, unverz. Handakten Rose, Protokoll Sekretariat, 29. 11. 1950.

44 BStU MfS AIM 127/54, Personalakte Reichelt, Bl. 12, Verpflichtungserklärung, 27. 9. 
glied des Sekretariats und des Parteivorstandes und einer der profiliertesten Politiker der DBD. Mehrmals bekleidete er Ministerposten für die DBD, zunächst als Nachfolger von Wilhelm Schröder als Landwirtschaftsminister im Sommer 195345. Während der fünfziger Jahre zählte er zu jenen Funktionären der DBD, die maßgeblich über die agrarpolitischen Inhalte und die Geschicke der Partei mitbestimmten. Dabei genoß Reichelt das besondere Vertrauen der SED in seine Kompetenz und Verläßlichkeit, das sich etwa in der Ernennung zum stellvertretenden Vorsitzenden des Zentralen Beirats für LPG beim Ministerrat niederschlug.

Erwin Körbers Interesse für Politik wurde erst im sowjetischen Antifalager 204046 geweckt und geformt. Er kam am 15. Juni 1921 im oberschlesischen Ratibor als Kind eines Musikers ${ }^{47}$ zur Welt. Nach dem Abitur 1939 wurde er zum Wehrdienst eingezogen. Vor 1949 gehörte er keiner politischen Partei an. Körber zählt wie Reichelt zur Generation derjenigen, die von der Schule weg ohne Ausbildung und Beruf zum Kriegsdienst verpflichtet wurden, in sowjetische Kriegsgefangenschaft gerieten und nach Antifa-Schulung zu Parteifunktionären aufstiegen. In anderen Berufsfeldern hatten sie nie Erfahrungen gesammelt. Nach der Rückkehr aus der Kriegsgefangenschaft 1949 gehörte Körber kurze Zeit der SED an und wurde im Februar 1949 in die DBD Thüringens delegiert. Parteiintern als "Umsiedler" geführt, sollte er vermutlich in diesem kaum von der Bodenreform berührten Land die Belange der Flüchtlinge und Vertriebenen im Auge behalten. Seine Parteikarriere führte ihn 1951 als hauptamtlicher Mitarbeiter zum Parteivorstand nach Berlin. Dort gehörte er bis $1971^{48}$ dem Sekretariat als Leiter der Abteilung Schulung und Aufklärung (ab Mitte 1954), der Haupt-Abteilung Organisation (1955) und als Kaderleiter (1962) $\mathrm{an}^{49}$. Anfang der sechziger Jahre qualifizierte er sich als staatlich geprüfter Landwirt, wie es einem Sekretär der Bauernpartei jetzt angemessen schien ${ }^{50}$.

Einfluß und Bedeutung der Antifa-Schüler in der DBD werden in der bisherigen Forschung unterschiedlich eingeschätzt. Zweifellos verstärkten sie das Grün-

1950. Er wählte den Decknamen „B. Heinrich“. BStU MfS AP 4387/92, Scholz, Bl. 9, Aktenvermerk des MfS-Mitarbeiters G.

451954 besuchte er als einer der ersten DBD-Kader die Zentralschule für Agrarpolitik des ZK der SED in Schwerin und wurde Staatssekretär im MLF. 1955 bis 1963 wurde er erneut Minister im genannten Ministerium. Ab 1959 war er Mitglied des ZV der VdgB. Nach dem Tod von Werner Titel wurde Reichelt von 1972 bis November 1989 Stellv. des Vors. d. Ministerrates und Minister für Umweltschutz und Wasserwirtschaft.

46 Das folgende nach ACDP VI-052-0017, Aufstellung PV 1960; Wernet-Tietz, Bauernverband, S. 222; Buch, Namen (1979), S. 164.

47 ACDP VI-052-0017, Aufstellung PV 1960. Buch, Namen (1979), S. 164, führt als Beruf des Vaters Eisenbahnangestellter an.

48 So Reichelt, Blockflöte, S. 375. Anderslautende Angaben (bis 1967) bei Wernet-Tietz, Bauernverband, S. 222.

49 Die Ernennung zum HA-Leiter wird in der Literatur unterschiedlich datiert; Reichelt, Blockflöte, S. 375 (1957); den Akten zufolge war Körber Nachfolger von Schnitzler auf dem Posten für Schulung und Aufklärung, dann von Dietrich Besler als Hauptabteilungsleiter Organisation, der diese Funktion nach dem IV. PT 1955 aufgab. ACDP VI-0520527, Protokoll Sekretariat, 18. 6. 1954; Protokoll des IV. PT, S. 272.

50 ACDP VI-052-0546, Protokoll Sekretariat, 13. 11. 1961. 
dungspersonal 1949 und gelangten vorzugsweise auf Sekretariatsposten ${ }^{51}$. Insgesamt ist das parteiinterne Kräfteverhältnis in größeren Zusammenhängen und über einen längeren Zeitraum hinweg zu untersuchen. Nur so kann die Einordnung im SED-dominierten Herrschaftssystem und das Zusammenspiel individueller Motive hinter den innerparteilichen Gruppierungen miteinander verknüpft werden. Die Frontbildungen verliefen bald quer zu den Parteigründergruppen. Reichelt warnt heute vor einer Überbewertung der Antifa-Kader; allerdings wurde er in der DBD anfangs aufgrund seiner Jugend von Goldenbaum ausgebremst $^{52}$. Allgemein stößt man hier auf generationell mitbedingte Konflikte im Wandel der Zusammensetzung der Parteiführung: Die altgedienten KPD-Kader wie Goldenbaum und Scholz ließen sich nur ungern von jungen, zwar Antifageschulten und hochmotivierten, aber weder kommunistisch sozialisierten noch in der Landwirtschaft ausgebildeten, dazu mit HJ- und NSDAP-Vorgeschichte behafteten Kadern bedrängen.

Die Bedeutung der zentral eingesetzten Antifa-Schüler läßt sich daran ablesen, daß sie aufgrund ihres Einblicks in Parteiinterna begehrte Geheiminformatoren des MfS waren ${ }^{53}$. Für den Untersuchungszeitraum ist die bedeutende Rolle der Antifa-Schüler erwiesen. Rietz und Reichelt schieden erst 1990 aus dem Führungszirkel aus; Rose wurde 1960 als Generalsekretär zurückgezogen und verließ 1963 den Parteivorstand. Schnitzler entfernte sich, offensichtlich auch aus gesundheitlichen Gründen, etappenweise von Führungsfunktionen in der DBD und schied ebenfalls 1963 aus dem Parteivorstand aus.

Im Grunde war die DBD schon Ende 1948 gezwungen, eigene Kader heranzubilden. Antifa-Schüler füllten nur zeitweise Lücken; ihr Zufluß versiegte Ende 1949 und reichte bei weitem nicht aus, um den Bedarf auf allen Ebenen zu decken. Im Jahr 1950 kam es zu dramatischen Engpässen, als die DBD zum einen zunehmend Staatsfunktionäre stellen mußte und zum anderen eine "Parteisäuberung“ betrieb. Im Sekretariat beklagte man intern 1950 die schwache Unterstützung seitens der SED; schon kurz nach der von sowjetischer Seite angeordneten Gründung sei eine weitere personelle Verstärkung ausgeblieben, mit der das DBD-Sekretariat aber gerechnet hatte. Sogar bei der Besetzung von Schlüsselpositionen wie des Personalleiters wurde die SED nicht initiativ ${ }^{54}$. Paul Scholz, der sich der Kaderfragen während der längeren Vakanz auf diesem Posten zusätzlich annahm, bat sogar das MfS um Unterstützung 55 .

51 Eine parteiübergreifende Studie fehlt. Wernet-Tietz, Bauernverband, S. 108, 122f. Kühne spricht von einem parteiinternen Gegensatz zwischen den Gründungsmitgliedern Goldenbaum und Scholz und den neu hinzugekommenen Antifa-Schülern im PV, übersieht jedoch, daß sich Scholz 1950 der Kritik der Antifa-Schüler gegen Goldenbaum anschloß, Kühne, Anfänge, S. 93 f.; siehe ACDP VI, unverz. Handakten Rose, Protokoll Sekretariat, 29. 11.1950.

52 Reichelt, Blockflöte, S. 34f. ACDP VI, unverz. Handakten Rose, Protokoll Sekretariat, 2. 12. 1950, Goldenbaum gab darin zu, den Kontakt zu jüngeren Kollegen und ihre „Entwicklung" unterschätzt zu haben.

$53 \mathrm{Vgl}$. S. 281-288.

54 ACDP VI, unverz. Handakten Rose, Protokoll Sekretariat, 29. 11. 1950.

55 BStU MfS AP 4387/92, Scholz, Bl. 8f. Bei Gesprächen zwischen MfS-Mitarbeitern und 
Diese Erfahrung ließ die DBD erkennen, wie wichtig die systematische Heranbildung des eigenen Parteinachwuchses war. Ab 1951 ging sie daran, Jungbauern und Mitarbeiter im Bereich der landwirtschaftlichen Verwaltung auf ihren Parteischulen auszubilden oder auf Verwaltungsschulen wie das Renommierinstitut "Walter Ulbricht" in Forst Zinna zu delegieren"5. Bis 1963 schaffte aus dieser Gruppe noch niemand den Sprung ins Sekretariat. Die Förderung des Funktionärnachwuchses und die generationelle Zusammensetzung der DBD war von Werbungsstopps, die die SED verfügte, unmittelbar abhängig. Besonders ab 1963 drohte eine Überalterung von Mitgliedschaft und Führung. Wie sehr der Einfluß der Parteischüler bis 1960, gemessen an ihrer Zahl, wuchs, und sie sukzessive sowohl die altkommunistisch geprägte Gründerelite als auch die Funktionärsgruppe der Antifa-Absolventen ablösten, demonstriert die Zusammensetzung des Parteivorstandes von 1960: Von 75 Mitgliedern hatten 25 die DBD-Zentralschule absolviert, 36 eine Landesparteischule durchlaufen, 16 beide Schultypen. Zwölf Personen hatten sonstige Lehranstalten wie Fachakademien, SED-Landwirtschaftsschulen und Universitäten besucht. Die acht Antifa-Schulabsolventen fallen quantitativ kaum ins Gewicht - Helmschrott, Hoffmann, Körber und Rietz -, sie besetzten allerdings vier von sieben Sekretariatsposten ${ }^{57}$.

\section{Organisatorischer Aufbau und innerparteiliche Funktionen}

Die folgende Analyse soll das Geflecht der innerparteilichen Kompetenzregelungen, der Anleitungsstrukturen, der personellen Zusammensetzung tragender Gremien und letztlich des politischen Entscheidungszentrums offenlegen. Die bisherigen Forschungsbeiträge zur Organisation des DBD-Parteiaufbaus beschrieben diesen unter der Prämisse, daß die Bauernpartei als "Transmissionsriemen“ der SED fungierte. Dieser im Prinzip zutreffende Ansatz verband damit häufig die Frage, inwiefern organisatorische Parallelen zur SED vorliegen; die Beiträge konstatierten, daß schon bei der Gründung der DBD Strukturprinzipien eingeführt wurden, die eine Ausrichtung am Vorbild der SED von Beginn an belegen ${ }^{58}$. Nach der Auswertung von nun zugänglichen Akten erscheint diese Sicht verengt; zum einen zeichnet sich ab, daß die DBD-Organisation über weite Strecken nicht mit derjenigen der SED zu vergleichen ist, zum anderen wird deutlich, wie unzureichend die Durchsetzung von solch zweifellos vorhandenen Strukturprinzipien über einen längeren Zeitraum hinweg gelang. Schließlich markiert die Praxis, Spit-

Scholz ist erwähnt, daß der Posten des Personalleiters mindestens seit August 1950 unbesetzt war. Am 16. 8. 1950 bat Scholz das MfS um Mithilfe.

$56 \mathrm{Zu}$ dieser zahlreichen, heterogen zusammengesetzten Gruppe gehörten z.B. Erwin Binder, Willi Grandetzka, Claus Howitz, Michael Koplanski, Siegfried Küster, Karl-Heinz Nordmann, Fritz Nixdorf, Werner Titel u.v.a.

57 ACDP VI-052-0546, Protokoll Sekretariat, 18. 12. 1961.

58 Wortmann, Parties, S. 284 ff.; Wernet-Tietz, Bauernverband, S. $118 \mathrm{ff}$. 
zen der Bezirks- und Kreisvorstände ehrenamtlich zu besetzen, einen wesentlichen Unterschied zur Organisation der SED 59 .

Bei der Organisationsgeschichte der DBD stehen nicht nur Machtverhältnisse, die von oben nach unten reichten, im Zentrum der Aufmerksamkeit, sondern auch Einflußmöglichkeiten von unten nach oben. Herauszuarbeiten sind auch jene Mechanismen der politischen Durchdringung, deren Aufgabe es war, die nicht mit den politischen Vorgaben konform gehenden Auffassungen anderer Gremien und Organisationsebenen möglichst reibungslos in die Partei einzubinden - und sei es auch nur, um sie anschließend gleichschalten zu können.

\section{Parteivorstand}

Der Parteivorstand war laut Statut von 1949 das oberste Gremium der Partei zwischen den Parteitagen ${ }^{60}$. Er sollte von den Landes- bzw. Bezirksdelegierten des mindestens alle zwei Jahre stattfindenden Parteitages gewählt werden. Sämtliche Länder- bzw. Bezirksorganisationen mußten im Vorstand vertreten sein. Die $\mathrm{Zu}$ sammensetzung des Gremiums wurde vorher in Absprache mit den zuständigen Stellen der SED festgelegt ${ }^{61}$. Bei der Wahl stimmten die Delegierten en bloc per Heben eines Handzettels oder durch Einwerfen eines Wahlscheines für den Wahlvorschlag der Wahlkommission, der immer einstimmig und ohne Enthaltungen angenommen wurde. Die Delegierten nahmen keinen Einfluß auf die Zusammensetzung des Gremiums. In der konstituierenden Sitzung des Parteivorstandes auf den Parteitagen wählten seine Mitglieder den Parteivorsitzenden sowie einen oder ab 1963 zwei Stellvertreter, den Hauptgeschäftsführer - so die Bezeichnung bis Ende 1950 - bzw. den Generalsekretär (1951-1960 - dann schaffte man die Funktion ab) sowie ein Sekretariat des Parteivorstandes. 1963 wurde das Sekretariat vom Parteivorstand lediglich bestätigt, nicht mehr gewählt ${ }^{62}$.

Der Vorstand sollte laut Statut von 1949 mindestens 17 Personen umfassen. Tatsächlich gehörten ihm 194819 und 194924 Personen an ${ }^{63}$. Auf dem II. Parteitag 1951 erhöhte sich die Zahl auf 49, auf dem III. Parteitag 1953 auf $55^{64}$ - erstmals waren alle Bezirke zu berücksichtigen -, und sie erreichte 196379 Mitglieder ${ }^{65}$. Mit zunehmender Größe schwand die Macht des Gremiums. In der Aufbauphase der Partei konnte sich der Parteivorstand wie alle Landes-, Kreis- und Ortsvor-

$59 \mathrm{Vgl}$. dazu auch Reichelt, Blockflöte, S. $60 \mathrm{f}$.

60 Statut von 1949, abgedruckt in Wernet, Rolle, S. 271-274, hier S. $272 \mathrm{f}$. Vgl. auch Statut von April 1948, abgedruckt in: Um ein antifaschistisch demokratisches Deutschland, S. 631-635. Vgl. auch die Ausführungen zum PV vornehmlich bis 1952 in Wernet-Tietz, Bauernverband, S. 120-123, und Wortmann, Parties, S. 284-288.

61 In den Quellen ist dies nicht immer nachzuweisen, aber sehr häufig. Vgl. auch die sorgfältige Steuerung der Personalbesetzung durch die AG BO im Zuge der Vorbereitungen zum VI. und VII. PT der SED 1960 und 1963 in Kapitel IX.2 und IX.6. Diese Praxis bestätigt auch Reichelt, Blockflöte, S. $59 \mathrm{ff}$.

62 Protokoll des VII. PT 1963, S. 295.

63 Wernet-Tietz, Bauernverband, S. 120.

64 Protokoll des III. PT 1953, S. 205-209.

65 Protokoll des VII. PT 1963, S. 287-290. Gleichzeitig wählte man 35 Nachfolgekandidaten. 
stände durch Kooptation von Mitgliedern vergrößern und verändern ${ }^{66}$. So hoffte man, die hohe Fluktuation in den Vorständen aller Organisationsebenen aufzufangen und die Zusammensetzung zu steuern. Der Parteivorstand wie alle Landes- bzw. Bezirks- und Kreisvorstände wählten sich als ausführendes Organ ein Sekretariat, das eigentliche Entscheidungs- und Machtzentrum. Der Parteivorstand konnte die Besetzung aller Parteiorgane nominell durch seine Entscheidungsbefugnis über sämtliche innerparteilichen Wahlordnungen regeln ${ }^{67}$. Über diesen Hebel gelang es, die eigene Zusammensetzung zu bestimmen: Als etwa die einzelbäuerlichen Mitglieder 1960 laut Wahlordnung in den Kreisen nicht länger als Parteitagsdelegierte in Frage kamen, erübrigte sich zugleich ihre Repräsentation im Parteivorstand.

Beim Parteivorstand existierte ein siebenköpfiges Parteischiedsgericht ${ }^{68}$. Bis 1960 war es der Hauptabteilung Kader zugeordnet, danach wurde es offenbar auf Anregung der SED-Arbeitsgruppe Befreundete Organisationen davon getrennt ${ }^{69}$. Erst im Zuge der Vollkollektivierung und der Entwicklung der DBD zu einer sozialistischen Partei ging die Parteiführung daran, die Aufgaben des Parteischiedsgerichtes schriftlich neu zu fixieren ${ }^{70}$. Außerdem sollte eine fünfköpfige Revisionskommission beim Parteivorstand die Kassenführung kontrollieren. Die Einrichtung von Revisionskommissionen sollte auf jede Organisationseinheit übertragen werden. De facto bestimmte Berthold Rose als Generalsekretär bis 1960 weitgehend allein über die Parteifinanzen.

Dieses statuarische Bild des Parteivorstandes spiegelt die reale Bedeutung des Gremiums nur unzureichend wider. Die entscheidenden politischen Vorgaben wurden nicht dort getroffen, weil der Parteivorstand nur ein weiteres Glied im letztlich SED-gesteuerten Anleitungs- und Kontrollapparat war. Auch in der DBD wurden maßgebliche Entscheidungen im Sekretariat gefällt und vorbereitet $^{71}$, wie schon die Lenkung der ersten Parteikonferenz am 16./17. Juni 1948 zeigte.

Zweifellos fungierte der Parteivorstand in der Gründungsphase 1948 als wichtiges Verbindungsglied zwischen der schlecht organisierten und unterbesetzten Berliner Geschäftsführung und den Landesverbänden. Zumindest bis Ende 1952 erfüllte er auch eine Funktion, die von unteren Parteigliederungen hin zur Parteispitze gerichtet war ${ }^{72}$. Insbesondere Berichte der Landesvorsitzenden, die sich auf

\footnotetext{
66 Statut von 1949, Ziffer 19, abgedruckt in Wernet, Rolle, S. $271 \mathrm{ff}$.

67 Ebd., Ziffer 24.
}

68 Vor 1955 wurde es von Hans Rietz als stellvertretendem Organisationssekretär kontrolliert, danach stand es bis 1972 unter der Leitung von Erwin Körber. Protokoll des III. PT 1953, S. 209; zu Körber: Reichelt, Blockflöte, S. 376.

69 ACDP VI-052-0324, Protokoll Präsidium, 5. 1. 1960, und Vorlage zu Parteischiedsgericht. Der Vorlage zufolge sollte Burkhardt den Vorsitz übernehmen, Körber blieb jedoch an der Spitze. ACDP VI-052-0540, Protokoll Sekretariat, 7. 12. 1959. SAPMO DY 30 IV 2/15/2, AG BO an Matern, 3. 8. 1959. Die AG kritisierte die Inaktivität des Gremiums.

70 ACDP VI-052-0325, Arbeitsordnung des Parteischiedsgerichtes vom 28. 6. 1960.

71 Sekretariat hieß das kleinere Leitungsgremium ab dem I. PT, zuvor trat man im "geschäftsführenden Ausschuß“ oder im „engeren Parteivorstand“ zusammen.

72 Noch 1952 klagte das Sekretariat darüber, daß die Mitglieder die Kreise und Bezirksorga- 
die Situation der Partei in den Kreisen bezogen, lieferten auf Parteivorstandssitzungen hilfreiche Informationen zum Zustand der DBD in den Ländern ${ }^{73}$ und konnten so das Vorgehen beeinflussen. Der Sitzungsturnus, der anfänglich alle vier Wochen Zusammenkünfte vorgab, begünstigte diese Rückkopplungsfunktion. Nach der Neugliederung 1952 und mit steigendem Einfluß der Sekretariate berief man die Sitzungen nur noch alle drei Monate ein; statt realer Information über die Lage der Partei stand nun die ideologische Formierung im Zentrum. In ellenlangen politischen Referaten gab der Vorstand den Diskurs der Partei vor, die Sitzungen liefen zunehmend ritualisiert ab ${ }^{74}$. In der Frühzeit 1948/49 fanden Anleitung und Kontrolle der Landesverbände vornehmlich über die Parteivorstandssitzungen statt, die je nach Thema um Gäste erweitert wurden. Die Steuerung war noch äußerst ineffektiv, wie Landesverbände und Sekretariat 1950 bedauerten ${ }^{75}$. Diese Schwäche eröffnete den Landesverbänden auch Handlungsspielräume, die eigenwillige Führungspersönlichkeiten aus den Ländern wie Richard Richter und Friedrich Martin bisweilen nach ihrem Gutdünken ausfüllten.

Anleitung und Kontrolle durch den Parteivorstand oder sein Sekretariat waren bis 1952 weder perfektioniert noch lückenlos. Ein Werkzeug hierfür stellte das Instrukteurwesen dar, besonders die Instrukteurbrigade des Parteivorstandes, die ab 1951 bestand. Die Instrukteure, die 1955 zwei Brigaden bildeten und der Abteilung Organisation zugeordnet waren ${ }^{76}$, durchbrachen die horizontale Gliederung der Parteigremien vertikal und lieferten schnell zuverlässige Informationen in die Zentrale. Das Instrukteurwesen erlaubte es dem Parteivorstand, unmittelbar auf die Parteiorgane in den Bezirken und Kreisen einzuwirken. Denn die Instrukteure nahmen automatisch an den jeweiligen Sekretariatssitzungen teil und informierten sich umfassend über die lokalen Probleme, vor allem auch bei den Gliederungen der SED.

Nach 1948/49 verlor der Parteivorstand die Funktion eines internen Informations- und Diskussionsforums zwischen den Sekretären und den Landesvertretern; er wurde nun vornehmlich Anleitungsgremium. Das Sekretariat des Parteivorstandes nutzte Parteivorstandssitzungen zur Weitergabe politischer Inhalte. Dabei dienten die ausufernden Grundsatzreferate auch zur Schulung, weil sie die leitenden Funktionäre in den Bezirken und Vertreter der DBD in LPG und VEG einfach und in regelmäßigem Abstand über die politische Agenda informierten. Diese Art der tagespolitischen Unterweisung konnten Parteischulen nicht leisten, da die Funktionäre die verschiedenen Typen von Parteischulen und Lehrgängen in der Regel nur einmal absolvierten. Diesen Funktionswandel der Parteivorstandssitzungen verdeutlicht auch der veränderte Tagungsmodus.

nisationen übergingen und sich mit Wünschen und Kritik sofort an den PV wandten. ACDP VI-052-0523, Protokoll Sekretariat, 24. 10. 1952.

73 Siehe dazu die Wortprotokolle der überlieferten PV-Sitzungen für 1948 und 1949, die sich in Offenheit und Informationsgehalt deutlich vom späteren Stil dieser Gremienprotokolle abheben, ACDP VI-052-0141 und 0142.

74 ACDP VI-052-0523, Protokoll Sekretariat, 24. 10. 1952.

75 ACDP VI, unverz. Handakten Rose, Protokoll Sekretariat, 29. 11. 1950.

76 Vgl. 2. Entwurf, Arbeitsordnung für den Apparat des PV, 31. 10. 1955, ACDP VI-0520530. 
Obwohl der Parteivorstand im Vergleich zur Gründungsphase einen Bedeutungsverlust verzeichnete, wirkte das Gremium nachhaltig traditionsbildend. Dies erfolgte zum einen über die Zusammensetzung seiner Mitglieder, die trotz hoher Fluktuation auch Konstanten aufwies, zum anderen wurde der politische Gehalt der Sitzungen im „Bauern-Echo“ popularisiert. Wenn die Parteiführung ihre politische Linie der Basis vermitteln wollte, dann geschah dies über die Parteivorstandssitzungen, ab 1955 auch über Verlautbarungen des Präsidiums.

Bis zum III. Parteitag vom September 1953, teilweise darüber hinaus, läßt sich ein erheblicher Austausch der Gründergruppen von 1948 ablesen. 1963 gehörten nur noch sechs Parteivorstandsmitglieder von 1949 dem nun 79köpfigen Gremium an ${ }^{77}$; diese zählten allerdings zum Gründungspersonal von 1948 und bekleideten mit Ausnahme von Ernst Rummel, einem Parteiveteran aus Mecklenburg, der inzwischen LPG-Vorsitzender geworden war, wichtige Funktionen in Partei oder Staat. Betrachtet man die Zusammensetzungen des Gremiums von 1953 und 1963, so waren von den 55 Mitgliedern 1953 nur noch 16 zehn Jahre später vertreten ${ }^{78}$. Kein Drittel (29\%) der Mitglieder von 1953 wurde 1963 wiedergewählt. Doch obwohl diese 1963 nur ein Fünftel der Vorstandsmitglieder stellten, waren sie weiterhin der machtvolle sanior pars der Sekretariatsmitglieder und Funktionäre in Parteischulen und Ministerien ${ }^{79}$. Bedeutungslos waren hingegen die letzten Vertreter der lokalen Gründer von 1948, Ernst Rummel und Heinrich Schmidt.

Neben dieser stabilen, in ihrer Zahl überschaubaren und dennoch einflußreichen Gruppe im Parteivorstand stand ein fluktuierender Teil des Gremiums. Seine Besetzung gab jeweils das Leitbild für die gewünschte Zusammensetzung der Parteibasis vor. Sie brachte zugleich den Kurs der DBD und damit den anvisierten künftigen Zustand der Partei zum Ausdruck. So wurden 1953 eine Reihe von Genossenschaftsbauern (19) in das Gremium gewählt, obwohl der Anteil der sogenannten "werktätigen Bauern" - wie Einzelbauern inzwischen bezeichnet wurden - an der Gesamtmitgliederschaft weitaus höher lag als im Parteivorstand (9). Unterrepräsentiert waren Jugendliche, weshalb man die sechs, die man nur hatte, umso mehr hervorhob - und Frauen (10), die 1953 immerhin rund 15 Prozent der Basis ausmachten ${ }^{80}$. Jugendliche und Frauen erwarben sich den Sitz im Parteivorstand in erster Linie durch Vorgaben der SED-Agrarpolitik und waren

77 Leonhard Helmschrott, Herbert Hoffmann, Ernst Goldenbaum, Ernst Rummel, Paul Scholz, Fritz Weißhaupt. Rose schied 1963 aus dem PV aus.

78 Burkhardt, Goldenbaum, Häber, Heinrich, Helmschrott, Hoffmann, Melz, Weißhaupt, Pech, Reichelt, Rietz, Rödiger, Ernst Rummel, Heinrich Schmidt (Mitbegründer), Scholz, Rudi Werner, Zirnstein. Vgl. Protokoll des III. PT der Demokratischen Bauernpartei Deutschlands 1953, S. 205-209 und Protokoll des VII. PT der Demokratischen Bauernpartei Deutschlands 1963, S. 287-291.

79 Dies gilt für Burkhardt, Goldenbaum, Helmschrott, Hoffmann, Melz, Weißhaupt, Reichelt, Rietz und Scholz, nur in zweiter Linie für Susanne Häber, Heinrich, Pech und Rödiger, die die Gruppe der Bezirksführungskräfte repräsentierten. Wenig einflußreich waren die Wiedergewählten Ernst Rummel, Heinrich Schmidt, Rudi Werner und Zirnstein.

80 Siehe Tabelle 7. 
z.B. Anwender sowjetischer Neuerermethoden, Vorsitzende im Club junger Agronomen, arbeiteten in MTS oder waren in der Gesellschaft für DeutschSowjetische Freundschaft aktiv. Wenige, im engen Sinne berufs- und leistungsbezogene Parteivorstandsplätze waren dagegen für sogenannte „Meisterbauern“ reserviert.

Die Jugendlichen verjüngten den Parteivorstand nicht dauerhaft, sondern schieden bis 1963 aus dem Gremium wieder aus. Ihr Einbau diente nicht dem langfristigen Parteiaufbau, sondern momentaner Taktik. 1963 war selbstverständlich kein Einzelbauer mehr im Parteivorstand vertreten, zumal schon 1960 „werktätige Bauern" als einfache Delegierte für den VI. Parteitag nicht mehr in Frage kamen ${ }^{81}$. Dafür rückte in den erweiterten Parteivorstand von 1963 eine Riege von neun Wissenschaftlern sowie überproportional viele Vorsitzende von LPG des Typs III (12) und Bäuerinnen ein ${ }^{82}$. Ihnen standen nur neun Vorsitzende von LPG des Typs I gegenüber. Stärker noch fällt auf, daß neben 25 Genossenschaftsbauern des Typs III nur drei Parteivorstandsmitglieder aus LPG des Typs I gewählt wurden $^{83}$ - in einer LPG Typ I zu arbeiten, war politisch immer weniger opportun.

Insgesamt war die Besetzung des Parteivorstandes gleichzeitig von Kontinuität und von politisch induziertem Wandel geprägt. Während die langjährigen Sekretariatsmitglieder auf Vorstandsposten noch die Parteitradition verkörperten, eilte die soziale Zusammensetzung des Gremiums insgesamt dem von der SED vorgegebenen Kurs hinterher, war darin aber der Verfaßtheit der Partei an der Basis voraus. 1963 fand auch unter den bislang kontinuierlich gewählten Mitgliedern des Parteivorstandes ein Wechsel statt. Altgediente Funktionäre wie Berthold Rose und Hans Schnitzler schieden aus, neue Spitzenfunktionäre, unter diesen viele inoffizielle Mitarbeiter des MfS, standen auf der Nachrückerliste ${ }^{84}$. Der Parteivorstand war gehalten, stets auch die Mitgliederzusammensetzung zu repräsentieren, und vollführte dabei einen Spagat zwischen der gegenwärtigen Struktur und den politischen Vorgaben. Dabei basierte die Zusammensetzung stets auf politischer Entscheidung. Letztere war getragen von der irrigen Vorstellung, daß sich die momentanen Verhältnisse genauso wie das ideologische Bewußtsein der Mitglieder den Erfordernissen entsprechend verändern ließen: Die Mitglieder des Jahres 1963 würden demnach der Maxime der „wissenschaftlich-technischen Revolution" schon folgen und ihre LPG des Typs I in eine des Typs III umbauen.

81 ACDP VI-052-0541, Vorlagen für Präsidiumssitzung, 11. 4. 1960. Nur unter den Nachfolgekandidaten der Revisionskommission stößt man auf einen Einzelbauern.

82 Vgl. Protokoll des VII. PT 1963, S. 284.

83 Ebd., S. 287-291.

${ }^{84} \mathrm{Zu}$ ihnen zählten Claus Howitz, Horst Jäschke, Michael Koplanski, Eberhard Mack, Werner Mitzscherling, Bruno Müller und Rudi Rothe. 


\section{Sekretariat und Präsidium}

Das Sekretariat war die Entscheidungs- und Schaltzentrale der DBD. Es gab den politischen Kurs der DBD vor. Folglich setzten SED und sowjetische Behörden hier die Hebel ihrer Steuerung an. Für Anleitung und Kontrolle der DBD bot sich dieses Gremium aus verschiedenen Gründen an: Zum einen garantierte die Praxis der Personalbesetzung des Sekretariats eine höchstmögliche politische Zuverlässigkeit, die laufend überprüft wurde. Zum zweiten konnte die Einflußnahme wahlweise über einzelne Sekretäre oder die Gesamtheit des siebenköpfigen Gremiums laufen. In jedem Fall bot sich ein kleines Büro für die Implementation der politischen Vorgaben an, um die Fernsteuerung vor der Basis wie der Öffentlichkeit möglichst zu verbergen. Damit das Sekretariat seinerseits die Anleitung auf den realen Zustand der Partei abstimmen konnte, sollten hier alle erheblichen Informationen zusammenlaufen. Es hätte wenig mit historischer Realität zu tun, wollte man das Sekretariat von vornherein als perfekt funktionierende, SED-gesteuerte Anleitungszentrale der DBD fassen. Seine jeweilige Organisationsform und das Einwirken auf die Partei hin zeigen vielmehr sowohl die Veränderungen in der DBD auf als auch indirekt den Wandel der SED-Zielsetzungen.

In der organisatorischen Ausformung lassen sich den Parteistatuten folgend drei Phasen unterscheiden. Die erste Phase umfaßt den Aufbau und die Stabilisierung der Partei und dauert bis zum II. Parteitag 1951. Das Statut von 1949 enthielt praktisch keine Festlegungen zum Sekretariat; es erwähnte lediglich, daß sich der Parteivorstand ein Sekretariat als „ausführendes Organ“ wählt, dem der Vorsitzende und sein Stellvertreter angehören ${ }^{85}$. Während dieser Zeit tagte das Sekretariat des Parteivorstandes bald etwa wöchentlich in Berlin ${ }^{86}$. Es setzte sich aus dem Parteivorsitzenden, den Leitern der vier Abteilungen, dem Chefredakteur des „Bauern-Echo“ sowie dem Hauptgeschäftsführer und dem stellvertretenden Parteivorsitzenden zusammen. Zusätzlich fanden unregelmäßig erweiterte Sekretariatssitzungen statt, zu denen das Führungspersonal der Landesverbände hinzugezogen wurde.

Das Sekretariat wies neben der personellen Konstanz von Goldenbaum, Scholz und Helmschrott eine Reihe von wechselnden Sekretären auf, die zwar häufig von der SED für den Parteiaufbau abgeordnet waren, aber nicht dauerhaft im Parteiapparat der DBD verbleiben wollten. Willi Adam, der 1948 die Abteilung Werbung leitete und als Vertreter der DBD in der DWK vorgesehen war, kehrte schon im Laufe des Jahres 1949 wieder zur SED zurück ${ }^{87}$, wo er im ZK-Apparat arbeitete. Auch Griebel schied aus der DBD wieder aus. Scheffler begann ab 1950 eine Karriere bei der Volkspolizei. Diese Personallücken fing man durch den Einsatz von heimkehrenden Antifa-Schülern auf, die so eine kontinuierliche Arbeit im Sekretariat sicherten: So wurde Rose im März 1949 höchstwahrscheinlich nach

85 Statut von 1949, abgedruckt in Wernet, Rolle, S. 271-274, hier S. 273, Ziffer 22.

86 Zur lückenhaften Überlieferung der Sekretariatsprotokolle aus der Frühzeit der Partei vgl. S. 20.

87 Biographisches Handbuch der deutschsprachigen Emigration, Bd. I, S. 5; ACDP VI-0520141, Protokoll PV, 26. 8. 1948. 
Adams Weggang als Leiter der Schulungsabteilung in das Sekretariat kooptiert ${ }^{88}$; Reichelt folgte auf Scheffler in der Abteilung Organisation 195089; Rietz, der bisher die Parteischule geleitet hatte, beendete die Vakanz auf dem Posten des Personal- bzw. Kaderleiters; Hans Schnitzler gehörte ab 1. April 1950 zu den Sekretären.

Anfang 1951 erreichte die Organisation des Sekretariats eine neue Stufe. Rose folgte Scholz, der als Minister ins Landwirtschaftsressort wechselte, im Amt des Hauptgeschäftsführers nach. Dieses wurde in ein Generalsekretariat umgebaut, das letztlich die Führungskompetenz des Parteivorsitzenden beschnitt und daher erst nach einem heftigen internen Streit zustande kam. Bis zum II. Parteitag 1951 stabilisierte sich das Sekretariat einigermaßen. Auf dem Parteitag wurde die Personalbesetzung der Sekretariatsposten mit hauptamtlichen Mitarbeitern lediglich bestätigt und nicht gewählt.

Eine zweite Phase reicht bis 1955. Auf den drei Parteitagen der Jahre 1951, 1953 und 1955 wurde das Sekretariat erheblich umgebaut. Man vergrößerte zwar das Führungsgremium, die tatsächliche Entscheidung blieb jedoch einem kleinen Kreis vorbehalten. Das 1951 konstituierte Sekretariat umfaßte 24 Personen und war damit halb so groß wie der Parteivorstand 90 . Drei Viertel der Mitglieder waren Neulinge im Gremium. Nur wenigen darunter - wie z. B. Dietrich Besler - gelang der Zutritt zum inneren Führungskern dauerhaft, denn schon der III. Parteitag 1953 verminderte die Zahl der Sekretäre wieder auf 1491. Da der IV. Parteitag 1955 als neues Leitungsgremium ein 17köpfiges Präsidium einführte, konnte die Zahl der Sekretäre weiter auf acht ${ }^{92}$ reduziert werden. Nahezu alle Sekretäre zählten zur engsten Führungsriege der hauptamtlichen Parteifunktionäre des Parteivorstandes in Berlin. Das Sekretariat setzte sich ab da aus einer reinen Funktionselite zusammen, denn ihm gehörte automatisch an, wer bestimmte Funktionsposten innehatte: Dazu zählten der Parteivorsitzende, der Stellvertreter, der Generalsekretär, die Hauptabteilungsleiter Organisation, Schulung, Agrarpolitik und Kader, der Chefredakteur des „Bauern-Echo“, sowie der Vorsitzende des Parteischiedsgerichts, sofern diese Position mit einem hauptamtlichen Funktionär besetzt wurde, was ab 1955 mit Erwin Körber der Fall war. Sowohl die Praxis der Kooptation wie auch die nachträgliche offizielle Bestätigung durch den Parteitag waren damit hinfällig geworden.

Ein 24köpfiges Sekretariat, wie es 1951 eingeführt worden war, erwies sich in der Praxis als zu groß und ineffektiv, um den Parteiauftrag der DBD auszuarbeiten, abzustimmen und durchzusetzen, dabei die SED-Anleitung diskret zu befolgen und mit eigener "schöpferischer" politischer Gestaltung aufzufüllen. Daher bildete man innerhalb des Sekretariats im Juli 1951 ein elf Personen zählendes

88 ACDP VI-052-0141, Protokoll PV, 5. 3. 1949, Rose war erstmals in diesem Gremium.

89 Reichelt, Blockflöte, S. 33.

90 Protokoll des II. PT, S. 218, Wernet-Tietz, Bauernverband, S. 122.

91 Protokoll des III. PT, S. 214. Gewählt wurden: Goldenbaum, Scholz, Rose, Reichelt, Besler, Rietz, Schnitzler, Helmschrott, Ernst-Walter Beer, Albert Rödiger, Arthur Pech, Heinz Heinrich, Erwin Körber und Susanne Häber.

92 ACDP VI-052-0316, Beschluß über Aufgabe des Präsidiums und des Sekretariats des PV, 18. 1.1956. 
engeres Sekretariat, in den Quellen häufig auch Arbeitssekretariat genannt ${ }^{93}$. Seine Zusammensetzung knüpfte noch an das Verfahren an, durch das engere Sekretariat die Vertreter der DBD in Regierungsämtern und in der VdgB(BHG) einzubinden und damit anzuleiten. Ein Sekretariatsbeschluß regelte im Oktober 1952 die jeweiligen Zuständigkeiten und das Vorgehen zwischen Arbeitssekretariat und Sekretariat. Interna und Führungsentscheidungen - im Parteijargon Beschlußvorbereitung und -durchführung - traf das engere Sekretariat, das immer $\mathrm{zu}$ Monatsbeginn, möglichst aber häufiger tagen sollte ${ }^{94}$. Zeitlich darauf abgestimmt sollte das umfassendere Sekretariat des Parteivorstands im letzten Drittel des Monats zusammentreten. In seine Zuständigkeit fielen alle Entscheidungen und Maßnahmen im Rahmen der vom Parteivorstand festgelegten Aufgaben, und es befand über den Kadereinsatz bis zur Bezirksebene. Auch dieser Beschluß schrieb die praktizierte Kompetenzverteilung nachträglich fest. Im Februar 1954 richtete man zur Geschäftsführung beider Sekretariate ein Büro des Sekretariats ein ${ }^{95}$, das mit Rudi Rothe, einem persönlichen Vertrauten Goldenbaums, besetzt wurde ${ }^{96}$.

Bis 1955 sind zwei Personalveränderungen im engeren Sekretariat von Bedeutung: Im Mai 1953 wurde es um Dietrich Besler als Leiter der Hauptabteilung Organisation erweitert ${ }^{97}$. Neben die Parteigründergruppe (Goldenbaum, Scholz, Helmschrott, Hoffmann) und die Antifa-Absolventen (Reichelt, Rietz, Schnitzler, Rose) gelangte damit erstmals jemand ins Sekretariat, der zwar zu den lokalen Gründern zählte, sich aber nicht von Beginn an zum inneren Führungszirkel rechnen durfte. Besler wurde im Mai 1954 von der Staatssicherheit als GI angeworben. Paradigmatisch verkörpert er damit zugleich den Vormarsch jener Sekretäre, die in Diensten des MfS standen. Von den neun Personen, die bis 1955 "engere Sekretäre" waren, hatten sich sieben zur Zusammenarbeit mit der Staatssicherheit verpflichtet. Lediglich Goldenbaum und Scholz waren nicht angeworben worden.

Zwischen der Vorbereitung zum IV. Parteitag 1955 und dem VI. Parteitag 1960 lag eine dritte Phase. In diese Zeit fällt die Bildung eines neuen leitenden Partei-

93 ACDP VI-052-0522, Protokoll Sekretariat, 17. 7. 1951, demnach wurden Goldenbaum, Scholz, Rose, Reichelt, Schnitzler, Rietz, Keuthe, Helmschrott, Hoffmann, Albrecht und Densdorf in das engere Sekretariat gewählt.

94 ACDP VI-052-0523, Protokoll Sekretariat, 24. 10. 1952. Arbeitssekretariatsprotokolle, die krisenhafte Wendepunkte der Partei thematisieren, oft verbunden mit parteiinternen Auseinandersetzungen, sind als Wortprotokolle nur in den sogenannten Handakten Rose überliefert. Auch im unverzeichneten Nachlaß Hoffmann, ACDP VI, finden sich Arbeitsprotokolle und Vorlagen dazu für das Jahr 1954.

95 ACDP VI-052-0526, Vorlage der Abt. Org./Kader, 4. 2. 1954, Sekretariatsbeschluß, 8. 2. 1954, ebd. Das Büro war für die Sitzungsvorbereitung und die Protokollführung zuständig; nach 1960 war der Sekretär des Büros zugleich persönlicher Referent des Vorsitzenden. ACDP VI-052-0325, beschlossene Vorlage des Sekretariats betr. Arbeitsordnung des Präsidiums und Sekretariats des PV, 19. 7. 1960.

96 Rothe unterschrieb am 3. 11. 1961 eine Verpflichtungserklärung für das MfS; BStU MfS AIM 3890/89, Personalakte Rothe; Bd. 2/1 und 2/2 Arbeitsvorgang.

97 BStU MfS AIM 3562/59, Bd. 2, Personalakte Besler, HA V, Abt. 3, 10. 5. 1954, Vorschlag zur Werbung. 
gremiums. Das auf dem IV. Parteitag ins Leben gerufene Präsidium hatte 17 Mitglieder. Im Kern traf weiterhin das Sekretariat alle tragenden Entscheidungen, das aufgrund der Verkleinerung auf acht Personen ein Arbeitssekretariat entbehren konnte. Daher ist der verschiedentlich geäußerte Vergleich des Präsidiums mit dem Politbüro der SED unangebracht ${ }^{98}$.

Die Entscheidung zur Einrichtung eines Präsidiums fiel sehr wahrscheinlich innerhalb der DBD, obgleich die Vorbereitung des Parteitages, auf dem der Beschluß gefaßt wurde, in enger Absprache mit den Anleitungsorganen der SED verlief ${ }^{99}$. Zwar gelangten auch Arbeitssekretariatssitzungen der DBD am 26. Juli und 1. August 1955 zu dem einvernehmlichen Ergebnis, auf dem anstehenden Parteitag ein umfassenderes Sekretariat aus 17 Personen und ein Arbeitssekretariat mit nur sieben Mitgliedern einzurichten ${ }^{100}$. Die von Rose vorgestellte Lösung unterschied sich jedoch in einem wesentlichen Punkt von der bisherigen Arbeitsweise zwischen erweitertem Sekretariat und Arbeitssekretariat: Den Sekretariatsmitgliedern sollte es künftig freistehen, an allen Sitzungen des Arbeitssekretariates teilzunehmen. Diese Änderung zielte auf mehr innerparteiliche Transparenz und versuchte, die vielbeschworene Kollektivität der Leitung zu erhöhen. Damit ist sie zugleich ein Reflex auf innere Führungskämpfe im Arbeitssekretariat ${ }^{101}$. Rose und Goldenbaum konstatierten ungewohnt einstimmig, daß das bisherige Verhältnis zwischen Arbeitssekretariat und Sekretariat ungenügend sei. Der Generalsekretär plädierte für ein Gremium, das schnell reagieren und bei „überraschenden politischen Situationen in Erscheinung" treten könne. Der Vorsitzende vermißte ein Organ, das ausführend beschließen könne. Damit sollte das Präsidium eine Lücke in der öffentlichen Wirksamkeit der Partei schließen, zumal der Bedarf an Außendarstellung mit zunehmender Gleichschaltung der Partei stieg. Der Parteivorstand war aufgrund der hohen Mitgliederzahl und des zwei- bis dreimonatigen Sitzungsturnus zu unbeweglich für aktuelle Verlautbarungen, das Sekretariat hingegen zu öffentlichen Deklarationen ebensowenig befugt wie das Arbeitssekretariat, das allerdings in der Lage gewesen wäre, flexibel zu reagieren.

Das Präsidium band personell sowohl Leitungskräfte der DBD aus den Bezirken als auch Parteivertreter in Regierungsämtern und in Massenorganisationen ein und folgte darin der bisherigen Praxis im erweiterten Sekretariat ${ }^{102}$. Zusätzlich

98 Bei Wortmann, Parties, S. 284, zudem fehlerhaft, Wernet-Tietz, Bauernverband, S. 123.

99 So ist in den Sekretariatsprotokollen, die sich mit der Vorbereitung des IV. PT beschäftigen, stets von einem engen Kontakt mit der SED-Abteilung Leitende Organe die Rede, vor allem, weil man kurzzeitig plante, auf dem IV. PT ein neues Programm und Statut zu beschließen, was dann jedoch unterblieb. Vgl. ACDP VI-052-0530, Protokoll Arbeitssekretariat 26.7. 1955 und 1.8. 1955.

100 Über die Bezeichnung der Gremien herrschte zunächst Uneinigkeit, ebd.

101 In der Vorbereitung des IV. PT war es zu Auseinandersetzungen um die Rolle und Präsenz von Generalsekretär Rose gekommen, der lt. einer frühen Planung für den IV. PT überhaupt nicht in Erscheinung treten sollte. Rose hingegen warf Goldenbaum vor, sich selbst und Scholz auf Parteitagen hervorzuheben. ACDP VI-052-0530, Protokoll Arbeitssekretariat, 6. 7. 1955. Vgl. hierzu auch Vorwort zum Beschluß über Aufgaben des Präsidiums und des Sekretariats des PV, 18. 1. 1956, ACDP VI-052-0316.

102 Vgl. dazu die Besetzung des Präsidiums 1955: Böhm, Eichhorn, Goldenbaum, Häber, 
gestattete die höhere Mitgliederzahl, die verschiedenen sozialen Gruppen der Parteibasis zu repräsentieren.

In der schließlich siebten Fassung eines Präsidiumsbeschlusses wurde das Präsidium als politisch leitendes Organ der Partei zwischen den Sitzungen des Parteivorstandes definiert; letzterem war es rechenschaftspflichtig ${ }^{103}$. Zu seinen primären Aufgaben zählte es, die politischen Stellungnahmen der Partei zu erarbeiten und zu verkünden. Als „besondere Aufgabe“ schrieb man dem Gremium zu, den „unteren Parteileitungen zu helfen, um die ideologisch-politische Arbeit zu verbessern und sie zu befähigen, die Arbeit mit den Mitgliedern besser zu organisieren"104. Damit sollte es dezidiert den Kontakt bzw. die Anleitung und Kontrolle der bezirklichen Parteigliederungen intensivieren. Für die Durchführung der Beschlüsse des Parteivorstandes verantwortlich, hatte das Präsidium eine weitreichende Kompetenz in der Beschlußfassung ${ }^{105}$ und hinsichtlich der Festlegung von Richtlinien. Damit verbesserte man drei Elemente der Parteiarbeit: Man schuf ein Gremium, das schnell offiziell reagieren konnte, das die Hoffnung nährte, die Verbindung zu den unteren Gliederungen auszubauen, und das ausführend beschließen konnte. Ein vierter ursprünglich anvisierter Punkt, nämlich die Kollektivität der Parteileitung zu verbessern, wurde insofern berücksichtigt, als den Präsidiumsmitgliedern das Recht eingeräumt wurde, „in allen gewählten Leitungen, Sekretariaten und Grundeinheiten der Partei die Durchführung der Beschlüsse des Parteivorstandes und des Präsidiums zu kontrollieren" ${ }^{106 .}$

Auch die Installierung des Präsidiums schuf keine tatsächliche Kontrolle über die Sekretariatsarbeit; letztere litt häufig unter internen Auseinandersetzungen und wurde maßgeblich von wenigen, jedenfalls nicht „im Kollektiv“ bestimmt ${ }^{107}$. Die Festlegung vom Januar 1956 hält sich bezüglich der Aufgaben des Sekretariates auffallend bedeckt: Es sollte die Sitzungen des Präsidiums vorbereiten, Vorschläge zur Tagesordnung machen und Vorlagen erarbeiten. Das Sekretariat war für die Durchführung der Beschlüsse des Parteivorstands - wie schon das Präsidium - und des Präsidiums verantwortlich. Die „Königswahl“ der Sekretariats-

Heinrich, Helmschrott, Hoffmann, Körber, Melz, Pech, Reichelt, Rietz, Rose, Rödiger, Else Schmidt, Schnitzler, Scholz; Protokoll des IV. PT 1955, S. 272.

103 ACDP VI-052-0316, Beschluß-Vorlage an Präsidium, 18. 1. 1956, mit Vermerk, wonach sie ohne Änderung beschlossen wurde. Überliefert ist eine früherer, dritter Entwurf vom 27. 10. 1955, dem das Präsidium am 1.11. 1955 nicht zustimmte.

104 Ebd., Beschluß-Vorlage an Präsidium, 18. 1. 1956.

105 Das Präsidium war insbesondere für folgende Felder zuständig: „für die ideologisch-politische Arbeit zur Lösung der politischen und agrarpolitischen Hauptaufgaben“, für die „,ideologisch-politische Erziehung“ der Mitglieder und die Durchführung von Versammlungen und Schulungen in den Grundeinheiten, für die Qualifizierung von Mitgliedern und Funktionären in Landesparteischulen und der Zentralen Parteischule, für die organisatorische Entwicklung und soziale Zusammensetzung der Partei, den Einsatz von Funktionären im Apparat des Sekretariats, des „Bauern-Echo“ und in Staatsämtern, sowie über Finanzfragen der Partei.

106 ACDP VI-052-0316, Beschluß-Vorlage an Präsidium, 18. 1. 1956.

107 In der Endfassung fiel ein Passus weg, der das Sekretariat beauftragte, „zur weiteren Verbesserung der kollektiven Arbeit, zur Hebung der persönlichen Verantwortlichkeit aller Mitarbeiter eine Arbeitsordnung für den Apparat des Sekretariats des Parteivorstandes zu beschliessen." Ebd. und Fassung vom 27. 10. 1955, ebd. 
mitglieder wurde insofern verändert, als nun dem Gremium neben den oben genannten Funktionsträgern als neues Mitglied auch der Vorsitzende des Parteischiedsgerichts angehörte. Damit saß die Parteikontrollkommission der DBD im engsten Führungszirkel. Diese interne Lösung hatte man 1955 einer offiziellen Statutenänderung vorgezogen. Denn um die Mitglieder zu beschwichtigen und um den politischen Gegnern keine Angriffsfläche zu bieten, versuchte man 1955 mit allen Mitteln den Eindruck zu vermeiden, daß sich die DBD in Richtung einer „Partei Neuen Typs“ verändern würde, die sich u.a. durch Kontrollinstrumentarien gegenüber der Basis auszeichnete. Davor warnte Rose in den programmatischen Debatten im Sekretariat vor dem IV. Parteitag ${ }^{108}$. Der Neuregelung zufolge gehörte der stellvertretende Parteivorsitzende Scholz nicht mehr zum Sekretariat. Die Gründe hierfür sind nicht explizit bekannt, hängen aber höchstwahrscheinlich mit einem Machtverlust zusammen, der ihn auch das Ministeramt kostete. Sein selbständiges Verhalten während der Diskussion um ein neues Programm dürfte Vorbehalte im ZK-Apparat gegenüber seiner Person geschürt haben; außerdem schwärzte Rose 1955 seine innerparteilichen Gegner Goldenbaum und Scholz in massiver Weise beim ZK an. Diese wiederum hatten im Vorfeld versucht, die Funktion des Generalsekretärs abzuschaffen und damit Rose loszuwerden ${ }^{109}$. Im Unterschied zum Entwurf vom Oktober 1955 sah die endgültige Fassung den Sekretär des neu eingerichteten Büros des Sekretariats nicht als Sekretariatsmitglied vor. Das Ausscheiden von Scholz und Rothe aus dem Sekretariat schwächte die Position Goldenbaums. Generalsekretär Rose hingegen ging unbeschadet aus der Umbildung hervor. Insgesamt war die Phase bis 1960 von einer offiziellen Arbeitsteilung zwischen den beiden Gremien bei tatsächlicher Führung durch das Sekretariat gekennzeichnet. Unübersehbar sind personelle Veränderungen in den Führungsorganen und das Eindringen neuer Funktionseliten, die neben dem eigenen Schulungsapparat seit 1957 auch Parteischulen der SED mit spezifisch agrarischer Ausrichtung absolvieren konnten.

Ein vierter Abschnitt ist von 1960 bis zum Ende des Untersuchungszeitraums anzusetzen. Die Endphase der Zwangskollektivierung im Frühjahr 1960 stellte die Leistungsfähigkeit des gesamten Apparates der DBD auf eine harte Probe. Nicht wenige Mitglieder und Funktionäre flüchteten in den Westen. Mit der Vollkollektivierung schien zugleich die Legitimation als eigenständige Partei bedroht. Nachdem die jahrelang anvisierten sozialistischen Produktionsverhältnisse offiziell erreicht waren, trat zunächst ein gewisses Vakuum in der politischen Aufgabenfindung ein. Noch vor dem Ende des sogenannten „sozialistischen Frühlings“ wurden im Sekretariat und in der künftigen Gesamtleitung der Partei wichtige Veränderungen eingeleitet. Im Januar 1960 kündigte Rose im Präsidium an, sich krankheitsbedingt vom Posten des Generalsekretärs zurückzuziehen. Zugleich sollte damit diese Funktion erlöschen. In der gleichen Sitzung wurde die Zusam-

108 ACDP VI-052-0530, Protokoll Sekretariat, 26. 7. 1955.

109 Dieser Schachzug Roses kam erst 1960 ans Tageslicht und trug dann zu seinem Rückzug bei; ACDP VI-052-0326, Protokoll Präsidium, 21.3. 1961. Zu den Versuchen Goldenbaums und Scholz', die sich hinter Besler verschanzten, siehe ACDP VI-052-0530, Protokoll Sekretariat, 26. 7. 1955. 
mensetzung des Sekretariats auf drei Positionen verändert. Mit Kurt Burkhardt und Stefan Zagrodnik kürte man zwei neue Sekretäre, mit Paul Scholz kehrte der stellvertretende Parteivorsitzende in das Sekretariat zurück ${ }^{110}$. Bis Juli 1960 erstellte man eine neue Arbeitsordnung für Präsidium, Sekretariat und die Abteilungen des Parteivorstandes 111 . Die im Vorspann der neuen Arbeitsordnung gefaßten Ziele - sie reichten von Verbesserung der operativen Anleitung bis zur "Hebung“ der persönlichen Verantwortung - belegen die bisher defizitäre Leitungstätigkeit des Präsidiums. Die Aufgabenzuschreibung der Sekretariatsmitglieder wurde den veränderten Umständen angeglichen. Losgelöst von einer Funktion als Hauptabteilungsleiter, gehörten dem Sekretariat künftig nur noch als „Sekretäre“ bezeichnete Personen an. Erneut paßte man mit organisatorischen Beschlüssen das nominelle Verfahren einem längst aufgrund politischer Erwägungen praktizierten Vorgehen an. Das Präsidium stand in einem Dilemma, innere Funktion und Aufgaben ließen sich schwer miteinander vereinbaren ${ }^{112}$ : Es war zu einem Spagat gezwungen zwischen politischem Tagesgeschäft mit der Basis einerseits und ideologischer Grundbestimmung einer deklamatorischen Politik des Parteivorstands andererseits. Die Transmission zwischen den unteren Gliederungen und dem Präsidium litt darunter, und zwar in beiden Richtungen.

Bereits ein Jahr vor den organisatorischen Veränderungen 1960 ist eine Einflußnahme des MfS auf die Arbeit des Sekretariats in neuer Qualität festzustellen. Das Vorgehen des MfS im Dienste der SED beschränkte sich dabei nicht auf eine Informationsbeschaffung über den Zustand der DBD, sondern es war nun auf minutiöse operative Anleitung insbesondere der IM unter den Sekretären und damit auf Grundentscheidungen in der Leitung der Bauernpartei angelegt.

\section{Abteilungen und Kommissionen}

Die Hauptlast der zentralen Parteiarbeit oblag den Abteilungen des Sekretariats des Parteivorstandes. Sie waren die Arbeitsstäbe des Sekretariats, erstellten Beschlußvorlagen für die Sekretariats- und Präsidiumssitzungen und waren für deren Umsetzung zuständig. Da sich die Gegenstände der Parteiarbeit jedoch in Abhängigkeit vom SED-bestimmten Gesamtkurs der Bauernpartei wandelten, mußte der Apparat diesen Richtungsänderungen öfter angepaßt werden. Offenbar bevorzugte die SED nach der unmittelbaren Aufbauphase der DBD bis 1949 indirekte Einflußnahmen auf die Parteiorganisation. Organisatorische Themen

110 ACDP VI-052-0324, Protokoll Präsidium, 25. 1. 1960. Zagrodnik wurde Leiter der HA Schulung und Aufklärung.

111 ACDP VI-052-0325, beschlossene Vorlage des Sekretariats betr. Arbeitsordnung des Präsidiums und Sekretariats des PV, 19. 7.1960. Diese Ausarbeitung hob den Beschluß über die Festlegung der Aufgaben des Präsidiums vom 24. 1. 1956 auf. Ebd., Änderungen und Ergänzungen zur Vorlage betr. Arbeitsordnung des Präsidiums und Sekretariats des PV, 23.7. 1960. Entwürfe der Arbeitsordnungen für den Apparat des PV, die so nicht beschlossen wurden, vom 31. 10. 1955 und 8. 11. 1955, sind in ACDP VI-052-0530 überliefert.

112 ACDP VI-052-0325, beschlossene Vorlage des Sekretariats betr. Arbeitsordnung des Präsidiums und Sekretariats des PV, 19. 7. 1960. Ebd., Änderungen und Ergänzungen, 23. 7. 1960. 
dürften mit ziemlicher Sicherheit auch anläßlich der Treffen mit dem ZK-Sekretär für Landwirtschaft Erich Mückenberger besprochen worden sein, deren Existenz gesichert ist, über deren Inhalte aber keine Protokolle vorliegen. Weniger die unmittelbare Anleitung scheint vorrangig gewesen zu sein - dieses Problem überließ man gerne der DBD - als vielmehr die Ausrichtung auf den politischen Kurs. $\mathrm{Zu}$ wichtigen Angelegenheiten gab es andererseits auch konkrete Politbürobeschlüsse.

Im folgenden ist keine lückenlose Organisationsgeschichte der Abteilungen und Kommissionen darzulegen, vielmehr nur markante Veränderungen. Die Besetzung der Positionen der Hauptabteilungsleiter gelang bis Ende 1960 einigermaßen vollständig. Dagegen erschwerten personelle Engpässe die Besetzung der nachgeordneten Abteilungen fast permanent ${ }^{113}$. Für Fluktuation und Kadermangel wäre ein ganzer Reigen an Ursachen zu nennen. Im Hinblick auf die Besetzung von Hauptabteilungs- und Abteilungsleiterposten sind vor allem die wiederkehrenden „Säuberungen“ auf Funktionsposten anzuführen, die nicht unbedingt mit Phasen der "Mitgliedersäuberung" in der Gesamtpartei korrespondierten. In der zweiten Hälfte der fünfziger Jahre erhöhte sich die Fluktuation der Führungskader durch ein Karussell fachlicher Qualifizierung und politischer Schulung. Wer dabei wann auf welche Schule delegiert wurde, war vor allem unter den Sekretariatsmitgliedern, von denen mindestens vier zugleich Hauptabteilungsleiter waren, ab 1959 ein Dauerthema, da es die innere Machtkonstellation berührte ${ }^{114}$.

In der Kaderpolitik, die auf die gestiegenen ideologischen Anforderungen reagieren mußte, kam es Mitte 1960 zu einer tiefen Zäsur. Künftig waren Parteivorstand sowie die Bezirks- und Kreisvorstände jeweils für die systematische Heranbildung von Nomenklaturkadern in ihrem Wirkungsbereich verantwortlich ${ }^{115}$. Abhängig von der Größe der Kreisvorstände sollten die unter Nomenklatur Genommenen pro Kreis 10-20 Personen umfassen, in den Bezirksvorständen 25-30 und beim Präsidium des Parteivorstandes 45-50. Ebenso waren die Leiter der Hauptabteilungen und Sekretäre für die Kaderentwicklung in ihrem Bereich zuständig und unterbreiteten der Kaderabteilung Vorschläge.

Im Untersuchungszeitraum basierte die Parteiarbeit fast durchgehend auf vier Hauptabteilungen bzw. Abteilungen ${ }^{116}$. Da die Leiter automatisch dem Sekretariat angehörten, wurden sie im Falle eines Wechsels ins Sekretariat kooptiert. Nach der Bildung der Abteilung Schulung, die Anfang 1949 unmittelbar auf sowjetische Veranlassung hin eingerichtet ${ }^{117}$ und mit dem späteren Generalsekretär Berthold Rose besetzt wurde, verfügte das Sekretariat über vier Abteilungen:

113 ACDP VI-052-0543, Protokoll Sekretariat, 20. 2. 1961.

114 Vgl. dazu S. 451, 455.

115 ACDP VI-052-0542, Vorlage an das Sekretariat des Präsidiums: Anhang zur Richtlinie für die kaderpolitische Arbeit der Partei, 4. 7. 1960.

116 Die Bezeichnung Hauptabteilung (HA) wurde erst eingeführt, als den HA Abteilungen zugeordnet waren. In der Anfangszeit, in der der Apparat noch weniger ausdifferenziert war, existierten nur Abteilungen.

117 ACDP VI-052-0519, Protokoll Sekretariatssitzungen 26. 10. und 28. 12. 1948. 
Organisation - Werbung ${ }^{118}$ - Schulung - Wirtschaft und Kommunalpolitik. Die Abteilung Wirtschaft und Kommunalpolitik unterstrich den Anspruch auf Themen gesamtwirtschaftlichen Zuschnitts, aber auch auf Präsenz in den kommunalen Vertretungen. So versuchte sich die DBD gerade in der Gründungszeit gegen den Vorwurf von LDP und CDU zu profilieren, als Interessenpartei ausschließlich für bäuerliche Belange einzutreten. Entgegen den Ankündigungen in Sekretariat und Parteivorstand 1948/49 scheiterte die Installierung eigener Abteilungen für Frauen und für Jugendliche ${ }^{119}$ zunächst an Personalknappheit. Obwohl man in den fünfziger Jahren zeitweise solche Abteilungen einrichtete, gehörten deren Leiter nicht wie ihre Kollegen dem Sekretariat an. Dies dürfte dem Selbstverständnis als Partei der werktätigen bäuerlichen Bevölkerung geschuldet sein, die keine nähere soziologische Aufgliederung vornahm, aber auch den Beschränkungen in der Mitgliederwerbung nach der Aufbauphase. Die wiederholten Berichte über eine verbreitete reservierte Haltung ländlicher Frauen und Jugendlicher ließen eine eigene Abteilung zusätzlich obsolet erscheinen. Als Teillösung richtete man Referate ein, die erst ab 1950 arbeiteten und anfangs keine nennenswerten Erfolge verbuchten ${ }^{120}$. Die laufende Neuorganisation der Frauen- und Jugendarbeit verweist darauf, daß dieser Bereich in den fünfziger Jahren organisatorisch wie inhaltlich weitgehend erfolglos blieb ${ }^{121}$.

Im Jahre 1950 wurden die Abteilungen Schulung und Werbung verschmolzen $^{122}$ und eine Abteilung für personalpolitische Angelegenheiten neu geschaffen; daneben existierte ab 1951 die Abteilung Schulung und Aufklärung. Diese Umbildung verlief parallel zu einer Parteisäuberungswelle 1950/51, in der sogenannte Großbauern aus den Parteileitungen, aus der VdgB und als Parlamentarier entfernt wurden. Außerdem löste 1951 die Abteilung Agrarpolitik die bisherige Abteilung Wirtschaft und Kommunalpolitik ab.

Im Vorgriff auf die Neugliederung in Bezirke beschloß das Sekretariat 1952 erneut, eine Abteilung staatliche Verwaltung einzurichten ${ }^{123}$. Ein solcher Beschluß

118 Die Abteilungen Organisation und Werbung wurden im Sommer 1948 eingerichtet und mit Schnitzler (Org.) und Adam (Werbung) besetzt. ACDP VI-052-0141, Protokoll PV, 26. 8. 1948.

119 ACDP VI-052-0519, Protokoll Sekretariat, 16. 10. 1948, ACDP VI-052-0143, Protokoll PV, 5. 9. 1949.

120 ACDP VI-052-0520, Protokoll Sekretariat, 30. 5. 1950. Frauenreferate wurden in diesem Jahr auch in den Ländern eingerichtet. Die Aktenüberlieferung des Referates Jugend setzt erst 1950 ein, vgl. ACDP VI-052-210/2, Referat Jugend 1950-1953. Ab August 1951 leitete Rudolf Nickstadt das Jugendreferat beim PV, ACDP VI-052-0522, Protokoll Sekretariat, 7. 8. 1951.

121 ACDP VI-052-0524, Protokoll Sekretariat, 2. 4. 1953, Beschluß zur Neuorganisation der Frauen- und Jugendarbeit. Der Beschluß führte zu Entlassungen von Frauenreferentinnen in den Bezirken: ACDP VI-052-0953, Protokoll Sekretariat BV Dresden, 15. 6. 1953.

122 So auch in den Ländern, vgl. SStAD BPA SED LL A/833, Stimmungsbericht 6. 4. 1950 der Abt. Schulung und Werbung der DBD Sachsen.

123 ACDP VI-052-236/2, Arbeitsanleitung für die Abt. Staatliche Verwaltung bei den $\mathrm{Be}-$ zirkssekretariaten, 6. 8. 1952, mit Bezug auf den Sekretariatsbeschluß vom 2. 8. 1952 war in den Bezirkssekretariaten eine Abt. Staatliche Verwaltung aufzubauen. ACDP VI-0520523, Protokoll Sekretariat, 2. 8. 1952. Siehe dazu auch ACDP VI-052-0522, Protokoll Sekretariat, 22. 4. 1952. 
war schon Anfang 1951 ergangen. Seine Umsetzung war jedoch höchstwahrscheinlich auf Betreiben der SED verhindert worden, da sie sich den Bereich und die Benennung „staatliche Verwaltung“ ebenso vorbehielt wie die verstaatlichte landwirtschaftliche Organisationsform der VEG ${ }^{124}$. Daher mußte sich die DBD einstweilen noch mit einer Abteilung „für Kommunalpolitik“ begnügen ${ }^{125} .1953$ ging die 1952 gebildete Abteilung staatliche Verwaltung in der Hauptabteilung Agrarpolitik auf ${ }^{126}$. Die organisatorische Zusammenführung beider Tätigkeitsfelder in eine Abteilung bedeutete zugleich eine Verengung des Tätigkeitsfeldes der Bauernpartei.

Am 1. August 1952 wurde die personalpolitische Abteilung aufgelöst. Künftig war jede Abteilung für die Kaderpolitik in ihrem Bereich zuständig. Gleichzeitig richtete man eine zentrale Kaderregistratur ein, um durch „einwandfreie und lückenlose Personalunterlagen“, die "wissenschaftlich und politisch überprüft sind“, die "Wachsamkeit in kaderpolitischen Fragen" zu gewährleisten ${ }^{127}$. Obgleich dieses Verfahren den enormen Kadermangel im Zuge des Verwaltungsumbaus ab August 1952 nicht beheben konnte, sollte es sicherstellen, daß im Zeichen der 2. Parteikonferenz der SED ausschließlich ideologisch für geeignet befundene Personen auf Funktionärsposten in der DBD gelangten. Die Kaderregistratur lag in der Obhut der Organisationsabteilung, die eine Schlüsselstellung im Parteiapparat innehatte. Der Organisationsabteilung unterstanden auch die Instrukteurbrigaden ${ }^{128}$. Nur die Abteilung Organisation behielt bis 1963 und darüber hinaus ihren Namen und ihr grundsätzliches Aufgabenprofil bei.

1953 benannte man die Abteilung Schulung und Werbung in Schulung und Aufklärung um, da ein Werbestopp seit Februar 1953 das Mitgliederwachstum der DBD einschränkte. Nach dem 17. Juni 1953 hieß die Abteilung kurzzeitig Agitation und Propaganda - eine Titulierung, die als Programm gegen den Aufstand und die im Zusammenhang damit erhobenen Forderungen zu verstehen ist ${ }^{129}$. Dem sogenannten „Neuen Kurs“ folgten im Frühjahr 1954 einige organisatorische Änderungen ${ }^{130}$, die sich aus der relativen Stärkung der Blockparteien im

124 Für diese Annahme spricht, daß Beschlußvorlagen mit konkreten Personalvorschlägen schon vorbereitet waren und das Sekretariatsprotokoll, in der diese Sache lt. Tagesordnung entschieden werden sollte, nicht überliefert ist. ACDP VI-052-0520, Protokoll Sekretariat, 1. 1. 1951, Personalvorlage dazu bei Protokoll Sekretariat vom 12. 3. 1951, ACDP VI-052-0521; ACDP VI-052-0522, Protokoll Sekretariat, 22. 4. 1952.

125 Zur Sekretariatssitzung vom 2. 4. 1951 ist kein Protokoll überliefert. Am 3. 4. 1951 wurden lediglich ${ }_{n}$ Arbeitsrichtlinien für die Arbeit in den Wahlkörperschaften und der Kommunalpolitischen Abteilung" beschlossen; ACDP VI-052-0521.

126 ACDP VI-052-0524, Protokoll Sekretariat, 2. 4. 1953.

127 ACDP VI-052-0523, Sekretariatsvorlage: Errichtung zentrale Kaderregistratur, undatiert [erste Hälfte August 1952].

128 In den Bezirkssekretariaten bestand nun Personalunion beim Organisationsleiter. Gleichzeitig war der stellvertretende Organisationsleiter besonders verantwortlich für Kaderfragen. ACDP VI-052-0523, Strukturplan der Partei, 2. 8. 1952.

129 ACDP VI-052-0525, Protokoll Sitzung kleines Sekretariat, 10. 8. 1953. Ähnlichkeiten mit der Bezeichnung der Agitprop-Abteilung im Organisationsaufbau der KPD dürften kein Zufall sein; vgl. Weber, Wandlung des deutschen Kommunismus, S. 263.

130 Zum folgenden ACDP VI-052-0526, Vorlage der Abt. Organisation/Kader, 4. 2. 1954, an das Sekretariat. 
Herrschaftsgefüge der DDR ergaben, nachdem deren Existenz in den Jahren 1952 und 1953 nicht immer gesichert schien. Künftig war der DBD-Parteiapparat wieder nach dem Viererschema Organisation, Schulung und Aufklärung, Agrarpolitik und - in Revision der Festlegung von 1952 - Kader aufgebaut. Außerdem wurden die vier Hauptabteilungen nicht nur wie bisher in Sachgebiete aufgegliedert, sondern in Hauptsachgebiete, die von Hauptsachbearbeitern oder Ressortleitern eigenverantwortlich geführt werden sollten ${ }^{131}$. Dies sollte zum einen die Sekretäre vom Alltagsgeschäft entlasten und für politische Grundsatzarbeit freistellen und zum anderen die Initiative der Ressortleiter fördern.

Nach dem Wandel der deutschlandpolitischen Konstellation 1955 fiel den Blockparteien eine neue Rolle in der gesamtdeutschen Arbeit zu. In der DBD wurde nun ein selbständiger Sektor Gesamtdeutsche Arbeit eingerichtet, den Siegfried Küster leitete. Obwohl der Sektor der Hauptabteilung Organisation zugeordnet war, sollte er ausdrücklich nicht vom zuständigen Sekretär Erwin Körber angeleitet werden ${ }^{132}$. Hinter dieser Entscheidung verbarg sich wohl der Einfluß Goldenbaums, der die gesamtdeutsche Arbeit als persönliches Steckenpferd betrieb, die er keinem Sekretärs-Rivalen überlassen wollte; so gehörte Goldenbaum auch dem im August 1953 gebildeten „Ausschuß für deutsche Einheit“ der DDR an ${ }^{133}$. Vor 1955 existierte zumindest zeitweise eine selbständige Abteilung, die sich der Deutschlandpolitik bzw. Westarbeit widmete. Ein Referat für Westarbeit war im Zuge der Mitarbeit der DBD im Gesamtdeutschen Arbeitskreis 1951 installiert worden ${ }^{134}$. Aufgrund des damals hohen Stellenwerts der Abteilung war ihr Leiter Otto Keuthe im Juli 1951 sogar in das engere Sekretariat bestellt worden ${ }^{135}$; er gehörte ihm nach 1953 jedoch nicht mehr an. 1953 teilten sich die Abteilungen Schulung und Organisation die Westarbeit der DBD, die nach dem 17. Juni auf Kosten der aufgelösten Westabteilungen von CDU und LDP per Politbürobeschluß ausgebaut werden durfte ${ }^{136}$. Neben den vier Hauptabteilungen existierten zwei selbständige Abteilungen, für Presse und Rundfunk sowie für Finanzen und Revision ${ }^{137}$.

131 Weitere Details der Aufgliederung in ACDP VI-052-0526, Vorlage und Beschluß in Sekretariatssitzung, 18. 2. 1954.

132 ACDP VI-052-0529, Protokoll Arbeitssekretariat, 10.5. 1955; Vorlage zur Festlegung der Aufgaben des Sektors vom 3. 10. 1955 ebd.

133 Vgl. Amos, Westpolitik, S. $138 \mathrm{f}$.

134 Vgl. dazu Scholz, Bauernopfer, S. $88 \mathrm{ff}$., passim. Der Gesamtdeutsche Arbeitskreis (GAK) führte erstmals im Mai 1950 eine gesamtdeutsche Beratung zur Land- und Forstwirtschaft in Eisenach durch. Er war maßgeblich mit sowjetischer Unterstützung durch die VdgB aus der Taufe gehoben worden und bemühte sich um Kontakte zu angesehenen westdeutschen Agrarexperten wie etwa Andreas Hermes. Hauptakteur war der Generalsekretär der VdgB Kurt Vieweg.

135 ACDP VI-052-0522, Protokoll Sekretariat, 17. 7. 1951. Keuthe gehörte 1950 auch zu den Kandidaten der DBD für den Nationalkongreß, ACDP VI-052-0520, Protokoll Sekretariat, 10. 8. 1950. Erst Ende 1950 gab es Überlegungen, ein Referat "Westarbeit“ einzurichten, ACDP VI, unverz. Handakten Rose, Protokoll Sekretariat 29.11. 1950, Nennung der Tagesordnung durch Goldenbaum.

136 SAPMO DY 30 J IV 2/2/282, Protokoll PB, 26. 5. 1953, Bl. 3, 13-15. ACDP VI-0520526, Protokoll Sekretariat, 1. 2. 1954.

137 ACDP VI-052-0530, 2. Entwurf der Arbeitsordnung für den Apparat des PV, 31. 10. 
Ein Politikum ersten Ranges war die Existenz und jeweilige Ausgestaltung der Abteilung Agrarpolitik. Versuche aus dem Jahr 1955, die Abteilung unabhängig von der Organisationsform (einzelbäuerlich - genossenschaftlich - verstaatlicht) und Institutionen wie MTS in die Sektoren Kader und staatliche Verwaltung, pflanzliche und tierische Produktion sowie Masseninitiative zu unterteilen, wurden nicht realisiert ${ }^{138}$. Ab 1960 versuchte die SED, die Abteilung Agrarpolitik aufzulösen und durch eine Abteilung Produktionspropaganda innerhalb der Abteilung Schulung zu ersetzen. Dies konnte Goldenbaum nur noch knapp verhindern, mit dieser Haltung war er aber im Sekretariat der DBD bereits isoliert ${ }^{139}$.

Einen flexiblen Typ von Organisationseinheiten stellten Kommissionen dar, die tagespolitische Anforderungen aufgreifen konnten. Sie arbeiteten teils auf allen Ebenen der DBD von der Zentrale bis zu den Kreisen, teils beschränkt nur auf Länder- bzw. Bezirks- oder Kreisebene. Nach ihrer Organisationsform und der personellen Zusammensetzung lagen sie quer zur sonst üblichen hierarchischen Gliederung der Parteigremien und nahmen damit in der Partei eine Art intermediäre Position ein. Vertreter aus den Kreisen und Sekretäre des Parteivorstandes berieten dort gemeinsam themenbezogen, wie die seitens der SED und ihrer Regierung formulierten politischen Vorgaben praktisch umzusetzen waren. Ein Beispiel hierfür ist die agrarpolitische Kommission beim Parteivorstand, die Ende 1951 ins Leben gerufen worden war, und im September 1956, nach dem XX. Parteitag der KPdSU in die Zentrale Agrarpolitische Kommission der DBD umbenannt, neuerlich auflebte ${ }^{140}$. Sie befaßte sich mit den agrarpolitischen Grundlinien der DBD und erstellte als ausführendes Organ auch Vorschläge zur Umsetzung von Ministerratsbeschlüssen, die die Landwirtschaft betrafen ${ }^{141}$. Der Zentralen Agrarpolitischen Kommission und ihren Pendants in den Bezirken und Kreisen fiel in der Partei die Funktion zu, sämtliche bäuerlichen Mitglieder zur Mitarbeit zu motivieren, um sie so politisch einzubinden. Während man durch Wahlordnungen und die Neuausgabe von Mitgliedsbüchern die selbständig wirtschaftenden Bauern bereits massiv aus den Sekretariaten und Kreisvorständen herauszudrängen suchte, waren sie in den agrarpolitischen Kommissionen 1957 und 1958 noch stark vertreten ${ }^{142}$. Es war offenbar einfacher, überregional unbekannte Per-

1955. Die Redaktion der Funktionärszeitschrift „Pflüger“ war von der Abt. Presse und Rundfunk abgekoppelt.

138 ACDP VI-052-0530, 2., hierin nicht beschlossener Entwurf der Arbeitsordnung für den Apparat des PV, 31. 10. 1955.

139 Siehe dazu BStU MfS AIM 3189/63, A-Vorgang Zagrodnik, Bl. 169-172, Treffbericht 6. 12. 1961, Bl. 103 f., Treffbericht 24. 8. 1960. Reichelt, Blockflöte, S. $206 \mathrm{f}$.

140 ACDP VI-052-0522, Protokoll Sekretariat, 23. 11. 1951, eine Sekretariatsvorlage zur Bildung einer agrarpolitischen Kommission beim PV, 16. 10. 1951, listet auf: Besler, Densdorf, Willi Modrenski, Ruth Neubauer, Fritz Scheffler, Luise Haussig, Obersinske, Peter Menz, Zimmermann, Claus Howitz und Heinrich Wiesner; ACDP VI-052-0159, Protokoll PV, 14./15. 9. 1956.

141 ACDP VI-052-0529, Protokoll Sekretariat, 15. 3. 1955.

142 ACDP VI-052-0522, Protokoll Sekretariat, 16. 5. 1952, Vorlage wegen Richtlinien für die Registrierung und statistische Erfassung der Mitglieder unserer Partei (GVS), 14. 5. 1952; ACDP VI-052-0535, Präsidiumsentwurf einer Vorlage an die 3. PV-Sitzung, 4. 11. 1957; 
sonen von den lokalen Parteiposten zu entfernen - zumal diese häufig aus eigenem Antrieb der Partei den Rücken kehrten - als prominente, fachlich profilierte und daher selbstbewußt auftretende Kommissionsmitglieder. Wenn sich Einzelbauern ab 1957 überhaupt noch für eine politische Mitarbeit gewinnen ließen, dann geschah dies vornehmlich in den agrarpolitischen Kommissionen.

Andere Kommissionen dienten der Anwerbung und Mobilisierung bestimmter Mitgliedergruppen für allgemein gefaßte politische Zwecke und im Rahmen spezieller Aktionen. Erst seit Ende März 1950 existierte eine Zentrale Jugendkommission der $\mathrm{DBD}^{143}$. Ihre Einrichtung hinkte der Bildung von Landesjugendkommissionen hinterher ${ }^{144}$, die seit der Staatsgründung zwar offiziell bestanden, de facto aber lange nur ein Schattendasein führten ${ }^{145}$. Die Kommissionstagungen sollten vorrangig den mäßigen Erfolg der FDJ unter der Landjugend verbessern. Jugendkommissionen propagierten außerdem jene Maßnahmen, mit denen die DBD ältere Mitglieder aufgrund von mangelnder Resonanz oder dezidierter Ablehnung nicht behelligen wollte. Dazu zählte etwa das Landarbeiterschutzgesetz und Bemühungen um Arbeitszeitverkürzungen für Bedienstete ${ }^{146}$.

Ein weiteres Stiefkind unter der Mitgliederschaft waren die Frauen. Deshalb richtete man im Laufe des Jahres 1950 Landesfrauenkommissionen ein ${ }^{147}$, die offenbar kein Pendant auf zentraler Ebene hatten, und ordnete flächendeckend die Gründung von Kreisfrauenkommissionen an ${ }^{148}$. Insgesamt erreichten die Jugend- und Frauenkommissionen weder einen durchgreifenden Mobilisierungserfolg noch eigenständige politische Impulse. Im Zuge der Parteireorganisation in der zweiten Jahreshälfte 1952 wurden auch die Frauen- und Jugendkommissionen neu gebildet. Dabei sollte vorrangig ihre Aufgabe in der Mitgliederrekrutierung für die Bauernpartei unterstrichen werden, insofern als Kommissionsvorsitzende jeweils ausschließlich "werktätige" Jugendliche bzw. Bäuerinnen in Frage kommen sollten und die bisherige Dominanz von Angestellten und Studenten sich nicht in den Vorsitzen zeigen durfte. Außerdem oblag es den Bezirkssekretariaten künftig, alle zwei Monate eingehend über Jugend- und Frauenfragen zu berichten ${ }^{149}$.

die Wahlvorschläge für die zentrale Agrarpolitische Kommission führten durchaus noch Einzelbauern an.

143 „Bauern-Echo“, 26. 3. 1950, S. 1 f.

144 Vgl. die Artikel zur Tagung von Landesjugendkommissionen im „Bauern-Echo" vom 10. 11. 1949, S. 1, 6 und vom 18. 11. 1949; Bericht über die Konferenz der Landesjugendkommissionen der DBD in Berlin am 17.11. 1949, vom 19.11. 1949, wonach bis zum 1. 1.1950 in jeder landwirtschaftlichen Schule eine Betriebsgruppe der DBD gegründet werden müsse.

145 ACDP VI-052-211/2, Bericht über die Tagung aller Landesjugendreferenten, 3. 11. 1951. In Thüringen waren für die Jahre 1949 und 1950 keinerlei Unterlagen vorhanden, viele Kollegen in Thüringen wüßten nicht, daß es eine Kreisjugendkommission gebe. Für Mecklenburg wurde die Tendenz berichtet, „den Landesjugendreferenten zum Laufburschen $[\mathrm{zu}]$ entwickeln".

146 „Bauern-Echo“, 19.11. 1949.

147 Thüringen war hier Vorreiter; „Bauern-Echo“, 22. 1. 1950, S. 3.

148 ACDP VI-052-0520, Protokolle Sekretariat, 8. 2. 1950 und 17. 10. 1950.

149 ACDP VI-052-0523, Protokoll Sekretariat, 24. 10. 1952. Idealiter sollten die Frauen- und 
Auf dem Feld der Kulturpolitik stand die DBD in den fünfziger Jahren vor enormen inhaltlichen, personellen und organisatorischen Problemen. Da kulturelle Tradition vornehmlich in einen langfristigen Prozeß eingebettet ist und Lebensweise, Selbstverständnis, Mentalität und Alltag in umfassender und tiefgreifender Weise prägt, stieß auch die DBD auf Gegenkräfte massiver traditioneller Beharrung. Zwar hob man 1949 als Auftakt mit einer kulturpolitischen Tagung an und berief 1953 eine erste Kulturkonferenz ein; auf letzterer zollte man bereits dem sozialistischen Verständnis Tribut und erkor die LPG zum Promotor der Kultur auf dem Land ${ }^{150}$. Doch stand die Kulturarbeit im Parteivorstand 1953 wie später auf tönernen Füßen, zumal es nicht gelang, das zuständige Sachgebiet personell zu besetzen. Erst nach der Vollkollektivierung 1960, als mit den einzelbäuerlichen Wirtschaften die Kerne traditioneller kultureller Beharrung zumindest offiziell als abgeschafft galten, wagte man im August 1960 mit der Gründung der "Kommission zur Unterstützung der kulturellen Massenarbeit und des Sportes“ später kurz „Kulturkommission“ genannt - einen organisatorischen Neuanfang im Parteivorstand ${ }^{151}$.

\section{Landes- und Bezirksverbände}

Die Entwicklung der Landesverbände vollzog sich bis zu ihrer Auflösung im August 1952 in zwei Etappen ${ }^{152}$. Dabei unterscheidet sich die Gründungsphase 1948/49 erheblich von den Konstellationen ab 1950. Die organisatorische Struktur der Landesverbände und -vorstände folgte im Prinzip der des Parteivorstandes. Die 20-30 Landesvorstandsmitglieder wurden formal nach Vorschlag der Kreisverbände auf Landesparteitagen gewählt, die alle zwei Jahre stattfanden. Die Landesverbände verfügten bei der Auswahl der Kandidaten für den Landesvorstand zwar noch über einen gewissen Spielraum, doch eine "Prüfung der Würdigkeit“ des Kandidaten sah schon das Statut von 1949 vor, womit sich ein Einfallstor für zentrale Kaderkontrollen öffnete ${ }^{153}$. Inoffiziell mußte die Zusammensetzung des Gremiums auch die personalpolitische Abteilung der SED-Landesverbände pas-

Jugendkommissionen 8-15 Mitglieder umfassen. Neben der Vorsitzenden sollte der Frauenkommission ein Mitglied des Kreisvorstandes des DFD, eine Kreismitarbeiterin der VdgB, sowie Kolleginnen aus der Sozialfürsorgeverwaltung angehören. Für die Jugendkommission galt entsprechend: Neben dem Vorsitzenden war ein Mitglied des KV der FDJ, ein Acker- oder Viehwirtschaftsberater, ein Fach- oder Hochschüler und ein Kreisinstrukteur vorgesehen, außerdem müßte ein LPG-Mitglied und ein Kreistagsabgeordneter vertreten sein.

150 ACDP VI-052-0523, Protokoll Sekretariat, 21. 11. 1952. ACDP VI-052-102/3, Protokoll der Kulturkonferenz, 5. 3. 1953.

151 ACDP VI-052-0325, Protokoll Präsidium, 8. 8. 1960. Zur Aufgabe der Kulturkommission vgl. ACDP VI-052-103/1, zusammengefaßtes Material der Abt. Schulung und Werbung vom 1. 12. 1963 über die Beratung der Kulturkommission des PV am 21.11.1963 in Dresden. ACDP VI-052-0186, Protokoll PV, 30. 8. 1963, Vorschläge für die Kulturkommission des PV.

152 Vgl. dazu etwas pauschal an den Statuten ausgerichtet: Wernet-Tietz, Bauernverband, S. $124 \mathrm{f}$.

153 Statut von 1949, Ziffer 23, abgedruckt bei Wernet, Rolle, S. 271-274, hier S. 273. 
sieren ${ }^{154}$. Dieser Bestätigungspraxis fehlte es solange an Durchschlagskraft, als weder der DBD-Parteivorstand noch die Landes-SED umfassend über die einzelnen Personen im Bilde waren. Die sorgfältige Prüfung aller Kandidaten für Parteiämter hielt 1949 mit den rasant ansteigenden Mitgliederzahlen nicht Schritt. Erst 1950 wurde das Kontrollnetz engmaschiger geknüpft. Die hohe Fluktuation in den Landesvorständen bis zu den ersten Landesdelegiertenkonferenzen 1949 ist daher weniger auf "Säuberungen“ als auf mangelnde Bindungskraft der DBD zurückzuführen. Das ursprüngliche Interesse vieler Landesvorstandsmitglieder erlahmte mit der Enttäuschung über den immer offensichtlicher von der SED gelenkten Kurs der DBD ${ }^{155}$. Während die in der Parteiarbeit erfahreneren ehemaligen KPD-Mitglieder und Antifa-Schüler in den Gremien blieben bzw. kooptiert wurden, nahm die eigentliche Zielgruppe, die parteilosen Klein- und Neubauern, ihr Parteiamt in den Landesvorständen häufig nicht mehr wahr. Insgesamt fehlten aber in der Führung der Landesverbände politisch versierte Kader. Allein die frühere Mitgliedschaft in der KPD machte aus einem frischgebackenen Neubauern und Kollegen noch keinen organisatorisch geschickten und ideologisch sicher auftretenden Funktionär. Solange kein geeigneter Ersatz in Aussicht stand - und über ein gewisses Potential an geschulten Mitgliedern verfügte die DBD erst ab 1950 -, schufen Kontrollen keine Abhilfe. Zudem zog auch der Parteivorstand in Berlin geeignetes Personal aus den Landesverbänden ab.

Wie der Parteivorstand hatten auch die Landesvorstände ein Sekretariat und waren in Abteilungen gegliedert. War die Zahl der Sekretariatsmitglieder 1948 aufgrund Personalmangels noch bescheiden, so gehörten den Sekretariaten 1949 bis zu zwölf Personen an ${ }^{156}$. Da die Landesverbände dieses Personal weder finanzieren konnten noch die bescheidenen Mitgliederzahlen einen solchen Apparat rechtfertigten, drang der Parteivorstand auf eine personelle Reduzierung der Sekretariate und Abteilungen ${ }^{157}$. Das begünstigte letztlich die Handlungsfähigkeit der Sekretariate.

Die Anleitung und Kontrolle der Parteiführung über die Landesverbände vollzog sich sowohl über einzelne Sekretariatsmitglieder der Landesverbände als auch über die Landesvorsitzenden. Dabei trat zuweilen ein Dualismus innerhalb der Landessekretariate auf, weil einzelne Sekretariatsmitglieder oft besser informiert waren als die Vorsitzenden ${ }^{158}$. Dieses Informationsgefälle rührte zunächst daher, $\mathrm{daß}$ sowohl die SED-Landesverbände als auch die sowjetischen Behörden in der Regel über eine Vertrauensperson in jedem Landessekretariat verfügten, die meist nicht mit dem Landesvorsitzenden identisch war ${ }^{159}$. Weiter geriet die Anleitung

${ }^{154}$ Exemplarisch für Mecklenburg 1948/49 bis auf die Ebene der Kreisvorstände, Bauer, Gründung, S. 305-311.

155 Zusammensetzung und Fluktuation der Landesvorstandsmitglieder Mecklenburg, ACDP VI, unverz. Best. LV Mecklenburg.

156 Wernet-Tietz, Bauernverband, S. 124.

157 ACDP VI, unverz. Best., Protokoll Sekretariat Sachsen-Anhalt, 13. 1. 1949.

158 Vgl. dazu etwa die Reibereien zwischen dem stellvertretenden Landesvorsitzenden Voss und Sejna im Sekretariat in Sachsen-Anhalt, ACDP VI, unverz. Best. LV Sachsen-Anhalt, Protokoll Sekretariat Sachsen-Anhalt, 30. 8.1949.

159 ACDP VI-052-0141, Protokolle PV-Sitzung, 7. 8. und 26. 8. 1948. 
der Landesvorsitzenden durch den Parteivorstand in der Anfangszeit häufig ins Hintertreffen, sei es, weil 1948 organisatorische Probleme dominierten, oder weil die Verbindung zu den Landesverbänden infolge von Goldenbaums Beanspruchung durch das Ministeramt 1949 immer schwächer wurde ${ }^{160}$. Außerdem lief in den Landesverbänden 1949 das Schulungswesen, das ebenfalls anleitende Elemente weitertrug, nur sehr zögerlich an ${ }^{161}$. Die Umsetzung mancher politischer Direktiven des Parteivorstandes in agrarpolitischen Fragen ließ in den Augen der Landesvorsitzenden zu wünschen übrig ${ }^{162}$. In dieser Situation vertraute das Landessekretariat Sachsen-Anhalt 1948 auf die eigenen Fähigkeiten und begann ohne Richtlinien von oben zu agieren ${ }^{163}$. Außerdem faßte man im Dezember 1948 den Beschluß, Einspruch gegen die Besetzung der DWK zu erheben, da der Landesverband Sachsen-Anhalt personell übergangen worden sei.

Im Vergleich dazu unterschied sich die Situation in den Landesverbänden nach der Staatsgründung deutlich. Mehrere Faktoren trafen dabei zusammen: Erstens wurde die DBD für ihren Personalbedarf nun weitgehend selbst zuständig, nachdem die SED ihre unmittelbare Unterstützung mit Parteikadern eingestellt hatte. Die DBD mußte ihrerseits Kader heranbilden und ungeeignete Personen jetzt auch auswechseln. Zweitens mußte sie sich im Jahr 1950 in der Umsetzung des Zweijahrplanes erstmals politisch bewähren und Meriten im Einsatz gegen den Klassenkampf der sogenannten „Großbauern“ verdienen. Daher nahm die DBD eine erste "Parteisäuberung" vor, in der vornehmlich die Landesvorstände und -sekretariate umgebildet wurden. Die größte Anstrengung für die DBD lag 1950 jedoch darin, die hohe Arbeitslast in der Vorbereitung der Landtags- und Kommunalwahlen im Herbst 1950 zu tragen und den anschließenden Personalbedarf bei der Besetzung staatlicher Ämter wirklich adäquat zu decken. Die Landesverbände halfen sich hier untereinander mit geeigneten Kadern aus. So griffen andere Länder dem schwach organisierten Landesverband Thüringen 1950 mit Personalabstellungen unter die Arme ${ }^{164}$.

Ihre Position als Scharnier zu den Kreisverbänden, die agrar- und kaderpolitische Aufgaben durchführen mußten, verursachte besondere Anforderungen an die Landesverbände. Die Organe der Landesverbände mußten mit zuverlässigen Kadern besetzt werden, die ein realistisches Gesamtbild über den ideologischen Zustand und die Arbeit der lokalen Kader zusammentragen sollten. 1950 schuf man in den Landessekretariaten das Amt des politischen Hauptgeschäftsführers, der den Landesvorsitzenden zur Entlastung, aber auch zur Kontrolle der Sekretariatsarbeit an die Seite gestellt wurde. Die Landesvorsitzenden hatten nach ihrer 1948 oft übereilt getroffenen Kür in den folgenden Jahren die Gelegenheit genutzt und ihre Leitungsposition ausgebaut. Vielfach waren sie zu Symbolfiguren auf-

160 ACDP VI, unverz. Handakten Rose, Protokoll Sekretariat, 29.11. 1950, Beiträge von Martin und Scholz.

161 Siehe ACDP VI-052-0143, Protokoll PV, 11. 7. 1949.

162 ACDP VI, unverz. Handakten Rose, Protokoll Sekretariat, 29. 11. 1950, betr. Dorfwirtschaftspläne in Sachsen.

163 ACDP VI-053-26/1, Protokoll Sekretariat LV Sachsen-Anhalt, 11. 11. und 9. 12. 1948.

164 Ebd., Protokoll Sekretariat LV Sachsen-Anhalt, 3. 2. 1950. 
gestiegen, begünstigt durch den Gründungsmythos, der sie begleitete. Zu ihrer Popularität unter den Mitgliedern trug auch bei, daß die Parteipresse bis Ende 1949 neben den zentralen Figuren Goldenbaum und Scholz fast ausschließlich ihre Personen und die Bedeutung der Landesverbände hervorhob ${ }^{165}$. Bis Ende 1951 schieden alle ursprünglichen Landesvorsitzenden aus ihren Ämtern aus. Obgleich sich die Motive dafür unterschieden, lassen sie als Gesamttendenz erkennen, daß die Gründergruppe der Landesvorsitzenden oft in heftige Auseinandersetzungen in den Landessekretariaten verstrickt war, die sich u.a. am politischen Kurs der Partei entzündeten. Der von der Berliner Zentrale dekretierte Rückzug des Landesvorsitzenden Sachsen-Anhalts, Richard Richter, stieß im dortigen Sekretariat offenbar auf Ablehnung, wie der auffällig pathetische Stil des Sitzungsprotokolls nahelegt, das seine erstmalige Abwesenheit kommentierte ${ }^{166}$. Wie sehr die von der SMAD und den Einheitssozialisten diktierte Zentralplanwirtschaft innere Friktionen und Legitimationsdefizite förderte, illustriert auch das Ausscheiden von Otto Voss, Mitglied im Gründungsparteivorstand von 1948, aus dem Sekretariat Sachsen-Anhalts; das Sekretariatsprotokoll notierte hierzu: „Kollege Voss ergreift das Wort und führt aus, daß es für seinen Nachfolger nicht leicht sein wird. Die Dorftumspolitik ist nicht mit dem Wirtschaftsplan in Einklang zu bringen." 167 Neben der Auswechslung Richard Richters durch Hermann Gräfe war nur noch die Ersetzung von Friedrich Martin durch Fritz Petersohn im engen Sinne nachweislich politisch begründet ${ }^{168}$. Die Reaktionen der Betroffenen beleuchten ihre Enttäuschung: Richter verpflichtete sich beim MfS und spitzelte gegen die Ortsgruppen der DBD, Martin floh in den Westen und berichtete über die gesteuerte DBD-Gründung vor dem Untersuchungsausschuß freiheitlicher Juristen ${ }^{169}$. Sämtliche Nachfolger auf den Landesvorsitzen hatten entweder eine sowjetische Antifa-Ausbildung oder Parteischulen von DBD bzw. SED absolviert. In den Landessekretariaten mußten sie sich noch 1952 oft erst gegen die Parteigänger der geschaßten Vorsitzenden durchsetzen ${ }^{170}$. Der auf Führungspositionen zunächst begrenzte Personalaustausch konnte die durch zentrale Anleitung

165 „Bauern-Echo“, Jg. 1948, Jg. 1949.

166 ACDP VI-053-26/1, Protokoll Sekretariat LV Sachsen-Anhalt, 4. 4. 1951. Zum Fall Richter vgl. ebd., Protokoll Sekretariat, 16. 3. 1951.

167 Ebd., Protokoll Sekretariat LV Sachsen-Anhalt, 31. 5. 1950.

168 Richter und Martin hielt man im engeren Sekretariat für „politisch zu schwach“. BStU MfS AIM 1363/53, Personalakte Rose (= „Brose“); Abt. VI des MfS, B1. 23, Notiz über Gespräch mit „Brose“, 24. 11. 1950, zu dem seit 1948 geplanten Rückzug von Richter. Kritik an der Berichterstattung beider auch in ACDP VI-052-0520, Protokoll Sekretariat, 30. 5. 1950. Dem Wechsel in den übrigen Landesverbänden lagen andere Motive zu Grunde. Pilarski versetzte man höchstwahrscheinlich auf Veranlassung der SED, obwohl ihn die DBD für ungeeignet einschätzte, als Leiter der personalpolitischen Abteilung nach Berlin. Ihm folgte Ernst-Walter Beer im Landesvorsitz. Rudolf Albrecht (Brandenburg) wurde 1951 von Arthur Pech abgelöst, nicht weil er persönlich politisch belastet war, sondern weil die Ermittlungen gegen seinen vorgesetzten Minister Hamann (LDP) auch ihn involvierten. Herbert Hoffmann (Thüringen) übernahm die Funktion eines Hauptabteilungsleiters im MLF und wurde daher 1949 im Landesvorsitz von Albert Rödiger abgelöst.

169 Unrecht als System, Teil 2, S. $32 \mathrm{f}$.

170 So Gräfe 1952, ACDP VI-053-26/1, Protokoll Sekretariat Sachsen-Anhalt, 13. 2. 1952. 
eingeengte Eigenständigkeit und vor allem das Bewußtsein einer regionalen politischen Tradition nicht vollends ausradieren. Dazu bedurfte es eines umfassenderen Wechsels der ganzen Funktionselite, hier etwa der Mitarbeiter in den Sekretariaten und Abteilungen, die erst im Laufe der fünfziger Jahre ausgebildet werden sollten.

Referate für Frauen und Jugend wurden ab März 1950 in den Landesverbänden eingerichtet ${ }^{171}$. Insgesamt hinkte die Organisation dem öffentlich proklamierten und berichteten Engagement der Landesverbände in dieser Hinsicht jedoch deutlich hinterher ${ }^{172}$. Außerdem behinderte die geringe Akzeptanz von Frauen und Jugendlichen in Parteiämtern zu Beginn der fünfziger Jahre die Arbeit der neuen Referate. Diese Ressentiments teilten die Funktionäre in den Landes- und Kreisverbänden mit der Mitgliederbasis ${ }^{173}$.

Bei diesen Fragen und in der Verdrängung sogenannter Großbauern aus den Parteileitungen war 1950 die Kaderpolitik der Landesverbände gefordert. Mehr noch als auf zentraler Ebene wiesen die personalpolitischen Abteilungen der Länder 1950 jedoch erhebliche Mängel auf ${ }^{174}$. Nach dem Vorbild der SED wurde ab April 1950 das Instrukteurwesen auch in den Landes- und Kreisverbänden eingeführt ${ }^{175}$. Es sollte Anleitung und Kontrolle verbessern, 1950 vor allem bei der Mitgliederüberprüfung und der Propaganda für die Wahlen helfen ${ }^{176}$. Diese „Feuerwehr" fing oft die gröbsten organisatorischen Defizite in den Landessekretariaten und vor allem in den Kreis- und Ortsorganisationen auf. Instrukteure gaben praktische "Hilfestellung" in der Durchführung tagespolitischer Aufgaben wie Propagandaaktionen oder stellten mit den Ortsgruppen Dorfwirtschaftspläne auf. Damit nahmen sie den unwilligen und/oder unfähigen Kreis- und Ortsgruppen oft die Arbeit ab, obwohl sie eigentlich zur Selbsthilfe anleiten sollten. Schließlich entsandte man Instrukteurbrigaden häufig zur Disziplinierung in politische Krisengebiete, sei es um lähmende Auseinandersetzungen in der DBD zu schlichten, oder die für schuldig Befundenen zur Rechenschaft zu ziehen und aus den Parteigremien zu entfernen ${ }^{177}$.

Die Reorganisation der DBD in Anlehnung an den Verwaltungsumbau im Sommer 1952 veränderte nicht nur den Parteiaufbau, sondern rührte auch an das innere Kräfteverhältnis der Partei. Die Errichtung kleinerer Einheiten zielte auf

171 Der LV Mecklenburg reagierte offenbar schneller als andere. ACDP VI, unverz. Best. LV Mecklenburg, Anforderungen an IN-Karten erstmals für die Leiter der Referate Frauen (Lotte Gutberlet) und Jugend (Georg Böhm) im März 1950. In Sachsen-Anhalt gab es die Referate erst ab Mitte 1950. ACDP VI-053-26/1, Protokoll Sekretariat LV Sachsen-Anhalt, 11. 12. 1950.

172 Vgl. „Bauern-Echo“, 5. 7. 1949, 10. 11. 1949, 18./19. 11. 1949.

173 ACDP VI-053-26/1, Protokoll Sekretariat LV Sachsen-Anhalt, 3. 3. 1950.

174 Ebd., Protokoll Sekretariat LV Sachsen-Anhalt, 9. 5. 1950; dort habe die personalpolitische Abt. nur dem Namen nach bestanden.

175 Siehe dazu oben, S. 162.

176 ACDP VI-052-0143, Beschluß PV, 27. 3. 1950. Umgesetzt im LV Mecklenburg im April 1950, ACDP VI, unverz. Best. LV Mecklenburg, Anforderungen der personalpolitischen Abt. an IN-Karteien April 1950 erstmals für den Landesinstrukteur (Paul Lipski). Vgl. auch Wernet-Tietz, Bauernverband, S. 124.

177 ACDP VI-052-0526, Protokoll Sekretariat, 25. 1. 1954. 
eine tiefere organisatorische und politische Durchdringung und die Zerschlagung traditioneller politischer Gepflogenheiten in den Kreisen. Insgesamt nahm damit die Macht der regionalen Vorsitzenden ab: Der Kreis der fünf Landesvorsitzenden erweiterte sich 1952 auf 15 Bezirksvorsitzende, die gegenüber dem Sekretariat des Parteivorstandes nicht etwa an Einfluß gewannen, sondern im Vergleich zum vorhergehenden Zustand an Bedeutung und Prestige verloren. Denn parallel zur Abwertung der Vorsitzenden hielt der Funktions- und damit Machtzuwachs der Sekretariate und ihrer Apparate an. Organisationsleiter Rietz schlug 1955 vergeblich vor, die Parteispitze solle regelmäßige Aussprachen mit den Bezirksvorsitzenden durchführen, damit diese nicht nur über die Bezirks-Abteilungsleiter informiert würden und so „bewußter auftreten“ könnten ${ }^{178}$.

Grundsätzlich profitierte die Kaderpolitik von der inzwischen stabilen Position der DBD im Herrschaftsgefüge der DDR. Erst der gestiegene Mitgliederbestand 1952 durchstieß man die Marke 85000 - erlaubte eine sorgfältigere Auswahl und Heranbildung einer Funktionselite. Dies stärkte den Parteiapparat, der sich so auf seine Aufgaben in Anleitung und Kontrolle konzentrieren konnte. Kurzum, die DBD wandelte sich vom Typus der kampagnenartig ad hoc agierenden Partei, die bis Ende 1952 mit ihrem eigenen Aufbau vollauf beschäftigt war, zusehends in Richtung einer programmatisch festgelegten, organisierten und kadergestützten Transmissionspartei.

Was bedeutete dies für die organisatorische Gestalt der Bezirksverbände? Weiterhin leitete der Apparat des Parteivorstandes die Bezirksverbände an und kontrollierte ihre Tätigkeit. Sowohl die Kaderentwicklung wie auch die Besetzung der Bezirkssekretariate und -abteilungen wurde in Abstimmung mit den Abteilungen des zentralen Sekretariates bzw. des Präsidiums geregelt und von dort aus überwacht ${ }^{179}$. Die Einrichtung einer zentralen Kaderregistratur beim Sekretariat des Parteivorstandes 1952 unterstützte dieses Verfahren. Im Zuge der Parteireorganisation ab August 1952 übernahm der jeweilige Leiter der Abteilung Organisation zugleich die Geschäftsführung der Bezirkssekretariate ${ }^{180}$. Der stellvertretende Abteilungsleiter Organisation war besonders für Kader verantwortlich, solange keine selbständige Kaderabteilung bestand; im zentralen Parteivorstand existierte eine solche erst ab Mitte 1953. Die Besetzungen im DBD-Bezirkssekretariat basierten prinzipiell auf Absprachen mit der Kaderabteilung der SED-Bezirksleitung. Dennoch verfügten die Bezirksleitungen oft über keinen genauen Einblick in den inneren Zustand der Sekretariate und wußten wenig Bescheid über die Qualität der Sekretäre der Blockparteien, wie die entsprechenden ZK-Stellen wiederholt monierten ${ }^{181}$.

178 ACDP VI-052-0529, Protokoll Sekretariat, 6. 4. 1955.

179 So gliederte sich die Kaderabteilung beim Sekretariat des PV in drei Unterabteilungen, die bestimmte Bezirke bearbeiteten. Siehe auch die Vorlage in ACDP VI-052-0539, Anlage Protokoll Sekretariat 14. 9. 1959, Richtlinie zur Auswahl, Zusammensetzung und Qualifizierung der Kreis- und Bezirksvorstände, 10. 9. 1959.

180 ACDP VI-052-0523, Protokoll Sekretariat, 2. 8. 1952, Beschluß über Strukturplan der Partei.

181 Siehe S. $250 \mathrm{ff}$. 
Der Wandel der DBD zu einer Transmissionspartei verlief nicht ohne Friktionen. So faßte das Sekretariat des Parteivorstandes Anfang 1954 - offenbar aus gegebenem Anlaß - einen „Beschluß zur Verbesserung der organisationspolitischen Arbeit der Bezirkssekretariate"182. Die Vorlage listete einen beeindruckenden Mängelkatalog auf. Dieser reichte von der „Unterschätzung der Beschlüsse des Parteivorstandes und des Sekretariates“ über „[m]angelhafte Arbeitsorganisation“, "planlose Einsätze in den Kreisvorständen und Ortsgruppen“ und „ungenügende“ Beschlußkontrolle bis zum Manko, überhaupt keine persönlichen Verantwortlichkeiten für Beschlüsse festzulegen. Zur Verbesserung erteilte die Zentrale schlicht den Ratschlag, die Mißstände abzustellen, und setzte auf eine Arbeitsplanung, die auf minutiösen Quartals- und Monatsplänen basieren sollte, in denen die politische Verantwortung strikt personalisiert war. Diese negative Bestandsaufnahme und die litaneihafte Wiederholung einer stets ähnlich lautenden Mängelliste belegt zugleich, daß der Parteivorstand seinerseits Anleitung und Kontrolle der Bezirksverbände nicht hinreichend bewältigte. Sie unterstreicht, wie ungenügend die Bezirksapparate noch 1954 funktionierten. Schließlich legten die aufgetragenen Verbesserungen den Finger auf die empfindlichste Schwachstelle: Die Bezirkssekretariate mußten vor allem in der Anleitung der Kreisvorstände und Ortsgruppen an Boden gewinnen.

Um die Bezirks- wie Kreisverbände und letztlich die Einzelmitglieder für politische Ziele zu mobilisieren, inszenierte man regelmäßig innerparteiliche Wettbewerbe, z.B. im Jahr 1954 anläßlich der Volkskammerwahlen ${ }^{183}$. Als erstrebenswert wurde etwa deklariert, die Mitgliederzahl zu erhöhen, höhere Ernteerträge in möglichst kurzer Zeit zu erwirtschaften, die Eintrittszahlen in Genossenschaften zu steigern oder - so 1954 - die Wahlbeteiligung anzuheben. Dazu wurden Formen der Vergemeinschaftung erprobt, die zunächst eine Parteiidentität stiften sollten, beispielsweise im Wettkampf um die Wanderfahne der DBD; darüber hinaus zielten die Wettbewerbe darauf, die Funktionäre Prüfungssituationen auszusetzen und die Mobilisierungskraft des Apparates zu testen. Der letztplazierte Bezirk erhielt die zweifelhafte Ehre, die "rote Laterne" zu empfangen ${ }^{184}$. Solange die wirtschaftliche Leistung und die fachliche Fähigkeit der Teilnehmer neben der politischen Loyalität in die Bewertung einflossen, stieß das Wettbewerbswesen auch auf ideelle Akzeptanz.

Im Zuge der Umstrukturierung der zentralen Parteiebene 1955 erblickte man auch Handlungsbedarf bei den Bezirkssekretariaten. So erfolgte die Anleitung der Bezirksvorstände ab 1955 zusehends nach dem Ressortprinzip, d.h. sie wurde zwischen den zentralen Abteilungen und ihren Pendants in den Bezirken geregelt. Damit gab man die Praxis übergreifender monatlicher Berichterstattung ${ }^{185} \mathrm{der}$

182 ACDP VI-052-0527, Protokoll und Vorlage zur Sekretariatssitzung am 13. 4. 1954. Beschlußfassung in der Sekretariatssitzung am 22. 4. 1954, ebd.

183 Vgl. z. B. ACDP VI-052-0528, Protokoll erweiterte Sekretariatssitzung, 27. 10. 1954; ACDP VI-052-0521, Protokoll Sekretariat, 10. 4. 1951.

184 ACDP VI-052-0528, Protokoll erweiterte Sekretariatssitzung, 27. 10. 1954, Bericht Besler.

185 ACDP VI-052-0529, Protokoll Sekretariat, 13. 6. 1955. 
Bezirkssekretariate auf und verlangte statt dessen schnelle, detaillierte Berichte zu Sachfragen.

Mit der Entwicklung hin zur Kaderpartei, die am Prinzip des „demokratischen Zentralismus" ausgerichtet war, wurde auf der zentralen wie auf der Bezirksebene eine schärfere Trennung zwischen den Aufgaben der Sekretariate und derjenigen der Vorstände, kurz „Leitungen“ genannt, vollzogen. Den Bezirksvorständen wuchs dabei die Funktion zu, alle offiziell opportunen Mitgliedergruppen zu repräsentieren, um diese in die politische Mobilisierung einzubinden. Die Entscheidungskompetenz der Vorstände nahm sukzessive ab, die der Sekretariate hingegen zu.

Während der Vollkollektivierung 1959/60 fürchtete die zentrale Parteileitung, daß die Organisationen in den Bezirken und Kreisen zumindest teilweise - besonders dann, wenn sie noch Einzelbauern als Mitglieder zählten - wegbrechen könnten. Eine Umwälzung wie die Kollektivierung konnte aber auf die aktive Mitarbeit der Bezirks- und Kreisorganisationen nicht verzichten. Allein über Sekretariatsbeschlüsse und Brigadeeinsätze war die Kollektivierung weder durchführbar noch dauerhaft zu erhalten. Die DBD war auf die Tatkraft der Funktionäre an der Basis angewiesen. Da nur diese die Situation und vor allem die Personen in den Dörfern kannten, mußten sie die Rückbindung an die Basis gewährleisten, wenn Instrukteurkommandos wieder abzogen. Nachdem in vielen Fällen einzelbäuerliche Mitglieder kurzum aus den Bezirksvorständen verdrängt worden waren, formulierte man einen neuen Anforderungskatalog für Delegierte in Bezirks- und Kreisvorständen. In auffälliger Weise, aber angesichts der politischen Konstellation verständlich, galten für Bezirks- und Kreisvorstandsmitglieder der DBD künftig die gleichen Kriterien. Es genügte nicht mehr, daß Kandidaten fest zur Bauernpartei stünden, sie mußten vielmehr ihre Treue zur „Arbeiter- und Bauernmacht" schon bewiesen haben ${ }^{186}$.

\section{Kreisverbände, Ortsgruppen und Stützpunkte}

Nachdem sich im Sommer 1948 die Landesverbände der DBD konstituiert hatten, sollte die gesteuerte Gründung der DBD sukzessive in einen kontrollierten Aufbau von Kreisverbänden und von dort aus in Ortsgruppen münden. Obwohl sich die überwiegende Zahl der Kreisverbände der DBD formal noch 1948 gebildet hatte, wurden diese erst 1949 politisch aktiv ${ }^{187}$. Die meisten Kreisverbände hatten sich parallel zum rasanten Mitgliederwachstum 1950 und 1951 organisatorisch so weit stabilisiert, daß man es nun wagte, ihre Vorstände und Sekretariate personell zu „säubern“. Denn erst zu diesem Zeitpunkt stand Ersatzpersonal zur Ver-

186 ACDP VI-052-0539, Vorlage an das Sekretariat des Präsidiums des PV: Richtlinie zur Auswahl, Zusammensetzung und Qualifizierung der Kreis- und Bezirksvorstände 10. 9. 1959. Beschluß ebd., 14. 9. 1959. In der Praxis lief dies auf eine höhere Repräsentanz der Genossenschaftsbauern hinaus.

187 So bestanden im Herbst 1948 in Mecklenburg bereits $21 \mathrm{KV}$, in Sachsen waren immerhin in 25 von 29 Kreisen insgesamt 1095 Mitglieder in 53 Ortsgruppen erfaßt. Von den sächsischen KV würden aber erst 8-10 tatsächlich politisch arbeiten. ACDP VI-052-0141, Protokoll PV, 3. 12. 1948. Vgl. ACDP VI-052-0520, Protokoll Sekretariat, 30. 5. 1950. 
fügung. Bis zur Reorganisation des Verwaltungsaufbaus der DDR 1952 verfügte die DBD über 121 Kreisverbände, danach stieg die Zahl auf 194188. Nach 1952 waren die Kreisverbände zwar kleiner und von daher prinzipiell leichter zu organisieren, zunächst jedoch vergrößerte sich die Diskrepanz zwischen Kaderbedarf und Kaderreservoir erheblich. Da der Bedarf höherer Parteigliederungen sowie in Regierung und Verwaltung vorrangig zu erfüllen waren, litten die mit hauptamtlichen Funktionären zu besetzenden Positionen in den Kreissekretariaten am stärksten unter der Kaderknappheit.

In der Organisationsstruktur der DBD nahmen die Kreisverbände eine Schlüsselrolle ein. Ihre politische Ausrichtung und personelle Besetzung entschied letztlich über die Durchschlagskraft der Partei vor Ort. Denn als unmittelbares Verbindungsglied zu den Grundeinheiten sollten sie diese systematisch erfassen und damit die direkte Mobilisierung der Landbevölkerung erreichen ${ }^{189}$. Andere Anleitungs- und Kontrollmechanismen gegenüber den Ortsgruppen, wie punktuelle und zeitlich begrenzte Instrukteureinsätze, taugten kaum dazu, die latente „Brandgefahr" dauerhaft einzudämmen. Daneben fiel den Kreisverbänden zumindest für eine gewisse Zeit die Funktion zu, die Interessen der ländlichen Bevölkerung in den Parteiapparat einzubringen. Diese Aufgabe sollten die ab Januar 1950 unter erheblichem organisatorischen Aufwand gegründeten Kreiswirtschaftskommissionen erfüllen. Sie waren außerdem für die Umsetzung des Wirtschaftsplanes in den Kreisen zuständig ${ }^{190}$. In ihnen wirkten 1950/51 überwiegend Neubauern mit, Altbauern verweigerten häufig ihre Unterstützung ${ }^{191}$. Insgesamt gelang nur eine mäßige Mobilisierung der Mitglieder über diese Einrichtungen, die in größerem Stil erst im Winter 1950/51 arbeiteten ${ }^{192}$. Viele hätten nur auf dem Papier existiert, andere betrachteten sich als eine „eigene Art VdgB“, resümierte der Abteilungsleiter Wirtschaft des Parteivorstandes, Otto Keuthe, im Juni 1951. Keuthes Forderungen gemäß sollten sich die Kommissionen weniger die Interessen der Bauern zu eigen machen als „rechtzeitig signalisieren, wenn Gefahren auftauchen, wachsam sein, vor allem gegenüber allen Schädlingen“. Sie sollten Meinungen einfangen, um sie politisch zu neutralisieren. Insgesamt dienten die Kom-

188 Wernet-Tietz, Bauernverband, S. 127.

189 Vgl. ACDP VI-052-0523, Vorlage Abt. Organisation betr. Strukturplan der Partei, 1. 8. 1952.

190 ACDP VI-052-26/1, Protokoll Sekretariat LV Sachsen-Anhalt, 29. 3. 1950. Ebd., Protokoll Sekretariat LV Sachsen-Anhalt, 31. 5. 1950. Schon 1949 hatte man sich um die wirtschaftsstrukturelle Durchleuchtung der Kreise mit Hilfe sog. „Kreisspiegel“ bemüht, die die DBD eigenverantwortlich für jeden Kreis anlegen wollte. Schon die Datenerhebung stieß auf Ablehnung der Landratsämter. ACDP VI-052-222/1, Kreisrat des LK Pirna an DBD, KV Pirna, 28. 12. 1949.

191 Instrukteurberichte aus verschiedenen Ländern, ACDP VI-052-222/1. Bis Mitte 1951 ging in keinem Land die Zahl der regelmäßig berichtenden Kommissionen über 3-4 hinaus. ACDP VI-052-235/4, Ausarbeitung von Otto Keuthe, Zur Agrarpolitik der DBD, 21.6. 1951.

192 ACDP VI-052-222/1, Auszüge Instrukteurberichte. Von regelmäßigen Tagungen der Kreiswirtschaftskommissionen wurde nur aus den Kreisvorständen Sangershausen, Wittenberg und Bernburg berichtet; in Bernburg habe die DBD sogar den besten Dorfwirtschaftsplan vorgelegt. 
missionen zwar dazu, den Fünfjahrplan zu propagieren und die Mitglieder zu mobilisieren, aber „durchweg stehen die eigenen Sorgen im Vordergrund dessen, was berichtet wird, selten sind es Vorschläge, wie etwas gebessert werden kann"193.

Während die Kreisvorstände ihre Aufgabe ehrenamtlich ausübten ${ }^{194}$, waren die Kreissekretariate nach Möglichkeit ab 1950, verbindlich ab August 1952 - im Idealfall - mit drei hauptamtlichen Funktionären besetzt, dem 1. und 2. Kreissekretär sowie einem Kreisinstrukteur ${ }^{195}$. Die Kreisvorsitzenden wurden auf den jährlich abgehaltenen Kreisdelegiertenkonferenzen oder ab 1961 Kreisparteikonferenzen gewählt. Auch auf dieser Organisationsebene wird der Funktionsunterschied zwischen Vorständen und Sekretariat deutlich: Wurden die Hauptamtlichen in den Sekretariaten von oben mit politisch möglichst einwandfreien Kadern besetzt, so gestattete man den Vorständen einen gewissen personellen Spielraum, wie an der weniger reglementierten sozialen Herkunft der Vorstände abzulesen ist. Letzteres war eine Mischung aus gewährtem Freiraum und gewollter Lücke. Denn die Vorstände sollten trotz ihrer Konstruktion auch die Sozialstruktur der Basis - im Parteiorgan ihren gesellschaftlichen Entwicklungsstand - widerspiegeln, die politische Debatte aufgreifen und oppositionelle Verhaltensweisen so bannen. Einzeln wirtschaftende Bauern übernahmen häufiger die ehrenamtliche Position eines Vorstandes denn die hauptamtliche Tätigkeit eines Sekretärs, weil unter letzterer ihre Betriebsführung litt und sie stärkerer Bevormundung ausgesetzt waren.

Während die Kreissekretariate 1950 und 1951 umfassend "gesäubert" wurden ${ }^{196}$, fand die weitgehende Verdrängung der „Großbauern“ aus den Vorständen erst phasenverschoben bis 1954 statt: Nach dem II. Parteitag der DBD 1951 waren noch 4,3\% aller Vorstandsmitglieder sogenannte "Großbauern“; erst nach dem III. Parteitag 1953 ging der Anteil auf 0,5\% zurück ${ }^{197}$. Seit der Reorganisation der Kreisverbände 1952 waren die Bezirkssekretariate dazu verpflichtet, Besetzungsvorschläge für die Kreise beim Parteivorstand zur Überprüfung und Bestätigung einzureichen ${ }^{198}$. Vor diesem Hintergrund ist die Zusammensetzung der Vorstände vor 1952 als Indikator für die Bindungskraft der DBD noch geeignet, da ein Engagement dort über bloße Parteimitgliedschaft hinausging und die Besetzung noch weniger kontrolliert wurde ${ }^{199}$.

193 ACDP VI-052-235/4, Ausarbeitung Otto Keuthe, Zur Agrarpolitik der DBD, 21.6. 1951.

194 So Reichelt, Blockflöte, S. 60, nach Wernet-Tietz, Bauernverband, S. 125, waren sie überwiegend ehrenamtlich tätig.

195 Die Kreissekretariate entlang der Zonengrenze und solche mit über 80 Gemeinden sollten mit vier hauptamtlichen Kräften ausgestattet sein. ACDP VI-052-0523, Vorlage Abt. Organisation betr. Strukturplan der Partei, 1. 8. 1952.

196 Beispielsweise ACDP VI-053-26/1, Protokoll Sekretariat Sachsen/Anhalt, 29.3. 1950; für Mecklenburg ACDP VI-052-0521, Protokoll Sekretariat Mecklenburg, 10. 4. 1951.

197 ACDP VI-052-154/1, Fragebogen 1953: Großbauern in den Ortsgruppenvorständen. Vgl. ihr Anteil an der Gesamtmitgliederschaft: 1951 4,6\%, 1953 3,9\%. Ebd., Zusammensetzung der Kreisvorstände 4. 4. 1951.

198 ACDP VI-052-0523, Vorlage Abt. Organisation betr. Strukturplan der Partei, 1. 8. 1952.

199 Es liegen keine durchgehenden statistischen Reihen zur Sozialstruktur der Kreisvorstände bis 1963 vor; die oft punktuell und stichprobenartig erhobenen Daten können aufgrund unterschiedlicher Erhebungskriterien nicht unmittelbar miteinander in Beziehung 
Die Kreisvorstände waren 1951 eine Domäne männlicher Erwachsener. Auffällig ist der Anstieg der Angestellten auf fast 30\%. Diese Zahl illustriert den Wandel der Sozialstruktur der ländlichen Bevölkerung und die Konstruktion einer neuen Führungsschicht mittels junger, in erster Linie politisch und oft nachgeordnet fachlich ausgebildeter Funktionseliten in den Apparaten der landwirtschaftlichen Organisationen ${ }^{200}$. Dagegen behielt sich die SED die Werbung von Arbeitern in landwirtschaftlichen Berufszweigen vor, worauf der geringe Anteil von $5 \%$ in der DBD hindeutet. Betrachtet man die im engeren Sinne bäuerlichen Vorstandsmitglieder, so hatte die DBD bis 1951 ihren Parteiauftrag erfüllt, vorrangig kleine und mittlere Neu- und Altbauern und vor allem auch die "Umsiedler" anzuwerben. Der Anteil der Neubauern von einem knappen Drittel (31,7\%) unter allen Kreisvorständen überstieg den altbäuerlichen von rund einem Viertel $(23,5 \%)$; der zu dieser Zeit noch gesondert ausgewiesene „Umsiedleranteil“ lag etwas darunter bei einem Fünftel $(20,7 \%)^{201}$. Damit korrespondieren Beobachtungen, wonach sich die „Umsiedler" innerhalb der dörflichen Gemeinschaft und der DBD-Basis oft inferior fühlten, es nicht wagten und z.T. nicht schafften, gegen die altbäuerliche Konkurrenz in politische Ämter vorzustoßen ${ }^{202}$. Die traditionellen Einflußbereiche eingesessener Dorfeliten waren 1951 noch deutlich spürbar.

Der Anteil an ehemaligen Mitgliedern der NSDAP lag beträchtlich hoch bei $17,1 \%$ - insbesondere wenn man bedenkt, daß die Rekrutierung der NSDAP unter der Bauernschaft als eher gering einzustufen war ${ }^{203}$. In welchem Maße die DBD ihre Funktionäre mit Unterstützung der SED, dadurch aber auch auf deren Kosten, heranzog, belegt der Anteil von gut einem Fünftel (21,5\%) ehemaliger SED-Genossen. Die kleine Schar vormaliger Mitglieder von CDU und LDP rührt aus dem insgesamt geringen Einbruch in die Mitgliedschaft bürgerlicher Parteien her; diese als suspekt eingeschätzten Parteiwechsler sollten tendenziell nicht in die Vorstände gelangen.

Die Kreisvorstandswahlen 1951 spiegeln das rasante Anwachsen der Partei204 und die personellen Vorgaben wider: Während die Sozialstruktur erhalten blieb, wurde der Anteil Jugendlicher von 11\% auf über 20\% festgesetzt; gleichzeitig kletterte der Anteil von Absolventen einer Landes- oder Zentralparteischule der DBD von $28 \%$ auf $35 \%{ }^{205}$. Auch die Zahl der sogenannten "Umsiedler" stieg

gesetzt werden. Zum folgenden: Tabelle 15, erstellt nach ACDP VI-052-154/3, Zusammensetzung der Kreisvorstände 4. 4. 1951, Aufstellung dort auch nach Ländern untergliedert.

200 So konnte die DBD in den VEABs, den MAS bzw. MTS, den Dorfgenossenschaften, der VdgB etc. eine Vielzahl mit der Landwirtschaft „verbundene“ Personen als Mitglieder gewinnen.

201 Die Statistik von 1951 ist die letzte, die den Umsiedleranteil gesondert von den Neubauern ausweist. Nur ganz vereinzelt finden sich danach noch Angaben über Umsiedleranteile in Parteigremien, wie z.B. für den PV 1960, ACDP VI-052-0017, Aufstellung PV 1960.

202 Vgl. z.B. ACDP VI-052-0141, Protokoll PV, 8. 10. 1948.

203 Broszat, Staat, S. 354.

204 Damit gehörten im Schnitt je 17 Personen den 121 Kreisvorständen an.

205 ACDP VI-052-154/3, Zusammenstellung der Kreisvorstände nach der Neuwahl 1951, 21. 7. 1951. 101 KV-Mitglieder waren der DBD erst 1951 beigetreten. 
jetzt von 350 auf 440 Vorstandsmitglieder an und lag damit knapp über der Zahl an Altbauern von 433. Insgesamt drang die DBD in ihrer Wachstumsphase 1950/51 auch in das traditionelle dörfliche Milieu ein. Zusammen mit dem überwiegend neubäuerlichen Mitgliederreservoir der Gründungszeit bildete sie damit eine Mischung von Tradition und Wandel in der ländlichen Gesellschaft ab, die in dieser Zusammensetzung keine andere Partei aufwies.

Grundsätzlich bemühte sich die Parteileitung bis Ende 1956 um eine ausgewogene Zusammensetzung der Kreisvorstände. In erster Linie sollten fachlich fähige und wirtschaftlich erfolgreiche "werktätige Bauern“, die ihre Parteiverbundenheit durch Loyalität zur SED-Herrschaft bewiesen hatten, sowie die stets als besonders förderungswürdig erachteten Frauen und Jugendlichen die Vorstände besetzen. Loyalität war im SED-Verständnis z. B. abzulesen an der Erfüllung der Ablieferungspflicht oder im Engagement für das Gemeinwohl des Dorfes. Die lokale Reputation des Kandidaten im Dorf spielte eine erhebliche Rolle ${ }^{206}$. Allerdings geriet dieses Besetzungskonzept im Zuge der forcierten Sozialisierung der Landwirtschaft in Konflikt mit dezidierten Parteivorgaben, denen zufolge Genossenschaftsbauern vorrangig und überproportional in die Parteileitungen zu wählen waren ${ }^{207}$, schon im Vorgriff auf eine erst noch herbeizuführende soziale Umwälzung auf dem Land.

Der Organisationsgrad und die Funktionstüchtigkeit der Kreisverbände kann auch als Indikator für Zustimmung und Ablehnung der Mitglieder gewertet werden, wobei aufgrund fehlenden statistischen Materials dazu nur qualitative Aussagen möglich sind ${ }^{208}$ : Während des Parteiaufbaus und des ersten Expansionsschubs 1950/51, der mit einer rigoroseren Kaderprüfung abgesichert werden sollte, gelang es zwar, die Kreisverbände zu stabilisieren, die Verantwortung für den politischen Kurs lastete jedoch weitgehend auf den hauptamtlichen Funktionären im Kreissekretariat. Die Vorstandschaft war dagegen politisch und sozial inhomogen zusammengesetzt. Die daraus resultierende Spaltung der Handlungsfähigkeit der Kreisverbände schränkte die Durchschlagskraft der DBD eminent ein. Die Mit-

206 Daher sollten keine Nominierungen für die Volkskammer ohne Zustimmung der Ortsgruppen erfolgen, da man vor Ort am besten wüßte, wie ein Kandidat tatsächlich sei.

207 Bis 1955 galt für Wahlordnungen der Grundsatz, in den Kreisvorständen den Anteil der Einzelbauern in den Grundeinheiten abzubilden; 1956 verzichtete man sogar auf eine dezidierte Festlegung. 1958 strich man eine Passage aus der vorbereiteten Wahlordnung, die die besten werktätigen Einzel- und Genossenschaftsbauern in einem Zug nannte. Im Zuge der Vorbereitungen des für 1959 geplanten VI. PT waren noch Einzelbauern als Parteitagsdelegierte vorgesehen. Bis zur tatsächlichen Durchführung des PT 1960 gab es offiziell nur noch Genossenschaftsbauern. ACDP VI-052-0521, Protokoll Sekretariat, 10. 4. 1951, ACDP VI-052-0524, Vorlage der Abt. Organisation an Sekretariat, 31. 3. 1953. ACDP VI-052-0525, Protokoll Sekretariat, 7. 12. 1953, mit Wahlordnung. ACDP VI-052-0529, Protokoll Arbeitssekretariat, 12. 3. 1955, ACDP VI-052-0533, Protokoll Sekretariat, 6. 11. 1956, Wahlordnung. ACDP VI-052-0535, Protokoll Sekretariat, 4. 11. 1957, Vorlage vom 1. 11. 1957, ACDP VI-052-0539, Protokoll Sekretariat, 19. 10. 1959, ACDP VI-052-0541, Protokoll Sekretariat, 14. 3. 1960.

${ }^{208}$ Für die DBD liegt keine auch nur ansatzweise durchgehende Berichterstattung etwa zur Sitzungshäufigkeit der Kreisvorstände, zur Durchführung der Ortsgruppenschulungen etc. vor. 
gliederbasis hoffte in dieser Phase zum größeren Teil auf wirtschaftliche Unterstützung durch die DBD angesichts der Mangelwirtschaft und war zum kleineren Teil enttäuscht von den politischen und wirtschaftlichen Zuständen. Fluktuation und Instabilität, aber auch zunehmend politische Ausbildung der Kader charakterisierten diesen Zeitabschnitt.

Nur dank Schulung und Personalüberprüfungen konnte die hohe organisatorische Last der Reorganisation der Kreisverbände im August 1952 aufgefangen werden. Die Kollektivierung trug das gesamte Spektrum dörflicher Konflikte in die Partei hinein und zerriß die Basis in Aktivisten und Desillusionierte. Trotz der Abdämpfung des Kollektivierungstempos nach dem Volksaufstand waren die Kreisverbände 1954 in eine tiefe Lethargie versunken ${ }^{209}$. Erst allmählich mußte das angeschlagene Vertrauen und Interesse der Einzelbauern für die DBD wiedergewonnen werden, was dann auch die Aktivität der Kreisverbände anregte. Nach dem lebhaften Zuspruch der Basis für die reformerischen Überlegungen von Kurt Vieweg im Jahr 1957 stellte das Sekretariat Anfang 1958 fest, daß sich Kreisvorstandsmitglieder aus der Parteiarbeit zurückzogen, weil sie mit dem Eintritt in eine LPG nicht einverstanden seien ${ }^{210}$. Der Vollzug der Zwangskollektivierung bis 1960 unter völliger Mißachtung einzelbäuerlicher Belange bewirkte einen weitgehenden Stillstand der Arbeit der Kreisverbände, sofern diese nicht schon vorher überwiegend mit Genossenschaftsbauern besetzt waren. Zahlreiche Kreisvorstandssitzungen waren 1960 mangels Beteiligung nicht beschlußfähig. Manche Verbände mußten neu gegründet werden. Man versuchte umso beharrlicher, passive Mitglieder zu reaktivieren, als Neuaufnahmen seitens der SED ab 1961 wieder strikter reglementiert wurden und mit den Büros der SED-Kreisleitungen einzeln abzusprechen waren. Erst durch die Mitarbeit der neu installierten dörflichen Führungseliten in den LPG und anderen sozialistischen Agrarbetrieben stabilisierten sich die Kreisverbände langsam wieder.

Die Ortsverbände hatten nach dem politischen Programm und dem Ziel einer schichtenspezifischen Transmissionspartei die Aufgabe, den bis 1948 nur unzulänglich politisch erschlossenen ländlichen Raum auf unterster Ebene zu durchdringen. Die DBD war von Anfang an auf das Wohnbezirksprinzip in ländlichen Gegenden verwiesen. Die sowjetischen Kommandanturen hatten festgelegt, daß eine Ortsgruppe aus mindestens zehn Mitgliedern bestehen müsse; bei drei bis neun Mitgliedern sprach man von Stützpunkten. Die Ortsgruppenvorstände wurden jährlich neu gewählt und zählten mindestens fünf Personen ${ }^{211}$. Die Grundeinheiten wurden von den Kreissekretariaten, vor allem den Kreisinstrukteuren angeleitet und kontrolliert; man versuchte ihnen beizubringen, politische Schwenks in Versammlungsbeschlüssen an die Basis weiterzugeben ${ }^{212}$. Da schon die Anlei-

209 ACDP VI-052-0525, Protokoll Sekretariat, 25. 7. 1952; ACDP VI-052-0523, Protokoll Sekretariat, 21. 11. 1952. ACDP VI-052-0526, Protokoll Sekretariat, 18. 1. 1954; ACDP VI-052-0528, Protokoll Sekretariat, 4. 10. 1954.

210 ACDP VI-052-0321, Protokoll Präsidium, 7. 1. 1958.

211 Wernet-Tietz, Bauernverband, S. 127; Statut von 1949, Ziffer 18, abgedruckt in: Wernet, Rolle, S. 271-274.

212 Die Kreissekretariate bereiteten daher Versammlungen der Ortsgruppen gemeinsam mit jenen Mitgliedern vor, die für die beabsichtigte Veränderung eintraten. Wenn ein groß- 
tung der Kreisverbände durch die Bezirkssekretariate an vielen Defiziten litt, pflanzte sich diese Tendenz erst recht in der Anleitung der Ortsgruppen fort, denn die Kreissekretariate verfügten kaum über entsprechend geschultes Personal213.

Ein Beispiel aus der Parteipraxis 1954 gewährt Einblick in die Durchsetzungskraft der Kreissekretariate gegenüber den Ortsgruppen: Danach waren die Kreise angesichts schwindender Mitgliederzahlen durch Ausschlüsse und Austritte massiver Kritik der Berliner Organisationsabteilung ausgesetzt. Die Kreissekretariate würden die Ortsgruppen und Stützpunkte ungenügend anleiten, die Austrittsmotive nicht erforschen, die Erfolge der Partei nicht popularisieren und zu wenig auf „Sorgen, Kritik und Anträge der werktätigen Bauern“ eingehen ${ }^{214}$. Besonders kritisierte man die hohe Zahl der Ausschlüsse von Einzelbauern und deren mithelfenden Angehörigen durch die Kreissekretariate, die anscheinend keine andere Parteistrafe als den Ausschluß kennen und praktizieren würden; außerdem würden sie die Abgestraften nicht über die Möglichkeit der Revision beim nächsthöheren Parteischiedsgericht informieren. Die Kreise vernachlässigten die ideologische Kärrnerarbeit mit allen Grundeinheiten und beschränkten sich auf die Anleitung von „Paradeortsgruppen“, die sie gerne besuchten, während Problemgruppen vereinsamten ${ }^{215}$.

Dieses Beispiel verdeutlicht zweierlei: zunächst die problematische Mittelstellung der Kreisfunktionäre, die zwischen ideologischem Druck von oben und der Reaktion der Mitglieder zerrieben zu werden drohten. Jedenfalls bekamen stets sie das Gros der Kritik oberer Leitungen zu spüren, denn diese richtete sich aus taktischen Gründen nie unmittelbar gegen die Basis. Darüber hinaus ist festzuhalten, daß ein erheblicher Teil der Ortsgruppen ohne Anleitung agierte. Diese Lücke schuf ideologischen Spielraum und ließ Platz zur Ausgestaltung des innerparteilichen Lebens. So waren im ersten Halbjahr 1954 nur insgesamt 34,5\% der Mitglieder in Ortsgruppenversammlungen anwesend, mit der Tendenz, im jahreszeitlich bedingten Arbeitsrhythmus im Sommer unter $30 \%$ zu rutschen 216 .

bäuerlicher Ortsgruppenvorsitzender abzuwählen war, mußte dafür erst ein Gegenkandidat gewonnen werden, der großbäuerliche Vorsitzende innerhalb der Mitglieder erst „isoliert“ - also seine Anhänger von seiner angeblichen Unzulänglichkeit überzeugt werden.

213 Zwar zeigen für 1954 überlieferte Zahlen, daß die Kreissekretariate in dieser Zeit ihre Anleitungsfunktion ernst nahmen: In der ersten Hälfte 1954 besuchten sie immerhin $86 \%$ der Ortsgruppenversammlungen und übertrafen die Besuchsquote des Vorjahres um $10 \%$. Diese Werte vermitteln jedoch insofern ein schiefes Bild, als die Zahl der in den Versammlungen erreichten Mitglieder, die für obiges Beispiel die Basis bildet, insgesamt gering war. ACDP VI-052-183/2, Bericht über die organisatorische Entwicklung der Partei, 25. 8. 1954; ebd., Veränderungen in den Vorständen unserer Ortsgruppen, 3. 8. 1954.

214 Ebd., Bericht über die organisatorische Entwicklung der Partei, 25. 8. 1954.

215 So erklärt sich der relativ hohe Anteil der vom Kreissekretariat besuchten Ortsgruppenversammlungen 1954, ebd.

216 Ebd., Versammlungstätigkeit: Einschätzung der Arbeit der Partei 1954. Ohne den BV Berlin, dort war die Erfassung mit $63 \%$ am höchsten, lag der Durchschnitt bei $31 \%$, am niedrigsten war die Beteiligung im BV Halle mit rund $26 \%$ der Mitglieder, am höchsten im BV Schwerin mit rund $40 \%$. Die Beitragskassierung bewegte sich zwischen $68 \%$ im BV Rostock und 99\% im BV Karl-Marx-Stadt und lag im Schnitt bei $83 \%$ einschließlich des BV Berlin. 
Auf die Frage, inwiefern die SED eine entscheidende Kontrolle über die $\mathrm{Zu}-$ sammensetzung der Ortsgruppenvorstände ausübte, gibt es keine pauschale Antwort $^{217}$. Nominell dürfte die lokale SED die Personalentscheidungen innerhalb der DBD-Ortsgruppe zwar tatsächlich bestätigt haben, in der Praxis hat diese Überwachung in vielerlei Hinsicht jedoch nur eingeschränkt gegriffen ${ }^{218}$. Grundsätzlich ist so lange nicht von einer umfassenden Kontrolle durch die SED auszugehen, als die SED-Ortsgruppen diese Prinzipien nicht selbst in der eigenen Parteiorganisation durchgesetzt hatten. D.h. zwischen dem Ausbau der SED zu einer „Partei Neuen Typs" mit umfassendem Kontrollapparat bis in die Grundeinheiten und der Kontrollaufgabe gegenüber den anderen Blockparteien bestand ein enger funktionaler Zusammenhang.

Je nach Umfang und Verhältnis aller Blockparteien vor Ort dürfte die SED sich außerdem vorrangig um den Zustand von CDU und LDP gekümmert haben, erst zweitrangig um die DBD, es sei denn, letztere war die lokale Hauptkonkurrentin. Diese Konstellation war vor allem in neubäuerlich geprägten Gemeinden Mecklenburgs und Brandenburgs häufiger anzutreffen, als von der Forschung bisher angenommen wurde. Denn oft bestanden in neubäuerlich dominierten Gemeinden nur SED und DBD; die Gründung der Bauernpartei, die überwiegend bisher Parteilose an sich band, verhinderte somit die Entstehung von Ortsgruppen bürgerlicher Parteien. Zwar verfügten die SED-Ortsgruppen insoweit an Einfluß, als sie einzelne für sie untragbare DBD-Vorstandsmitglieder entfernen konnten. Diese "Waffe“ taugte jedoch nur für den Einzelfall. Die grundsätzliche soziale Zusammensetzung der Ortsgruppenvorstände war zwar auch durch allgemeine SED-Vorgaben definiert, die Durchführung hing jedoch von Anordnungen der DBD und mehr noch vom tatsächlichen Vollzug ab. Allein die Bestätigung durch die SED-Ortsgruppe war also kein geeignetes Steuerungsinstrument hierfür. Es hätte die SED zu offensichtlich zum Neinsager gegenüber der DBD gestempelt, worauf wiederum die Ablehnung der DBD-Kollegen gedroht hätte.

Zur Organisationsgeschichte der Parteibasis, den Ortsverbänden, liegen quantitativ und qualitativ die wenigsten Informationen vor ${ }^{219}$. Der von oben nach unten konstruierte Gründungsverlauf im Jahr 1948/49 mündete 1950 in einen Gründungsboom ${ }^{220}$. Allein in 14 Monaten, von Januar 1950 bis Februar 1951, stieg die Zahl der Ortsgruppen von 2769 auf $4205^{221}$. Bisweilen unterschied die Parteispitze daher zwei Generationen von Ortsgruppen: solche der Anfangszeit

217 Wernet-Tietz, Bauernverband, S. 127, spricht von einer allgemeinen Bestätigung aller Ortsgruppenvorstände durch die SED, wobei er sich auf Mitteilungen des Ost-Büros der SPD stützt.

218 Vgl. z.B. auch die Zunahme der Aufnahmen von Großbauern 1958 (7), die vermutlich nicht von der SED gebilligt worden sein dürfte. ACDP VI-052-160/7, Einschätzung der organisatorischen Entwicklung in den Monaten März bis April 1958, 5. 5. 1958.

219 Quellenmaterial aus der Provenienz von Ortsgruppen sind nicht überliefert. Teilweise finden sich eingehendere Beschreibungen einzelner Ortsgruppen in Brigadeberichten.

220 Zum folgenden Organisationsstatistiken der DBD 1948-53, ACDP VI-052-154/1, 179/1, $180 / 2,183 / 1$.

221 ACDP VI-052-154/1, Organisatorische Entwicklung der DBD 1950; ebd., Organisatorische Entwicklung der DBD der letzten 5 Monate, vom 1. 10. 1950 bis 28. 2. 1951. 
und die ab 1950 neu gegründeten. Weil sich die „alten“ Ortsgruppen in Zeiten politisch härterer Gangart gegen sogenannte "Großbauern" und der Produktionspropaganda zur Durchsetzung des Wirtschaftsplans zurückhielten und politisch inaktiv blieben, mußte sich die Parteileitung mit dem neu eingeschlagenen Kurs vorrangig auf die jüngeren Ortsgruppen stützen 222 .

1952/53 stagnierten die Zugänge an Mitgliedern und Ortsgruppen: Während die Partei bis dahin erhebliche Wachstumsraten verbuchen konnte, wurde die Zahl der Neuaufnahmen von 17167 im Jahre 1952 von den erstmals fast ebenso hohen Abgängen überschattet 223. Dennoch befand sich die Partei noch bis Februar 1953 auf Wachstumskurs. Die Krise des Jahres 1953 zeichnete sich im Organisationsstand der Grundeinheiten bereits im Frühjahr ab und korreliert hier mit dem gleichzeitig voll durchgreifenden Kollektivierungsdruck der DBD und der schon seit Ende 1952 anhaltenden Wirtschaftskrise auf dem Land ${ }^{224}$. Im Februar 1953 erreichte die Anzahl der Ortsgruppen den Höchststand von 5133, begleitet von 1723 Stützpunkten (zusammen 6856) und 312 Betriebsgruppen ${ }^{225}$. Die Betriebsgruppenzahl wurde auf Veranlassung der SED schon im folgenden Monat März auf 88 heruntergedrückt, die Zahl der Ortsgruppen sank bis Ende 1953 auf 4844, mit 1902 Stützpunkten (zusammen 6746) und nur noch 18 Betriebsgruppen. $\mathrm{Zu}$ diesem Zeitpunkt konnten die sinkenden Mitgliederzahlen noch durch den Umbau von Ortsgruppen in Stützpunkte aufgefangen werden. Parallel sank die Mitgliederzahl ebenfalls ab Februar 1953 von 86280 auf 81704 im Dezember 1953226. Trotz Mitgliederverlust schaffte es die DBD insgesamt, ihren bis dahin erreichten Organisationsapparat über die Krise 1953 hinüberzuretten. Sie war als Partei auf dem Land also fest installiert.

Ab 1955 wurde die weitere Untergliederung großer Ortsgruppen in Wohnbezirksgruppen vorgenommen. Ortsgruppen in Städten hießen nun Stadtbezirksgruppen 227 . Das sollte die praktische Parteiarbeit straffen und erleichtern. Schulungsprogramme für Ortsgruppen hoffte man so effektiver durchführen zu können. Die Revision der Mitgliederzahlen im Jahr 1956 durch die Neuausgabe von Parteibüchern trug - neben anderen Faktoren - zu einem Abgang von insgesamt 10532 Personen oder 12,2\% der Mitglieder von 1955 bei $^{228}$. Dieser Verlust führte jedoch nicht zum Absinken der Ortsgruppenzahl. Denn im August 1957 verfügte die Partei bei niedrigerer Mitgliederzahl über mehr Ortsgruppen als 1955

222 ACDP VI-052-0520, Protokoll Sekretariat, 30. 5. 1950.

223 ACDP-VI-052-194/4, Entwicklung der Partei; ebd., Entwicklung des Mitgliederstandes der DBD.

224 Vgl. Mitter, „Am 17.6. 1953 haben die Arbeiter gestreikt“, S. $79 \mathrm{ff}$.

225 Vgl. dazu die monatlichen Organisationsberichte für das Jahr 1953, ACDP VI-052-183/ 1.

226 Ebd., Organisationsbericht für Februar und Dezember 1953.

227 ACDP VI-052-0528, Protokoll Arbeitssekretariat, 9.11. 1954, erwähnt erstmals die Untergliederung in Wohnbezirksgruppen. Ebd., Protokoll Arbeitssekretariat, 15. 12. 1954, Entwurf Wahlordnung für Neuwahl der OG-Vorstände im Jahre 1955.

228 Berechnet nach ACDP VI-052-194/4, Entwicklung der Mitgliederbestände der DBD. Vgl. grundsätzlich ACDP VI-052-0318, mit Präsidiumsprotokollen abgelegtes „vorläufiges statistisches Material zu Parteiabgängen 1956“ und Kritik Roses daran, 7. 8. 1956. 
(6369 OG 1957 - 5960 OG 1955)229. Die Mitgliederzahl war bis 1951 so weit angestiegen, daß den Ortsgruppen im Durchschnitt 18,8 Mitglieder angehörten. Von diesem Polster bestehender Grundeinheiten zehrte die DBD trotz Stagnation und Mitgliedereinbußen. Allerdings fiel die durchschnittliche Mitgliederzahl in den Einheiten von 18,8 Mitgliedern 1951 auf 16,7 1953, 14,5 1955 und nur noch 13,1 $1957 \mathrm{ab}^{230}$. Diese Verminderung war z.T. jedoch auch gezielt durch die Aufteilung großer Einheiten in Wohnbezirksgruppen herbeigeführt worden ${ }^{231}$. Für das Zwangskollektivierungsjahr 1960 ist festzustellen, daß sich die Organisation und Werbung der Partei auf schon lange erobertes Terrain zurückzog und kein Neuland dazugewann, sondern schwach organisierte Grundeinheiten verlor ${ }^{232}$. Insgesamt war die Partei Anfang der sechziger Jahre in etwa auf dem Stand von 1955 eingefroren ${ }^{233}$.

\section{Betriebs- und Schulgruppen}

Während die bürgerlichen Parteien sich bis zur Einschränkung der Betriebsgruppen zu einem wesentlichen Teil auf diese stützen konnten, spielten diese keine besondere Rolle in der $\mathrm{DBD}^{234}$. Schon aufgrund ihres Mitgliederprofils, das überwiegend durch bäuerliche Existenzformen und nur in zweiter Linie durch unselbständige Angestellte in landwirtschaftlichen Betrieben, Verwaltungen sowie durch ländliche Arbeiter geprägt war, konnte die DBD diese Organisationsform am Arbeitsplatz nicht für ihre Zwecke nutzen. Für die flächendeckende Gründung von Betriebsgruppen dürfte es außerdem hinderlich gewesen sein, daß die Partei in den Jahren ihres größten Zuwachses 1950/51 organisatorisch überlastet war.

Dennoch gibt es Indizien dafür, daß auch die DBD gern mit selbständigen Betriebsgruppen gearbeitet hätte, wenn nicht SED-Weisungen dies die meiste Zeit verhindert hätten. Die Zusammenfassung der Mitglieder an ihrem Arbeitsort er-

229 ACDP VI-052-194/4, Entwicklung der DBD [Fassung bis 1985 mit handschriftlichen Korrekturen].

230 Berechnet nach ebd.

231 So waren im Jahr 1960 rund 400 OG in rund 800 Wohnbezirksgruppen aufgeteilt. Vgl. ACDP VI-052-185/3, diverse Einschätzungen zur organisatorischen Entwicklung der Partei 1960.

232 So sank die Anzahl der OG und Stützpunkte von Dezember 1959 bis Dezember 1960 von 5924 OG - wovon 377 in 887 Wohnbezirksgruppen aufgeteilt waren - und 1392 Stützpunkten auf 5843 OG und 1407 Stützpunkte. Hingegen wurden 397 OG zu 936 Wohnbezirksgruppen ausgebaut. ACDP VI-052-186/1 und 186/2.

233 Erklärungsbedürftig sind voneinander abweichende Zahlen zu den OG in unterschiedlichen DBD-Statistiken. Die Angaben in den monatlichen Organisationsberichten unterscheiden sich von jenen Angaben, die in den "Handakten Ermisch" in Akt ACDP VI052-194/4 angeführt und in den 80er Jahren nachträglich erstellt wurden. Letztere berücksichtigen bei der Anzahl der OG auch die Wohnbezirksgruppen in diesen OG, wenngleich dies aus der Statistik nicht unmittelbar hervorgeht, sondern nur logisch zu erschließen ist. Da diese Materialien hauptsächlich auf den organisatorischen „Bestleistungen" zu den jeweiligen Parteitagsterminen beruhen, haftet ihnen ein beschönigender Zug an. Die Tiefstände zwischen 1960 und Ende 1962 wurden von der offiziellen Parteistatistik nicht systematisch erfaßt.

234 Vgl. dazu Richter, Ost-CDU, S. 323-328. 
leichterte die Koordination und damit die Effektivität der Parteitätigkeit. Sogar die Betriebsgruppenarbeit einer Blockpartei, die ihr politisches Handeln eng auf die SED abstimmte, rührte letztlich am Alleinvertretungsanspruch der SED; letztere verteidigte ihr Terrain um so mehr, wenn Kernbereiche der Legitimation wie „Betrieb“ und „Arbeit“ betroffen waren, die an ihrem Image als Arbeiterpartei rüttelten. So lange für die $\mathrm{DBD}$ jedoch nicht verboten sein konnte, was anderen Parteien noch erlaubt war, versuchte die SED, die Betriebsgruppenarbeit der DBD gegen die Ausweitung der Organisierung bürgerlicher Parteien in den Betrieben einzusetzen.

Betriebsgruppen der DBD wurden erst ab 1952 in Organisationsstatistiken erfaßt. Sicherlich bestanden sie bereits vorher, denn ein Sprung von Null auf rund 200 Gruppen scheint unrealistisch. Ab Frühjahr 1952 stieg deren Zahl kontinuierlich an. Im Februar 1953 war der Höchststand von 312 Betriebsgruppen erreicht. Einen Monat später schrumpfte ihre Zahl auf 88 und pendelte sich ab Mitte 1953 auf 14 ein; die 16 Betriebsgruppen des Jahres 1959 bestanden bei den 15 Bezirkssekretariaten und beim Ministerium für Landwirtschaft in Berlin. Damit war nichts von der ursprünglichen Zielsetzung übrig geblieben. Die Partei war zum Betrieb erklärt worden und nutzte die Betriebsgruppe zur Disziplinierung der Funktionäre 235 .

Es dürfte kein Zufall sein, daß die DBD ihre Betriebsgruppen im Frühjahr 1952 zum gleichen Zeitpunkt ausbaute, als diejenigen der CDU massiv behindert wurden $^{236}$. Die SED war auf die Mitarbeit der DBD im soeben forcierten Vorgehen gegen einzeln wirtschaftende Bauern und beim „Aufbau der Grundlagen des Sozialismus" in der Landwirtschaft angewiesen. Diese vorübergehende Sonderentwicklung der DBD-Betriebsgruppenarbeit hatte nur instrumentellen Charakter, wie das abrupte Ende der Gruppen und ihr Aufgehen in den Ortsverbänden im Februar 1953 demonstrierte. Gleichzeitig stellte auch die LDPD die Arbeit ihrer Betriebsgruppen ein ${ }^{237}$. Das Aus für die DBD-Betriebsgruppen ging mit Veränderungen des Parteiapparates einher: Im April 1953 wurden die vorher selbständigen Abteilungen für Staatliche Verwaltung und für Agrarpolitik, wie erwähnt, zusammengelegt. Ein Grund hierfür war höchstwahrscheinlich, daß eine separate Anleitung der Betriebsgruppen, die sich großteils bei staatlichen Verwaltungen und der $\mathrm{VdgB}(\mathrm{BHG})$ gebildet hatten ${ }^{238}$, infolge ihrer Überleitung in Ortsgruppen obsolet geworden war ${ }^{239}$.

235 ACDP VI-052-0546, Protokoll Sekretariat, 23. 11. 1961.

236 Richter, Ost-CDU, S. 325.

237 Ebd., S. 326.

238 Vgl. die Auflistung für 1952 [ohne Mecklenburg]: danach bestand das Gros der Betriebsgruppen bei Verwaltungen (61 BG mit 714 Mitgliedern) und der VdgB(BHG) (64 BG mit 633 Mitgliedern), 15 bei VEG, 13 bei MAS, 5 ,allgemeine Betriebsgruppen “ [alle in Thüringen], 3 bei VEAB, 2 bei der DSG und 2 in Molkereien. ACDP VI-052-183/1, Betriebsgruppen der DBD, Stand 30. 4. 1952, 2. 5. 1952.

239 Begründung zu Beschluß über Neuorganisation der Frauen- und Jugendarbeit und $\mathrm{Zu}-$ sammenlegung der Abt. Staatliche Verwaltung und Agrarpolitik. ACDP VI-052-0524, Protokoll Sekretariat, 2. 4. 1953. 
Von 1950 bis Herbst 1954 verfügte die DBD über sogenannte Schulgruppen, die die Mitglieder in Hoch-, Fach- und Spezialschulen erfaßten ${ }^{240}$. Ab 1951 erfolgte die Koordinierung über einen Arbeitsausschuß der Hoch- und Fachschulgruppen $^{241}$. Die Bildung von Schulgruppen hing eng mit der Jugendarbeit der Partei zusammen. Als wichtigste Aufgabe führte der Arbeitsausschuß 1951 an, Hilfe für ein erfolgreiches Studium der Mitglieder zu gewähren, um den Bedarf an Fachkräften zu befriedigen. Daran war der Auftrag geknüpft, Parteischulungsjahre durchzuführen und Kontakt mit der FDJ zu halten ${ }^{242}$. Solange die Partei extensive Wachstumsraten verbuchte und dazu die Anwerbung von Jugendlichen erwünscht war, sollte sie durch Jugendkommissionen und Schulgruppen in attraktiverem Licht erscheinen. Mit dem Abflachen des Zuwachses ab 1953 geriet die Existenz der Schulgruppen in Begründungspflicht. Euphemistisch formuliert als "Verbesserung der politischen Arbeit in den Bezirks- und Kreisstädten" wurde am 30. August 1954 das Ende der Schulgruppen durch ihre Eingliederung in die Orts- und Stadtbezirksgruppen verfügt ${ }^{243}$.

\section{Soziale Zusammensetzung der Ortsgruppenvorstände}

Die soziale Zusammensetzung der Ortsgruppenvorstände spiegelt mit einigen signifikanten Ausnahmen die der Mitgliedschaft wider. Während die altbäuerlichen Kreise die Bauernpartei 1948 äußerst reserviert und abwartend aufnahmen und sie hauptsächlich unter den Neubauern Mitglieder gewann, gelang 1950/51 ein umfassenderer Einbruch in das altbäuerliche Lager. Eine Auflistung der Grundeinheiten im September 1952 ergibt folgendes Bild244: Von den 4369 erfaßten Ortsgruppen - der Bezirk Magdeburg fehlt in dieser Aufstellung - bestanden gut ein Viertel (1138) zu über der Hälfte aus Altbauern, 132 Grundeinheiten (3\%) waren sogar reine Altbauernortsgruppen ${ }^{245}$. Dem geringen Anteil der Neubauern an der bäuerlichen Bevölkerung entsprechend bestanden nur 69 Ortsgruppen $(1,6 \%)$ ausschließlich aus Neubauern, allein 29 davon lagen im Bezirk Neubrandenburg.

240 Aufruf zur Gründung von Schulgruppen in „Bauern-Echo“, 19.11. 1949. Während die DBD 1950 noch 2544 Mitglieder in insgesamt 96 Hoch- und Fachschulen erfaßte - wobei das Übergewicht an Fachschulen mit 83 Gruppen und 1891 Mitgliedern signifikant ist -, hatte sich deren Zahl 1954 auf 70 Schulgruppen mit 2075 Mitgliedern verringert. ACDP VI-052-154/1, Teil 2, Aufstellung: Anzahl Schulgruppen (DBD) an Idw. Fach- und Hochschulen, Stand 20.4. 1954.

241 Die spärliche Überlieferung belegt, daß die Schulgruppenarbeit der DBD noch am Anfang stand. Vgl. Schriftwechsel in ACDP VI-052-211/2.

242 Ebd., Ausschuß für Fach- und Hochschulgruppen an Hoch- und Fachschulgruppen der DBD, 5. 12. 1951.

243 ACDP VI-052-0527, Protokoll Arbeitssekretariat, 23. 8. 1954.

244 ACDP VI-052-154/1, Auswertung der Zusammenstellung der Grundeinheiten der Bezirke im Monat September [ohne Bezirk Magdeburg], 12. 11. 1952. Diese Auswertung ist in dieser Form einmalig.

245 Nach Bezirken verteilten sich die OG mit über 50\% Altbauernanteil wie folgt: Erfurt (193), Cottbus und Gera (je 144), Dresden (113), Chemnitz [!] (100). Reine Altbauernortsgruppen gab es in nennenswerter Höhe nur in den Bezirken Potsdam (28), Gera (27), Cottbus (19) und Erfurt (17), ebd. 
Bereits 318 (7,3\%) Gruppen bestanden mehrheitlich aus Angestellten. Der Zeitpunkt der Erhebung gestattet noch Einblick in die Beteiligung "großbäuerlicher“ Mitglieder. So hatte gut ein Zehntel (11,2\%) der Grundeinheiten über $20 \%$ „großbäuerliche" Mitglieder, knapp 3\% sogar überwiegend. Völlig gescheitert war die DBD bis dahin in der Anwerbung von Frauen: In über einem Fünftel der Ortsgruppen (knapp Tausend oder 21,3\%) gab es kein einziges weibliches Mitglied, in fast vier Zehnteln der Grundeinheiten (rund 1700 oder 38,7\%) nur einen geringen, nicht näher bezeichneten Frauenanteil. Insgesamt verfügte die DBD über den geringsten Frauenanteil aller Blockparteien ${ }^{246}$.

Obwohl sich die Quote "großbäuerlicher" Mitglieder in Grenzen hielt, weist die Aufstellung auf eine bestimmte Problemlage hin: Die sogenannten Großbauern mußten innerhalb eines Dorfes nicht zahlenmäßig dominieren, um entscheidenden Einfluß auszuüben. Aufgrund der meist besseren schulischen wie beruflichen Ausbildung und der Wirtschaftskraft ihrer Höfe übernahmen sie häufig eine Führungsrolle auf dem Land, zumal die Großgrundbesitzer dafür nicht mehr in Frage kamen ${ }^{247}$. Mit dem Eindringen der DBD in das traditionale ländliche Milieu mußte sie in Kauf nehmen, daß die Meinungsführer in den Dörfern in die Patei gelangten.

Die DBD verfolgte gegenüber den „großbäuerlichen“ Mitgliedern die Taktik, sie vorrangig aus den Leitungen der Ortsvorstände zu verdrängen und durch klein- und mittelbäuerliche Kollegen oder LPG-Mitglieder zu ersetzen ${ }^{248}$. Ein Parteiausschluß galt als weniger geeignetes Mittel, weil dies häufig oppositionelle Diskussionen in den Grundeinheiten geradezu provozierte. Das traditionelle Milieu widersetzte sich der Absicht, einzelne Angehörige herauszubrechen. Außerdem erhoffte sich die Parteileitung, daß die konformen Mitglieder in der politischen Auseinandersetzung dazulernten, am "Gegnerkontakt" politisch reiften. Bis 1954 waren "Großbauern“ aus den Vorständen weitgehend verschwunden ${ }^{249}$. Das Fortwirken traditioneller Eliten in Führungspositionen illustriert auch folgendes: Während 1953 nur ein halbes Prozent der Ortsvorstandsmitglieder über 20 ha Grund und Boden besaßen, traf dies im gleichen Zeitraum auf 3,3\% der Ortsgruppenvorsitzenden $\mathrm{zu}^{250}$. Idealerweise sollten die Ortsvorsitzenden

246 Im Dezember 1950 lag der Anteil weiblicher Mitglieder in der Ost-CDU im Länderdurchschnitt (ohne Berlin) bei rund 40\%. Zu den weiblichen Mitgliedern der CDU 19471950, Richter, Ost-CDU, S. 392; Weber (Hg.), Parteiensystem, S. 533.

247 Vgl. Bauerkämper u.a., Führungsgruppen, S. $88 \mathrm{f}$.

248 So meinte Rose in der Hochphase antigroßbäuerlicher Agitation im Frühjahr 1953: „Man soll nicht sagen, raus mit den Großbauern aus der Partei, sondern rein mit den Kleinbauern in die Parteileitungen [...] dort, wo Grossbauern sich reaktionär bewegen, werden wir sie mit den Grundeinheiten entfernen." ACDP VI-052-0524, Protokoll Sekretariat, 30. 1. 1953.

249 Vgl. ACDP VI-052-154/1, Fragebogen 1953: Großbauern in Ortsgruppenvorständen in Partei. Wählt man als Basis nur die Grund besitzenden bäuerlichen Mitglieder, so waren zum 14. 7. 1952 8\% der bäuerlichen Mitglieder "Großbauern“. Ihr Anteil sank erst ab Frühsommer 1953 und lag im Dezember 1953 bei 3,9\%. Zahlen aus den monatlichen Organisationsberichten in ACDP VI-052-183/1 [1952 und 1953] und 183/2 [1954].

250 Geringer ist im Vergleich dazu der Anteil der Kleinbauern unter den 1. Vorsitzenden, höher der Anteil der Mittelbauern. Der bäuerliche Charakter wurde auch durch Genossen- 
der bäuerlichen Schicht angehören. Daher waren „Neubauern“, „Altbauern“ und LPG-Mitglieder im Vergleich zu ihrem Gesamtanteil unter den Vorstandsmitgliedern stärker repräsentiert als die Gruppe der Angestellten, Arbeiter und Sonstigen ${ }^{251}$. Nach der Rücknahme des massiven Kollektivierungsdruckes stieg der Anteil der mittleren Bauern (hier 5-20 ha) 1954 an. Sie stellten dann über vier Fünftel $(82,5 \%)$ der Ortsgruppenvorsitzenden und $77,7 \%$ der Vorstandsmitglieder. Aus der Aufstellung zu den Ortsvorsitzenden geht weiter hervor, daß diese Funktion in aller Regel Männersache war. So bekleideten nur 3,2\% Frauen diesen Posten, obwohl diese noch rund ein Zehntel der Vorstandschaften ausmachten. Die LPGMitglieder der DBD nahmen in den Vorständen wie als Ortsgruppenvorsitzende kontinuierlich einen festen Platz ein, obgleich ihre prozentuale Beteiligung 1954 rückläufig war. Ihre Etablierung als neue ländliche Führungselite in der DBD war politisch vorgegeben.

Die Quote der Angestellten unter der Ortsgruppenvorstandschaft erreichte 1954 bereits ein Fünftel (20,5\%). Obwohl sie nach dem Willen des Sekretariats des Parteivorstands die bäuerlichen Mitglieder von den Posten der Vorsitzenden nicht verdrängen sollten, waren 1954 gut 12\% der 1. Vorsitzenden Angestellte ${ }^{252}$. Bis Anfang 1961 dürfte ihr Anteil in den Vorstandschaften relativ konstant geblieben sein 253. Zusammen mit "Sonstigen“" waren sie 1961 mit knapp einem Viertel $(24,7 \%)$ in diesen Gremien vertreten. Die Zahl der Angestellten verursachte auch den relativ hohen Anteil von Parteimitgliedern in LPG des Typs III mit 45,8\% im Vergleich zu Mitgliedern der Typen I und II mit 27\% ${ }^{254}$. Zwar stellte die neue

schaftsbauern auf dem Ortsgruppenvorsitz unterstrichen; monatliche Organisationsberichte in ACDP VI-052-183/1 [1952 und 1953] und 183/2 [1954]; ACDP VI-052-154/1, Veränderung der Zusammensetzung der Partei seit Januar 1954, 24. 6. 1954 [Entwurf].

251 Die LPG-Mitglieder unter den 1. Vorsitzenden waren vordem hauptsächlich Neubauern, die nach der Aufstellung von 1951 eindeutig mehr Ortsgruppenvorsitzende als die altbäuerliche Gruppe stellten. Von 4131 Ortsgruppen lagen am 1.8. 1951 die Daten von 3773 Ortsvorsitzenden vor. Davon waren $1518(40,2 \%)$ Neubauern, $1364(36,1 \%)$ Altbauern, 303 mithelfende Angehörige (8\%), $17(0,45 \%)$ Gärtner, $44(1,2 \%)$ Pächter, 20 $(0,53 \%)$ Handwerker, $105(2,8 \%)$ Sonstige, $78(2,1 \%)$ Landarbeiter und $377(10 \%)$ Angestellte. ACDP VI-052-154/3, Zusammenstellung der neuen Ortsvorsitzenden, 1.8. 1951 [also nach den Ortsgruppenneuwahlen 1951].

252 Monatliche Organisationsberichte in ACDP VI-052-183/2 [1954]; ACDP VI-052-154/1 Veränderung der Zusammensetzung der Partei seit Januar 1954, 24. 6. 1954 [Entwurf].

${ }^{253} \mathrm{Zwar}$ beruhen die dazu überlieferten Angaben auf einer vorläufigen Auswertung von 747 Ortsgruppen-Neuwahlen, dennoch können diese als repräsentativ gelten, da sie verglichen mit Mitgliederstatistiken dieser Zeit ein stimmiges Bild ergeben. ACDP VI-052186/1, Einschätzung der organisatorischen Entwicklung unserer Partei, 8. 2. 1961 [vorläufiger Stand]. Vgl. dazu ebd., Analyse der organisatorischen Entwicklung im III. Quartal 1960, 3. 11. 1960; Analyse der organisatorischen Entwicklung im II. Quartal 1960, 14.7. 1960; Organisationsbericht IV. Quartal 1960, 31.12. 1960 (als reine Angestellte $13,9 \%$ angeführt, Genossenschaftsbauern $69,3 \%$ ).

254 Da die LPG des Typs II nur einen geringen Teil der Gesamtzahl an LPG ausmachten, handelt es sich hier vornehmlich um solche des Typs I. Aufgrund der verschiedenen Eigentumsverhältnisse und Bewirtschaftungsweisen gehörten Angestellte vorrangig dem Typ III an. Zahlen der LPG-Mitglieder nach Abschluß der Ortsgruppenvorstandswahlen, ACDP VI-052-186/2, Mitteilung Abt. Organisation an Sekretariat zu Abschluß der Neuwahlen der Ortsgruppenvorstände, 28. 4. 1961 [ohne separate Angaben zu Angestellen]. 
Funktionselite der sozialistischen Landwirtschaft - LPG-Vorsitzende (24\%), Brigadiere (32,1\%) und Arbeitsgruppenleiter (11,6\%) - insgesamt über zwei Drittel $(67,7 \%)$ der Vorstandsmitglieder. Offenbar hatten die Mitglieder aber noch zu Jahresbeginn 1961 damit gezögert, diesen ihr unumschränktes Vertrauen auszusprechen und sie einhellig als Führungsgruppe zu den Kreisparteikonferenzen zu delegieren, wie Einschätzungen der Abteilung Organisation monierten ${ }^{255}$. Höchstwahrscheinlich zeigt dieses Verhalten die Ressentiments der zwangsweise zu Genossenschaftsbauern beförderten Kollegen gegenüber den allzu eifrigen Vorstreitern des Sozialismus in der eigenen Partei.

Der Wandel der Transmissionsfunktion der DBD, der zu einer anhaltenden Umwälzung der Zusammensetzung der Mitgliedschaft führte, konnte nur durch permanente Schulung, fachliche Ausbildung und Kontrolle der Kader erlangt werden. Bis 1963 hatte sich die sozialstrukturelle Zusammensetzung der Kader in den Kreisen durch neue dörfliche Eliten im Vergleich zur Parteigründungszeit fundamental verändert.

\section{Mitglieder}

\section{Probleme der Parteistatistik}

Die von der Organisationsabteilung der DBD erarbeiteten Statistiken zur Mitgliederentwicklung können generell als zuverlässig gelten. Zwar enthalten sie bisweilen Unstimmigkeiten, die jedoch in der Art der statistisch-methodischen Anlage bzw. aufgrund des Aktenzusammenhanges in der Regel offensichtlich sind und sich in Kenntnis der SED-Anleitung meist eindeutig begründen lassen. Die SED war über den Zustand der Bauernpartei ebenso gut oder schlecht informiert wie die Organisationsabteilung der DBD256. Erst ab 1950 verfügte die $\mathrm{DBD}$ über eine einigermaßen funktionierende Organisationsberichterstattung, wenngleich die erhobenen Kategorien der sozialen Zusammensetzung noch sehr lückenhaft waren. Detaillierteres Wissen, das die über die monatlich, später quartalsweise erstellten Organisationsberichte der DBD hinausging, versuchte die SED durch inoffizielle Mitarbeiter des MfS in den DBD-Organisationsabteilungen zu beschaffen, sofern diese Daten nicht ohnehin über offizielle Kontakte an die SED gelangten. DBDFunktionäre führten regelmäßig Gespräche mit sowjetischen Vertretern. Daher ist davon auszugehen, daß letztere über die Grundzüge der Parteientwicklung im Bilde waren. Berichte, die eigens für die SKK angefertigt wurden, sind allerdings die Ausnahme und dürften ausschließlich auf deren Veranlassung hin erstellt worden sein, so z. B. unmittelbar vor Durchführung der 2. Parteikonferenz der

255 ACDP VI-052-186/1, Einschätzung der organisatorischen Entwicklung unserer Partei, 8. 2. 1961 [vorläufiger Stand].

256 In den Akten des ehemaligen Zentralen Parteiarchivs der SED liegt eine durchgängige Organisationsberichterstattung der DBD erst ab 1953 vor. Vgl. SAPMO DY 30 IV 2/15/56 bis 64 und vergleichende Analysen zu allen Blockparteien von 1953 bis 1960 in DY 30 IV $2 / 15 / 2$ und 3 . 
$\mathrm{SED}^{257}$. Hinsichtlich des Anteils sogenannter Umsiedler, die einen großen Teil der Gruppe der Neubauern ausmachten, bestehen auffällige Informationslücken. Die Statistiken zur Sozialstruktur unterscheiden nicht zwischen Hausfrauen und Rentnern ${ }^{258}$. Beide Gruppen wurden zusammen als Restgröße erfaßt.

Zwei methodische Überlegungen sind der Analyse der Parteistatistiken voranzuschicken: Sie erlauben nur bedingt Rückschlüsse auf Verhaltensweisen der Mitglieder, wie politische Reaktionen. Eine Ursachenforschung scheitert daran, daß die Mitglieder oftmals keine Begründungen für ihr Verhalten, wie z. B. Parteiaustritte, lieferten und die DBD nicht alle in diesem Zusammenhang bedeutsamen Parameter registrierte, etwa weil diese im ideologisch definierten Erhebungsraster nicht vorgesehen waren. Entscheidend jedoch ist das Faktum, daß die DBD in politischer Ausrichtung und organisatorischer Entwicklung umfassend durch die SED gesteuert war. Zahlenmäßige Veränderungen der Mitgliedschaft sowie deren soziale Gliederung sind daher in erster Linie durch Zugeständnisse oder Verbote der SED und ihrer Durchsetzung verursacht, erst davon abgeleitet durch den Erfolg oder Mißerfolg der DBD-Politik oder durch bewußte Entscheidungen der Basis.

\section{Mitgliederentwicklung}

Aussagen zur Mitgliederentwicklung und zur sozialen Schichtung der DBD gehörten, wie bei allen Blockparteien während des Bestehens der DDR, zu den bestgehütetsten Geheimnissen ${ }^{259}$. Vergleicht man die nun vorliegenden gesicherten Daten mit den Vermutungen in der Bundesrepublik bis 1989 und mit den offiziösen zeitgenössischen Angaben, so läßt sich feststellen, daß die Wahrheit zwischen beidem angesiedelt ist ${ }^{260}$. Die im Westen verfügbaren Angaben zur DBD-Basis, die auf Einschätzungen politischer Gegner beruhten, unterschätzten ihre Mitgliederzahl.

Bis zum März 1952 stiegen die Mitgliederzahlen rasant an ${ }^{261}$. Mit jährlich rund 30000 Neuaufnahmen in den Jahren 1949 und 1950 und 22000 im Jahr 1951 kletterte der Stand im März 1952 auf eine im Untersuchungszeitraum nie wieder erreichte Höchstmarke von nominal fast 88000 . Erst nach dem Machtwechsel von Ulbricht zu Honecker und einer damit einhergehenden moderateren Politik gegenüber den Blockparteien erlangte die DBD 1975 diese Zahl erneut und kletterte in den achtziger Jahren deutlich über die Schwelle von 100000.

In der Expansionsphase dienten innerparteiliche Wettbewerbe zwischen den Ortsgruppen bzw. den übergeordneten Einheiten als Stimulans. Die Parteiverbundenheit einzelner Mitglieder wurde erprobt, indem z.B. Männer verpflichtet

257 ACDP VI-052-183/1, Organisationsbericht Juni 1952 mit Vermerk „für SKK“.

258 Aufgrund des arbeitszentrierten Gesellschaftsbildes der DDR und speziell einer an Hof und Arbeit ausgerichteten Selbstauffassung der ländlichen Bevölkerung bestand kein Anlaß, diese in den produktiven Arbeitsprozeß im engeren Sinne nicht eingebundenen Mitglieder gesondert zu erfassen.

259 Lapp, Zusammensetzung, 339-341.

260 Vgl. die bei Wernet-Tietz, Bauernverband, S. 118, abgedruckten Angaben.

261 Siehe Tabelle 5. 
wurden, ihre Ehefrauen anzuwerben, oder Jugendliche auf ihren Bekanntenkreis angesetzt wurden. Nominell hatte man dabei die politisch korrekte soziale Zusammensetzung der Basis im Blick. So sollten vorrangig parteilose Kleinbauern und "untere Mittelbauern" erreicht werden; auch die bisher parteilosen sogenannten Umsiedler sollten möglichst systemloyal integriert, d.h. nicht an LDPD und CDU verloren werden. Die im marxistischen Verständnis schon auf einer anderen gesellschaftlich-politischen Entwicklungsstufe angesiedelten Landund Forstarbeiter sowie andere Arbeiter im ländlichen Milieu durften möglichst nicht angesprochen werden; es war der DBD verboten, im Terrain der SED zu fischen.

Bis 1952 wurde die soziale Zusammensetzung der Partei zwar grundsätzlich kontrolliert - dies galt sowohl auf seiten der DBD als auch auf seiten der SED, mit deren Kreisleitungen im Prinzip jeder Neuzugang abgeklärt werden mußte ${ }^{262}$. Die Wirkung dieser Kontrollen blieb jedoch sehr begrenzt, wie die Zahl von rund acht Prozent als „Großbauern“ klassifizierter Mitglieder bis dahin illustriert. Dies ist um so mehr bemerkenswert, als bereits $1950 \mathrm{im}$ Zuge der Kandidatenaufstellung für die Landtags- und Kommunalwahlen eine erste "Parteisäuberung" stattgefunden hatte. Insgesamt war der Parteiapparat der DBD zu einer umfassenden Kontrolle der Basis nicht in der Lage und teilweise auch nicht willens. Außerdem verschleierten vor allem die "großbäuerlichen" Mitglieder ihre Daten zu Hofgrößen und Hektarzahlen in erheblichem Maße, um in die Partei aufgenommen zu werden oder in ihr bleiben zu können ${ }^{263}$.

Der Parteiapparat wurde erst ab März 1952 angehalten, die Organisationsstatistik aller Ebenen gründlich zu durchleuchten, um zu realistischen Mitgliederzahlen und zu einem Überblick über die tatsächliche Sozialtruktur der Partei zu gelangen. Hierfür ordnete die Parteispitze von März bis Juni 1952 einen Umtausch aller Mitgliedskarten in Mitgliedsbücher an ${ }^{264}$. Im Juni erließ das Sekretariat weitere Anweisungen für eine zentrale Kaderregistratur.

Bei dieser Gelegenheit sollten sogenannte Großbauern aus der Partei, vor allem aus den Leitungen entfernt werden. Dies dürfte im Vorgriff auf die neue Qualität der politischen Aufgaben 1952 geschehen sein: Allein die Umbildung im staatlichen Verwaltungsaufbau, die mit der Abschaffung der Länder einherging, erforderte deutlich mehr und nicht weniger Kader; außerdem hatte der „Klassenkampf “ auf dem Land mit der Verordnung über devastierte Flächen vom 20. März 1952 schon vier Monate vor der 2. Parteikonferenz der SED eine neue Phase erreicht. Sicherlich steht auch ein von der SKK bis Juni 1952 eingeforderter detaillierter Organisationsbericht im Zusammenhang mit der Mitgliederüberprüfung: Entweder kontrollierte er die Erfüllung von Maßgaben, die die SKK befohlen

262 Diese faktischen Anforderungen auch bei Wernet-Tietz, Bauernverband, S. 118. Ab Mitte 1951 sollten die Kreissekretariate der DBD monatliche Mitgliederberichte bei den SEDKreisleitungen einreichen, ebd.

263 Vgl. die sich wiederholenden Berichte dazu: ACDP VI-052-0522, Protokoll Sekretariat, 22.4. und 16. 5. 1952.

${ }^{264}$ Kühne, Anfänge, S. 102, dort Verweis auf unverz. Akten zur Leitungstätigkeit 1953. ACDP VI-052-0522, Protokoll Sekretariat, 16.5. 1952 und Vorlage zu „Richtlinien für die Registrierung und statistische Erfassung der Mitglieder unserer Partei“, 14. 5. 1952. 
hatte, oder er gab sogar den Anstoß zu einer umfassenden Inspektion. Im Ergebnis wurden von März bis September 1952 9572, über das ganze Jahr 1952 sogar 11627 Mitglieder aus der Parteistatistik gestrichen265. Außerdem traten 1952 12293 Mitglieder aus, 730 wurden ausgeschlossen, so daß sich die Summe der 1952 erfaßten Abgänge auf 24650 beläuft und damit mehr als ein Viertel der Mitgliedschaft umfaßte. Allerdings hatten viele der über den Mitgliedsbuchumtausch Überprüften schon lange vor 1952 die Partei verlassen ${ }^{266}$. Dies wirft ein bezeichnendes Licht auf die Schwäche der Organisationsabteilungen in der Expansionsphase der Partei. Sie hatten weder einen genauen Überblick über die Mitgliederzahl noch kontrollierten sie die soziale Zusammensetzung streng.

Anfang Februar 1953 setzte die SED dem weiteren Wachstum der DBD per Politbürobeschluß ein Ende 267. Die Bauernpartei sollte auf dem erreichten Stand eingefroren werden. Die Übermittlung dieser Entscheidung in die Dörfer verlief zügig. Wie schon 1952 nahm die DBD auch im Jahr 1953 wenige, aber auffällige nachträgliche Korrekturen an ihren Organisationsberichten vor ${ }^{268}$, indem sie die Mitgliederzahlen von April und Mai 1953 nach unten korrigierte. Im Endeffekt sollten damit reale Organisationsstatistiken erzielt werden; gleichzeitig demonstrierten die gesunkenen Zahlen gegenüber der SED, wie sehr man ihre Anweisungen befolgte. Schließlich gestattete die SED der Bauernpartei im Dezember 1953, durch sogenannte „individuelle“ Anwerbung - im Unterschied zu der von Parteieinheiten "organisierten" - von "werktätigen Einzelbauern" die seit Juni, dem Monat des Volksaufstandes, kumulierten Mitgliederverluste sowie die „laufenden", also monatlich festgestellten Abgänge auszugleichen ${ }^{269}$. Es blieb jedoch verboten, neue Ortsgruppen zu gründen und Angestellte, Landarbeiter oder Genossenschaftsbauern in die DBD aufzunehmen. Hingegen räumten die Genossen der DBD ein, Grundeinheiten dort auszubauen, wo CDU und LDP über Einfluß in den Dörfern verfügten ${ }^{270}$. Die DBD folgte den Anweisungen der SED und faßte in den folgenden Jahren immer wieder entsprechende Sekretariatsbeschlüsse ${ }^{271}$. Das hinderte die Bezirks- und Kreisverbände jedoch nicht daran, eigene Wege zu suchen und Lücken zu nutzen, indem sie Arbeiter mit „mehr oder minder großem Grundstück“ als bäuerlich definierten ${ }^{272}$. Das Absacken der Mit-

265 Siehe dazu Tabelle 14.

266 Von den 1571 Mitgliederabschreibungen im Juni 1952 gingen allein 1417 auf das Konto des Mecklenburger Landesverbandes, der damit „Karteileichen“ der Gründungszeit bereinigt haben dürfte.

267 SAPMO DY 30 J IV 2/2/260, Protokoll PB, 3. 2. 1953, Anlage 7. Siehe dazu auch Vorlage des Sektors BO vom Januar 1953, SAPMO DY 30 IV 2/15/3, Bericht der Abt. LOPM, 23. 1. 1953.

268 Einzelne Monatsberichte wurden kurzerhand auf einen anderen Monat umdatiert. Außerdem korrigierte man Mitgliederzahlen erneut nach unten.

${ }^{269}$ SAPMO DY 30 IV 2/15/3, Schlußfolgerungen des Sektors BO zum Bericht vom 15. 12. 1953.

270 SAPMO DY 30 IV 2/15/4, Besprechung des Sektors BO mit Instrukteuren dieses Sektors aus Bezirken, 9. 11. 1954.

271 ACDP VI-052-0528, Protokoll Arbeitssekretariat, 15. 12. 1954, Beschluß zur Verbesserung der sozialen Zusammensetzung der Partei.

272 So in Suhl, wo man "ungeachtet wiederholter Hinweise“ weiterhin Arbeiter aufnehme; 
gliederzahlen 1956 ist auf eine weitere Parteiüberprüfung und Neuausgabe von Mitgliedsbüchern zurückzuführen ${ }^{273}$. Zudem stieg die Zahl der „Republikflüchtigen “ unter den Parteiangehörigen 1956 auf 1622 an $^{274}$.

Einen Teil der ausgetretenen oder gestrichenen Mitglieder gewannen die Kreisverbände oftmals durch persönliche Überzeugungsarbeit zurück. Der Anstieg der Mitgliederzahlen bis Ende 1959 korreliert mit der Zunahme des genossenschaftlichen Teils der Landwirtschaft. Zwar war es der DBD nach SED-Vorgaben weiterhin nur erlaubt, die laufenden Abgänge durch Neuaufnahmen zu kompensieren; diese sollten sich auf „werktätige“ Einzelbauern und -bäuerinnen und die mithelfenden jugendlichen Angehörigen beschränken. Dennoch wilderten die DBD-Bezirksverbände unter potentiellen SED-Aspiranten und warben Genossenschaftsbauern an. Dafür ernteten sie regelmäßig Kritik der Organisationsabteilung ${ }^{275}$. Die SED befand sich in einer Zwickmühle. Letztlich konnte sie den kompetenten Funktionären der DBD, ihren unverzichtbaren Hilfstruppen in den Kollektivierungskampagnen, die Werbung von Genossenschaftsbauern nicht gänzlich verbieten, wenn sie nicht riskieren wollte, ihren Juniorpartner völlig unglaubwürdig erscheinen zu lassen. Es wäre den DBD-Funktionären und Parteiaspiranten schwer zu vermitteln gewesen, warum eine Partei wie die DBD, die die Kollektivierung offiziell propagierte und tatkräftig unterstützte, keine LPG-Bauern aufnehmen sollte.

Sobald die Kollektivierung 1960 offiziell als abgeschlossen galt und sich im Jahr darauf stabilisierte, schränkte die SED das Wachstum der DBD und ihren Werbespielraum wieder stärker ein ${ }^{276}$. Bis Ende 1960 waren die Werbungen auf Ehefrauen von Genossenschaftsbauern und DBD-Mitgliedern zu begrenzen ${ }^{277}$, denn viele Frauen waren häufig nicht in die LPG miteingetreten. Als es offiziell nur noch Genossenschaftsbauern gab, mußte die SED der DBD notgedrungen einräumen, unter diesen zu werben, um ihre hohen Abgänge 1960/61 und die Passivität der Mitglieder aufzufangen. Hingegen sollten Schüler und Studenten für die DBD als Mitglieder nicht in Frage kommen. Über dieses Tabu setzte sie sich noch 1962 hinweg, motiviert durch die nicht zu übersehende Überalterung der Partei278. Allerdings geschah dies in einem so bescheidenen Ausmaß, das sich in der Organisationsstatistik kaum niederschlug. Die künftige Führungselite in einer nun

SAPMO DY 30 IV 2/15/11, Bericht der SED über die Entwicklung des BV Suhl der DBD 1954, Februar 1955.

273 Berechnet nach ACDP VI-052-194/4, Entwicklung der Mitgliederbestände der DBD, siehe Tabelle 5. ACDP VI-052-0531, Protokoll Sekretariat, 2. 1. 1956. Vgl. grundsätzlich dazu ACDP VI-052-0318, Protokoll Präsidium, 7.8. 1956, vorläufiges statistisches Material zu Parteiabgängen 1956.

274 SAPMO DY 30 IV 2/15/3, AG BO, Gegenüberstellung einiger Zahlen der Mitgliederabgänge der kleinbürgerlich-demokratischen Parteien im Jahr 1956.

275 ACDP VI-052-160/7, Einschätzung der organisatorischen Entwicklung für März/April 1958, 5. 5. 1958. Die Bezirksverbände begründeten die Aufnahme von LPG-Bauern damit, daß deren Angehörige bereits DBD-Mitglieder seien.

276 SAPMO DY 30 J IV 2/2/702, Protokoll PB, 9. 5. 1960, Bl. 3, Punkt 7.

277 ACDP VI-052-186/1, Einschätzung der organisatorischen Entwicklung unserer Partei im Jahr 1960, 8. 2. 1961; ACDP VI-052-186/2, Org.-Bericht zu I. Quartal 1961.

278 ACDP VI-052-186/3, Bericht Abt. Organisation an Sekretariat, 8. 2. 1963. 
sozialisierten Agrarwirtschaft sollte ihren Platz unbedingt in der SED einnehmen. Der VII. Parteitag der DBD im Jahr 1963 übernahm offiziell das Programm der SED. Er markiert hinsichtlich der Mitgliederzahlen den Beginn einer Erstarrung, die bis zu Ulbrichts politischem Ende anhielt.

\section{Mitgliederstruktur}

Im Untersuchungszeitraum konnte der DBD laut Statut jeder beitreten, der das 16. Lebensjahr vollendet hatte und „der werktätigen bäuerlichen Bevölkerung angehört oder mit ihr verbunden ist" ${ }^{279}$. Der letzte Zusatz eröffnete ihr bezüglich der Anwerbung der auf dem Land ansässigen Bevölkerung einen erheblichen Spielraum. Dennoch darf diese vordergründig liberale Formulierung nicht darüber hinwegtäuschen, daß Anzahl und Struktur der Mitgliedschaft von der SED gesteuert war.

Während Ende 1949 die neubäuerlichen Mitglieder eindeutig dominierten - sie dürften einschließlich eines Anteils an mithelfenden Angehörigen rund $50 \%$ aller Parteiangehörigen ausgemacht haben -, zeichnete sich bis Ende 1950 in allen Landesverbänden ein Vordringen zur altbäuerlichen Bevölkerung ab. Es wäre jedoch verfehlt, auf ein ausgeglichenes Mischungsverhältnis von neu- und altbäuerlichen Parteigängern $\mathrm{zu}$ schließen ${ }^{280} \mathrm{Zu}$ heterogen war die soziale und berufliche Zusammensetzung von Landesverband zu Landesverband, auch wenn regional undifferenzierte Übersichten diese Unterschiede verwischen.

Nie war die Bauernpartei so bäuerlich geprägt wie Ende 1950. Rund vier Fünftel $(78 \%)$ der Mitglieder zählten zur Schicht der selbständigen Bauern und der vom Tätigkeitsprofil her kaum davon zu trennenden mithelfenden Angehörigen $^{281}$. Bis zum Dezember 1953, nach dem Abbruch des ersten Kollektivierungsanlaufs, sank dieser Anteil auf rund $65 \%$. Inmitten der neuen verschärften Kollektivierungsphase nach dem V. Parteitag der SED 1958 erreichte ihr Anteil wieder die 70-Prozentmarke und pendelte sich dort ein. Grundsätzlich besteht zwischen Kollektivierungsschüben, Mitgliederentwicklung und dem Anteil unter der bäuerlichen Bevölkerung folgender Zusammenhang: Die DBD konnte ihre Agitation für die Vergenossenschaftlichung zwar stets in einen Zuwachs vor allem an bäuerlichen Mitgliedern ummünzen. Allerdings reagierten diese unmittelbar danach auf Zwang und die wirtschaftliche Misere in den desorganisierten Produktionsgenossenschaften häufig mit Austritt und Flucht. Prozentual kaum ins Gewicht fielen Pächter, die 1 bis 1,5\% der Basis ausmachten, sowie die Kate-

279 Statut der Demokratischen Bauernpartei Deutschlands, in der auf dem 1. PT am 2./3. 7. 1949 beschlossenen Fassung, abgedruckt in: Wernet, Rolle, S. 271-274, hier 271; ebenso die spätere, in anderen Punkten veränderte Fassung von 1957, ACDP VI-052-0535, Vorlage Statut an Sekretariat, 11. 5. 1957.

$280 \mathrm{Vgl}$. Tabellen 9 und 7.

281 Methodisch ist dabei die soziale Schichtung innerhalb der bäuerlichen Bevölkerung zu berücksichtigen: Wer arbeitet wie auf welchen Höfen mit? Bei „Großbauern“ und wirtschaftlich potenten Mittelbauern waren Frauen oft nur für Hausarbeit, nicht für Feldoder Stallarbeit zuständig. Andernorts war die Arbeitsbelastung der Frauen und Kinder erheblich. 
gorie „Handwerker und Gewerbetreibende“. Allerdings zeigt die Existenz der letztgenannten Mitgliedergruppe Ende 1949, daß die DBD als „Partei des Dorfes" diese Schicht ursprünglich anzog. Aufgrund der SED-gelenkten Zielgruppenspezifik ist es nicht verwunderlich, daß ihr Anteil bis 1960 unter ein Prozent abrutschte.

Die Gruppe der Angestellten umfaßte jene neuen landwirtschaftlichen Berufe, die in der Planwirtschaft expandierten ${ }^{282}$. Im Laufe der fünfziger Jahre errangen Angehörige dieser Berufsgruppen zusehends die Funktion einer neuen Führungselite im ländlichen Milieu. Sie verdrängten traditionale Führungsschichten wie Dorfhonoratioren alt- und großbäuerlicher Herkunft, Dorfschullehrer oder Vertreter des Raiffeisen-Genossenschaftswesens. Im Dezember 1949 stellten die Angestellten erst rund ein Zehntel der Mitglieder. Nach der Gleichschaltung des landwirtschaftlichen Genossenschaftswesens und vor dem Kollektivierungsauftakt betrug ihr Anteil im Juni 1952 14\%. Im Dezember 1954, nachdem die DBD Einzelbauern sowohl durch ihren politischen Kurs 1952/53 als auch durch die Wirkungslosigkeit angekündigter Vergünstigungen enttäuscht hatte, war die Angestelltenquote auf fast $17 \%$ angewachsen, die Quote bäuerlicher Parteigänger hingegen auf $65 \%$ abgesunken. Nach der Vollkollektivierung machte das Segment der Angestellten knapp 12\% aus. Diese Verschiebung geht hauptsächlich auf die strikten Reglementierungen der Anwerbungen zurück, die ausschließlich Bäuerinnen und Bauern für eine Neuanwerbung vorsahen. Im Jahre 1954, als der „Klassenkampf“, die vermeintliche Ursache der Krise 1953, noch als Interpretationsmuster galt, teilte die DBD die Vorbehalte der SED gegen Angestellte, die nach marxistischer Auffassung keiner revolutionären Klasse angehörten und daher „im Klassenkampf versagen“ würden ${ }^{283}$. Der Mitgliederrückgang unter den Angestellten der VdgB im Dezember 1959 hängt auch mit der Legitimationskrise der Massenorganisation zu dieser Zeit zusammen, die bei der einzelbäuerlichen Klientel an Glaubwürdigkeit einbüßte ${ }^{284}$. Insgesamt drängte die SED die DBD mit beträchtlichem Erfolg von der Mitgliederrekrutierung unter den Angestellten der VdgB und der Verwaltungen zurück. Das Ausscheiden vieler DBD-Funktionäre aus ihren Positionen in den örtlichen Volksvertretungen entsprach dieser Entwicklung. Machten die Angestellten in $\mathrm{VdgB}(\mathrm{BHG})$ und Verwaltung 1952/53 noch rund $9 \%$ der Mitglieder aus, so schrumpfte ihr Anteil um mehr als die Hälfte auf rund $4 \%$ in den Jahren 1960 und 1961. Parallel dazu pendelte der Anteil „sonstiger Angestellter" seit 1954 konstant bei 7 bis $8 \%$.

Im Grunde sollte die DBD keine Angehörigen der „Arbeiterklasse“ aufnehmen. Schon die Anwerbung von Landarbeitern wurde mißtrauisch registriert. Im Winter 1949 wiesen DBD-Statistiken zwar knapp 4\% Land- und Forstarbeiter aus; weitere Angehörige der Arbeiterschicht verbargen sich jedoch höchstwahrscheinlich hinter der Sammelkategorie „Sonstige“ mit zusätzlichen rund 4\%, zu-

282 Angestellte in VEAB, VdgB, im Staatsapparat usw.

283 So Rietz nach den Neuwahlen 1954, ACDP VI-052-0526, Protokoll Arbeitssekretariat, 23. 3. 1954.

2841960 mußte die VdgB das Wort „Einzelbauer“ aus dem Statut entfernen. SAPMO DY 30 J IV 2/2/735, Protokoll PB, 29. 11. 1960, Bl. 2. Siehe Tabelle 7. 
mal ab 1952 ein etwa gleichhoher Prozentsatz an „sonstigen Arbeitern“ angeführt wurde. Der Anteil an Arbeitern betrug in den fünfziger Jahren rund $8 \%$ und stieg in der Vollkollektivierungsphase auf über $9 \%$. Allerdings sind darin teilweise die bisher unter "mithelfende Angehörige“ geführten Personen inbegriffen, die vor allem beim Eintritt in LPG des Typs III ohne individuelle Wirtschaften den Status unselbständiger Arbeitnehmer erhielten. Grundsätzlich wuchs im Zuge der Vollkollektivierung ab Ende 1959 der Anteil unselbständig Beschäftigter unter den DBD-Mitgliedern; er illustriert damit den politisch gelenkten Strukturwandel von einer auf Eigentümern basierenden hin zu einer von Arbeitnehmern dominierten Agrargesellschaft.

Angehörige der sogenannten „Intelligenz“, seit 1959 als Wissenschaftler klassifiziert, waren im behandelten Zeitraum Mangelware in der DBD. Die früheste überlieferte Aufschlüsselung vom Mai 1952 führt insgesamt 874 Angehörige der Intelligenz auf, untergliedert aber aufgrund unvollständiger Informationen der Landesverbände nur 663 Personen nach Berufen ${ }^{285}$. Das Gros nahmen Lehrer ein (552), gefolgt von Ärzten (37) und Diplomlandwirten (10). Insgesamt war die DBD eine Partei, die wenig von Personen mit Hochschulausbildung geprägt wurde; aber deren Mitgliederanteil nahm ab 1957 durch die Delegierung an SEDSchulen zu. Das Schwergewicht der Qualifizierung lag eindeutig auf der Fachschul- und weniger auf der Hochschulausbildung. Daher verfügte die DBD gegen Ende der fünfziger Jahre über ein Reservoir an berufserfahrenen und fachlich geschulten Kadern, die auch für die SED attraktiv waren. Die Anwerbung von Angehörigen der "Intelligenz" wurde der DBD erschwert, da sie ab 1955 über keine eigenen Hoch- und Fachschulgruppen verfügte, als Partei im Ausbildungsbereich also nicht präsent war. Deshalb ging vor allem der Anteil an Schülern und Studenten zurück. Zum einen benötigte die SED diese landwirtschaftlichen Kader dringend selbst; zum anderen häuften sich Übertritte von der DBD zur SED gerade unter Schülern und Studenten, die sich zu Recht eine erfolgreichere Karriere dank eines SED-Parteibuches versprachen. Daneben spielte die gezielte Abwerbung und Anforderung so mancher erfahrener und geschulter DBD-Kader für die SED - wie im Fall Dietrich Besler - eine Rolle286.

Zum Bildungsgrad der Mitglieder können keine quantitativen Erkenntnisse vorgelegt werden, weil Übersichten dazu fehlen. Angaben in Kaderbeschreibungen $^{287}$ erlauben jedoch die qualitative Aussage, daß die DBD-Mitglieder fast nie Abitur, ganz wenige eine Mittelschulbildung, und die überwiegende Mehrheit von geschätzt $90 \%$ eine Volksschulbildung hatten. Hierin schlug sich das ausgeprägte Bildungsgefälle zwischen Stadt und Land eindeutig nieder.

285 ACDP VI-052-183/1, Aufschlüsselung der Intelligenz, Stand 30. 4. 1952. Nach Ländern unterteilt ergibt sich folgendes Bild: Die LV mit den meisten Mitgliedern der „Intelligenz" sind Sachsen-Anhalt (226) und Thüringen (215), also dort wo einst Zentren agrarischer Ausbildung und Forschung bestanden, gefolgt von Brandenburg (160), Sachsen (143), Mecklenburg (102) und dem Stadtverband Berlin (28).

286 Hinweise auf einen beabsichtigten Wechsel ab Ende 1958, ACDP VI-052-0538, Protokoll Sekretariat, 6. 10. 1958. ACDP VI-052-0322, Protokoll Präsidium, 19. 12. 1958.

287 Kaderbeschreibungen liegen häufig den Sekretariats- oder Präsidiumsprotokollen bei. 
Insgesamt dominieren in der sozialen Zusammensetzung der DBD die Konstanten, da genossenschaftsbäuerliche Mitglieder bis 1963 großteils aufgrund ihres beruflichen Werdegangs und mentalen Prägung als bäuerliche Parteiangehörige gelten müssen. Dieses gleichbleibende Erscheinungsbild verweist trotz aller Krisen der DBD auf eine hohe Integrationskraft unter der bäuerlichen Klientel wie auch unter den anderen Mitgliedergruppen. Da man zeitweise um jedes Mitglied mit der SED ringen mußte, war der Beitritt zur DBD meist eine bewußte Entscheidung für die DBD und gegen die SED.

Im Hinblick auf die Repräsentation der DBD in den lokalen und regionalen Vertretungen ist festzustellen, daß die Partei verhältnismäßig wenige Bürgermeister stellen durfte. Deren Anzahl schwankte relativ konstant um ein halbes Prozent der Mitglieder, in absoluten Zahlen um 450 bis 490 Personen, und stieg auffälligerweise trotz sinkender Mitgliederzahlen 1961 an. Vielleicht sollte dies dazu beitragen, im lokalen Bereich die arg strapazierte und großteils verspielte Glaubwürdigkeit wiederzuerlangen. Der Anstieg der Zahl von Kreistagsabgeordneten 1961 ist nicht auf demokratische Wahl, sondern auf die Kooptation von für "fähig" befundenen Genossenschaftsbauern in die Kreistage zurückzuführen ${ }^{288}$. Auch dieser Vorgang fügt sich damit in die Konstruktion einer neuen politischen Führungsschicht auf Kosten traditionaler ländlicher Führungsgruppen ein.

Betrachtet man frühere politische Bindungen der DBD-Mitglieder, so zeigt sich eindeutig, daß die Bauernpartei bis Ende 1950 mit der SED um ländliche Mitglieder konkurrierte. Während des Gründungsvorgangs stellte die SED eine beträchtliche Anzahl von Funktionären für leitende Positionen ab; außerdem wuchs die DBD in dieser Zeit auch auf Kosten der SED. So setzte sich der Landesverband Mecklenburg im Juli 1948 zu 21,6\% aus SED-Mitgliedern zusammen ${ }^{289}$. Bis kurz vor dem I. Parteitag 1949 betrug der Anteil ehemaliger SED-Mitglieder 12,4\% dieser hohe Prozentsatz wurde auf dem Parteitag nach unten korrigiert wiedergegeben 290 .

Bei der Suche der DBD nach neuen Mitgliedern ging man zunehmend dazu über, den Blockparteien, darunter vorrangig der CDU, weniger der LDP, Mitglieder abzujagen ${ }^{291}$. Insgesamt hielt sich der Einbruch in deren Lager jedoch mit maximal 1,6\% (CDU) und 1,3\% (LDP) in Grenzen, wenngleich diese Angaben nicht über erhebliche Konkurrenzverhältnisse in bestimmten Ländern und lokalen Konstellationen hinwegtäuschen dürfen. So zeigen frühe, nach Ländern aufgegliederte Angaben vom September 1949292, daß der Einbruch in die Mitgliedschaft von CDU und LDP vor allem in Thüringen erfolgte: Von den insgesamt 347 Übertritten aus der LDP fielen allein 128 auf Thüringen; ebenso tauschten 234 von insgesamt 486 ehemaligen CDU-Mitgliedern in diesem Land das Parteibuch.

288 ACDP VI-052-186/2, Organisationsbericht für das III. Quartal 1961.

289 Kühne, Anfänge, S. 97.

290 Ebd., ACDP VI-052-154/1, Organisatorische Entwicklung der DBD vom 1. PT im Juli 1949 bis zum 2. PT am 6./7. Juni 1951; ACDP VI-052-0003, Protokoll des 1. PT, S. 85.

291 Zumindest für 1949 ist diese Feindifferenzierung nachzuweisen. Monatsbericht 21. 1. 1949, ACDP VI, unverz. Handakte Rose; Kühne, Anfänge, S. 98.

292 ACDP VI-052-154/1, Anzahl der bisher aus anderen Parteien übergetretenen Mitglieder, 28. 7. 1951. 
Überdurchschnittlich hoch lag dagegen die Zahl ehemaliger SED-Angehöriger in Sachsen-Anhalt, wo 1050 von bis dahin insgesamt 3958 Genossen zur DBD wechselten. Mit dem Erstarken der NDPD, sie zählte am 1. Januar 1954103402 Mitglieder ${ }^{293}$, stiegen zwar die Übertritte zur DBD, der Anteil stagnierte aber bei unerheblichen $0,1 \%$. Ganz offensichtlich reüssierte die DBD in ihrem Parteiauftrag, vorrangig Parteilose zu binden. Im Jahr 1955 und danach gehörten rund $94 \%$ der DBD-Mitglieder vor ihrem Eintritt keiner anderen Partei der DDR an.

Parteiwechsel suchte man zunehmend zu unterbinden. Um zu verhindern, daß „Säuberungen“ und einzelne Parteiausschlüsse durch die Aufnahme in eine andere Blockpartei unterlaufen würden, galt höchstwahrscheinlich seit Anfang der fünfziger Jahre das Prinzip, keine von anderen Parteien ausgeschlossenen Mitglieder aufzunehmen ${ }^{294}$. Erst nach einem entsprechenden Beschluß des DBD-Sekretariates bezüglich von der SED ausgeschlossener Mitglieder vom April 1951, der den Kreisverbänden diskret mündlich übermittelt wurde, sank die Quote ehemaliger Genossen sichtlich. Zentrale Parteistellen warnten die Kreise eindringlich davor, sich darüber hinwegzusetzen; denn wer mit dem Kurs der SED in Konfrontation geraten war, komme auch für die DBD nicht in Frage. Die Korrekturen in der Parteistatistik in der ersten Hälfte des Jahres 1953 förderten neben real niedrigeren Mitgliederzahlen auch zu Tage, daß der Anteil ehemaliger Genossen von 4,9\% im Dezember 1952 auf 4,5\% bis zur Jahresmitte 1953 gesunken war ${ }^{295}$.

$\mathrm{Zu}$ ehemaligen Mitgliedschaften in der NSDAP liegen keine Gesamtangaben vor. Die frühere NSDAP-Zugehörigkeit war - wie 1948 in allen anderen Blockparteien - kein Hinderungsgrund für einen DBD-Beitritt. Allerdings intervenierten übergeordnete Parteistellen bei Bekanntwerden auffälliger Häufungen von ehemaligen NSDAP-Mitgliedern in einzelnen Ortsgruppen oder Kreisverbänden; über die Bezirkssekretariate sollten entsprechende „Diskussionen“ ausgelöst und die inkriminierten DBD-Funktionäre aus den Leitungspositionen entfernt werden. Konzentrationen von ehemaligen NSDAP-Mitgliedern stellte man 1955 beispielsweise in den Sekretariaten der sächsischen Kreisverbände Dippoldiswalde, Pirna und Freital fest. Als Indiz für einen Gesamtanteil ehemaliger Angehöriger der NSDAP kann gelten, daß sich die Kreisvorstandsmitglieder 1955 insgesamt zu immerhin $11 \%$ aus solchen zusammensetzten ${ }^{296}$. Ungleich rigider ging man gegen ehemalige NSDAP-Mitglieder vor, die Parteiämter und -funktionen bekleideten. Insbesondere wenn sie diesen Makel verschwiegen und zu vertuschen suchten, der Partei gegenüber also "mangelndes Vertrauen“ an den Tag legten, forderten stalinistisch gerierende Parteikader die rituelle Verdammung. Die brisantesten „Fälle“ waren diejenigen, die einen Aufnahmeantrag oder eine Mitgliedschaft zunächst

293 SAPMO DY 30 IV 2/15/2, Bericht Sektor BO zur „Entwicklung der kleinbürgerlichdemokratischen Parteien in der Zeit zwischen dem IV. und V. Parteitag unserer Partei“, 31. 5. 1958.

294 ACDP VI-052-0521, Protokoll Sekretariat, 10.4. 1951, Rückbezug darauf und damit Geltungsnachweis in ACDP VI-052-0524, Entwurf, Vorlage an alle BV [26. 5. 1953]. Zur Beschlußlage hinsichtlich einer Aufnahme von Mitgliedern bürgerlicher Blockparteien siehe ACDP VI-052-0522, Protokoll Sekretariat, 7. 8. 1951.

295 Siehe monatliche Organisationsberichte für 1953 in ACDP VI-052-183/1.

296 ACDP VI-052-0318, Protokoll Präsidium, 7. 8. 1956. 
leugneten, dann immer nur so viel zugaben, wie ihnen schwarz auf weiß nachgewiesen werden konnte, so etwa Ernst-Walter Beer ${ }^{297}$.

Der Organisationsgrad der DBD-Mitglieder in den Massenorganisationen variierte ${ }^{298}$. Für DBD-Mitglieder, in erster Linie für die bäuerlichen, sollte die Mitgliedschaft in der VdgB ohnehin selbstverständlich sein. Obgleich die Leitungsebene der VdgB auf die Bildung einer Partei für ihre Klientel mit Animositäten reagierte, trugen viele VdgB-Mitglieder die Gründung der DBD durch ihren Beitritt mit und übernahmen Funktionärsaufgaben. Parallel zum Vordringen der DBD in altbäuerliche Schichten und zur Zunahme von Mitgliedern ohne Land fiel der VdgB-Organisationsgrad ab. In der VdgB dominierten anfangs neu- und kleinbäuerliche Mitglieder, während sich die Mehrheit der Altbauern eher fernhielt. Altbauern gehörten bis zur Gleichschaltung des ländlichen Genossenschaftswesens mit der VdgB überwiegend den Raiffeisen-Genossenschaften und weniger der Massenorganisation VdgB an. Gewisse politische Ressentiments behielten sie sowohl gegen die 1949 einsetzende Bildung universeller Dorf- und Kreisgenossenschaften anstelle ausdifferenzierter Spezialgenossenschaften als auch gegen die am 20 . November 1950 vereinigte und damit gleichgeschaltete $\mathrm{VdgB}(\mathrm{BHG})^{299}$ bei. Außerdem ist belegt, daß bäuerliche DBD-Mitglieder aus finanziellen Gründen - aber auch, weil sie sich von der VdgB(BHG) 1952 politisch bedrängt fühlten - die Doppelmitgliedschaft kündigten, um die Beitragskosten für die $\mathrm{VdgB}(\mathrm{BHG})$ zu sparen 300 .

Die Mitgliederüberprüfungen und -schulungen hatten oft zur Folge, daß die Parteiangehörigen zum Beitritt zu Massenorganisationen veranlaßt wurden. Ende 1952 gehörte erst gut die Hälfte der DBD-Jugend der FDJ an, wobei die Distanz unter Jugendlichen altbäuerlicher Herkunft besonders ausgeprägt war. Nach der Vollkollektivierung stieg der FDJ-Anteil unter den jugendlichen Parteimitgliedern auf nahezu 90\%. Obwohl die Distanz der weiblichen Mitglieder zum Frauenbund (DFD) allmählich abnahm, erreichte der Organisationsgrad kaum über $40 \%$ und illustriert insgesamt die Abneigung der Frauen in der DBD, sich ins Netz der Massenorganisationen einzufügen. Erfolg verbuchten die anhaltenden Bemühungen um eine Steigerung der Organisationsquote in der Gesellschaft für Deutsch-Sowjetische Freundschaft; allerdings überschritt die Quote erst 1955 $30 \%$. Angestellte und Arbeiter waren nahezu vollständig im FDGB vertreten also in vergleichsweise höherem Maße als die bäuerlichen Mitglieder in der $\mathrm{VdgB}^{301}$. Im Zuge der Kollektivierungskampagne Ende der fünfziger Jahre setzten gezielte Werbungen für weitere Massenorganisationen ein. Dadurch sollte das neu gesteckte Ziel eines "hohen gesellschaftlichen, politischen und kulturellen Niveaus" auf dem Lande befördert werden. So sollte die Mitgliedschaft im Deutschen Turn- und Sportbund ${ }^{302}$ vermeintlich anzeigen, daß dieses "Niveau“ stieg.

297 Der Umgang mit dieser Problematik bei Spitzenfunktionären vgl. S. 469.

298 Siehe Tabelle 11.

${ }^{299}$ Kurek, VdgB, S. 186 f.; Dreesen, Bedeutung, S. 18; Buss, Struktur, S. 120 f.

300 ACDP VI-052-0522, Protokoll Sekretariat, 16. 5. 1952, TOP: 1, Ausführungen Rose.

$301 \mathrm{Vgl}$. Tabelle 11 mit Tabelle 7.

$302 \mathrm{Vgl}$. Tabelle 11. 
Bis dahin waren die Dorfeinwohner weder durch Interesse für den Massensport noch durch Bindungen an Sportvereine aufgefallen, sondern gehörten Feuerwehren und anderen Traditionsvereinen an.

Eine Analyse der sozialen Differenzierung innerhalb der landbesitzenden bäuerlichen Mitglieder muß sich - mangels Daten für andere Kriterien - hauptsächlich auf den Bodenbesitz beschränken ${ }^{303}$. Bedingt durch die Zuteilungsgrößen der Parzellen während der Bodenreform lag die landwirtschaftliche Nutzfläche (LNF) bei neubäuerlichen Betrieben in der Regel bei maximal 15 ha; Neubauern bewirtschafteten mehrheitlich jedoch bis zu 10 ha. Das statistische Material der DBD erlaubt keine Aufgliederung des klein- bis mittelbäuerlichen Besitzes bis 15 ha in alt- und neubäuerlich. Dagegen führten fast ausschließlich Altbauern Betriebe ab 15 ha. Aus den Statistiken geht der ausgesprochen klein- und neubäuerliche Zuschnitt der DBD bis 1951 hervor ${ }^{304}$. Insgesamt sank der Anteil der Mitglieder mit bis zu 5 ha zeitweise nur unerheblich unter die Zehn-Prozent-Marge und betrug dann im Juni 1960 wieder rund $11 \%$. Ab diesem Zeitpunkt wurde intern die weitere Untergliederung in Betriebsgrößenklassen aufgegeben, da nach dem offiziellen Abschluß der Vollkollektivierung hier keine Verschiebungen mehr stattfanden. Die Angehörigen dieser Gruppe waren inzwischen fast vollständig Produktionsgenossenschaften beigetreten. Einen Sonderfall in der Betriebsgrößengruppe bis 5 ha bildeten die Gärtnereibetriebe, die zwar unter diese Betriebsgrößenklasse subsumiert wurden, ihrer Wirtschaftskraft nach die kleinbäuerlichen Betriebe jedoch bei weitem übertrafen. Im Dezember 1962 gab es noch 0,3\% „individuell wirtschaftende Bauern“ in der DBD, worunter zu mehr als einem Drittel erfolgreiche Gärtnereibetriebe fielen ${ }^{305}$.

Erst 1952 führte man eine weitere Unterteilung in 10-15 und 15-20 ha LNF ein. Daraus läßt sich ablesen, daß das Gros dieser Klassen aus Betrieben bis 15 ha bestand, demnach zu den unteren Mittelbauern zu rechnen war. Bis 1952 stieg der Anteil von Höfen dieser Kategorie von rund 15\% Mitte 1949 auf knapp unter 20\% und blieb bis Mitte 1960 weitgehend stabil. Der leichte Rückgang Ende 1959 ist sicherlich auf Flucht und Austritte unter den von der DBD enttäuschten Mittelbauern zurückzuführen. Im Juli 1949 stellten die klein- und mittelbäuerlichen Betriebe mit bis zu 20 ha insgesamt 72\% der Mitglieder; ihr Anteil sank wegen der

303 Je nach wirtschaftlicher Struktur des Landbesitzes und der Agrarregion sind für die betriebswirtschaftliche Bewertung eines ldw. Betriebes unterschiedliche Faktoren einschlägig. Neben der nominellen Hektar-Zahl sind solche Faktoren u.a. die Bodenqualität (Bodenwertzahl), Art der Bewirtschaftung, Spezialisierungs- und Intensivierungsgrad der Bewirtschaftung (z. B. Dichte des Viehbesatzes), Arbeitskräfteintensität, Mechanisierungs- und Maschinisierungsgrad. Außerdem läßt sich zwischen Voll- und Nebenerwerbsbetrieben, Alt- und Neubauern unterscheiden. Zwar fehlte Neubauern oft ldw. Berufserfahrung, allerdings gab es auch unter ihnen einen Teil ehemaliger Landarbeiter, etwa jene, die aus den agrarisch geprägten Ostgebieten des Deutschen Reiches stammten und oft Ausbildung und Fachkenntnisse besaßen.

304 Im Dezember 1950 stellten die Neubauern immer noch 36\% der Mitglieder und die Anzahl der Betriebe bis 10 ha lag im Februar 1951 noch bei rund 36\%, siehe Tabelle 9 und 10.

305 ACDP VI-052-186/2, Bericht Abt. Organisation an Sekretariat, 8. 2. 1963. Danach gab es zum 31. 12. 1962 noch 262 individuell wirtschaftende Mitglieder, allein 79 im KV Meißen. 
Zunahme der landlosen Mitglieder auf nur noch 56\% im Dezember 1951, kletterte bis Juni 1955 wieder auf $63 \%$ und erreichte im Juni 1960 65\%. Damit prägte diese Betriebsgrößengruppe die Zusammensetzung der Mitgliedschaft kontinuierlich. Die DBD war überwiegend Partei der kleinen und mittleren agrarischen Eigentümer, solange diese in der DDR existierten ${ }^{306}$.

Der DBD gehörten auch Eigentümer von bäuerlichen Betrieben mit über 20 ha an, die mit der 2. Parteikonferenz der SED offiziell als sogenannte Großbauern klassifiziert wurden. Bis dahin überwog in der DBD ein differenzierteres Verständnis davon, wen man als sogenannten Großbauern faßte und somit politisch diskriminierte. Diese Definition enthielt sowohl harte, rational nachvollziehbare Kriterien, wie die Anzahl der beschäftigten familienfremden Arbeitskräfte, als auch weiche, der Beliebigkeit anheimgestellte Faktoren, wie die „politische Einstellung“. Über letzteres Verfahren konnte jeder Bauer, auch solche unter 20 ha, als "Großbauer" und politischer Gegner stigmatisiert werden. Der Anteil der Bauern unter den Mitgliedern, die über 20 ha besaßen, betrug Mitte 1949 rund 6\%. Erst infolge der Parteiüberprüfungen 1950/51 konnte er bis Ende 1951 auf rund $4 \%$ gedrückt werden. Der signifikante Anstieg des "großbäuerlichen“ Anteils 1952 beruht auf zwei verschiedenen Ursachen: Zum ersten hatte ein Teil dieser Parteiangehörigen bis dahin offensichtlich erfolgreich ihre realen Besitzverhältnisse verschleiert; ein quantitativ nicht näher bestimmbarer Teil an „Großbauern“ rangierte lange Jahre unter der Rubrik „Mittelbauer“ bis 20 ha und führte ein von „Säuberungen “ unbehelligtes Parteidasein ${ }^{307}$. Zum zweiten drängten ab dem Frühjahr 1952 relativ viele "Großbauern" gerade in die DBD. Mitte Juli 1952 machten sie unter den bäuerlichen Mitgliedern - also nicht innerhalb der Gesamtmitgliedschaft - sogar $8 \%$ aus 308 . Offenbar entschieden sich viele aufgrund des rigiden Vorgehens gegen selbständige Bauern zu diesem Schritt, verlieh ihnen doch die Mitgliedschaft in der DBD das Siegel, auf der richtigen politischen Seite zu stehen.

Mitglieder der "großbäuerlichen“ Betriebsgrößenklasse konnten trotz Diffamierung im Gefolge der 2. Parteikonferenz ihre Position bis Juni 1953 bemerkenswert stabil mit immerhin noch 5,2\% der Gesamtmitglieder behaupten ${ }^{309}$ - unter den bäuerlichen Mitgliedern lag ihr Anteil sogar noch bei 6,2\%. Erst nach der Junikrise 1953 wurde ihr Anteil bis Januar 1954 auf 3,8\% aller DBD-Angehörigen $^{310}$ gesenkt. Dabei galt parteiintern die Devise, rückkehrwillige geflüchtete und ausgeschlossene „Großbauern“, entgegen den offiziellen Zugeständnissen des

306 Genossenschaftliches Eigentum wird hier nicht darunter gefaßt, weil die Verfügungsrechte über dieses Eigentum weitgehend eingeschränkt waren.

307 ACDP VI-052-0522, Protokoll Sekretariat, 22. 4. 1952.

308 ACDP VI-052-183/1, Organisationsbericht, 14. 7. 1952.

309 Diese Beobachtung bestätigte die SED-Abteilung Leitende Organe. Sie führte im Januar 1953 aus, daß der Abgang der Klein- und Mittelbauern wesentlich höher liegt als bei den großbäuerlichen Betrieben. Der Zugang von Bauern mit mittelgroßen Landwirtschaften wiege den hohen Abgang der Klein- und Mittelbauern nicht auf. SAPMO DY 30 IV 2/ 15/3, Bericht Abt. LOPM, 23. 1. 1953.

310 Siehe monatliche Organisationsberichte für 1953 und 1954, ACDP VI-052-183/1. 
sogenannten „Neuen Kurses“, möglichst nicht wieder aufzunehmen ${ }^{311}$. Nach 1953 sank der „großbäuerliche“ Mitgliederanteil nur allmählich von 3,3\% im Juni 1955 auf schließlich 2,4\% im Juni 1960. Bis zum Abschluß der Vollkollektivierung gab es demnach einen kleinen, aber stabilen Kern sogenannter Großbauern, der beharrlich in der DBD verblieb.

Frappierend hoch ist der Anteil an LPG-Mitgliedern in der DBD im Juni 1953312. Viele Parteiangehörige, die mit ihren klein- und neubäuerlichen Wirtschaften in finanzielle Engpässe geraten waren und denen es sowohl an Ausstattung als oft auch an Fachwissen fehlte, waren schon zu diesem Zeitpunkt in LPG eingetreten, wenn auch oftmals nicht aus freien Stücken. Offensichtlich schlossen sich DBD-Mitglieder kaum früher als andere Bauern den LPG an. Vor dem Kollektivierungsschub 1959/60 gehörte noch kein Drittel - im Februar 1959 30\% der bäuerlichen Mitglieder - den Produktionsgenossenschaften an. Noch im Dezember 1959 war es insgesamt nur rund die Hälfte, erst zum Juni 1960 betrug ihr Anteil über $95 \%$ der bäuerlichen Mitglieder ${ }^{313}$.

Damit hatte sich die DBD von einer vornehmlichen Eigentümerpartei zu einer Arbeitnehmerpartei gewandelt. In der Phase ungebremsten Wachstums der Partei 1951 stieg der Anteil landloser Arbeitnehmer auf fast 40\%; dies beweist das Werbepotential der DBD bei einer Gruppe, die die SED nicht primär an eine Partei der werktätigen Bauern abzugeben bereit war. Der steigende Prozentsatz von landlosen Mitgliedern resultierte auch aus dem Umstand, daß die „Säuberungen“ 1952 und 1953 hauptsächlich bäuerliche Mitglieder trafen, der Anteil von Mitgliedern ohne Land deshalb in Relation anstieg.

Die DBD war bis 1963 nie eine Partei der jungen Generation. In den Gründungsjahren hatten es Jugendliche besonders schwer sich durchzusetzen. $\mathrm{Zu}$ nächst dominierte die Generation der Altkommunisten; während des Ausgreifens der Partei in altbäuerliche Domänen mußten sich Jugendliche gegen den ländlichtraditionalen Führungsanspruch behaupten. Die Durchsetzungschancen junger, mithelfender Angehöriger von Altbauern blieben sowohl durch traditionelle Regeln beschränkt wie auch besonders seit Anfang 1951 durch eine tiefe Skepsis der Parteiführungsgremien gegenüber altbäuerlichem Nachwuchs, sobald die Hofgröße der Eltern über 15 ha lag314. Die Parteiführung sah sich aufgrund des niedrigen Frauen- und Jugendanteils in den Ortsgruppenvorständen sogar gezwungen, eigens Nachwahlen anzuberaumen, um diese Prozentsätze zu erhöhen ${ }^{315}$. Im

311 ACDP VI-052-0524, Entwurf eines Dokumentes betr: Aufnahmeanträge in unsere Partei [undatiert], dessen Inhalt den Kreissekretären mündlich zu erläutern war, bei Protokoll Sekretariat, 26. 5. 1953, abgelegt.

312 Näher zu den LPG-Bauern in der DBD S. 362.

313 Errechnet aus Gesamtmitgliederzahl Dez. 1962 und ACDP VI-052-186/3, Bericht Abt. Organisation am 8. 2. 1963 an das Sekretariat. Siehe auch Tabelle 24.

314 ACDP VI-052-222/1, Kreisspiegel, undatierter Instrukteurbericht des Landrates zum Kreis Niesky (1951). Vgl. die Straffung der Parteiarbeit 1951, die besonders die Kaderauswahl betreffen sollte, entsprechender Beschluß ACDP VI-052-0520, Beschlüsse Sekretariatssitzung, 30. 12. 1950, Vorlage der Abt. Organisation; dazu auch ACDP VI-052-0521, Beschlüsse Sekretariatssitzung, 2. 4. 1951, datiert auf den 3. 4. 1951: Arbeitsrichtlinien für die Arbeit in den Wahlkörperschaften und der Kommunalpolitischen Abteilung.

315 ACDP VI-052-0521, Protokoll Sekretariat, 10. 4. 1951. 
Juni 1952 machte das Segment der Jugendlichen, hier der 16- bis 25-Jährigen, immerhin fast ein Fünftel (19\%) aus. Bis Februar 1953 kletterte dieser Anteil weiter, danach fielen die relativen Werte.

Bis 1972 liegen weder Statistiken noch verstreute Zahlenangaben zum Anteil der 26- bis 40-Jährigen, der Erwachsenen bis zum Rentenalter und schließlich der Mitglieder im Alter ab 65 vor. Generalsekretär Rose warnte jedoch schon Anfang 1955 im Sekretariat vor der drohenden Überalterung der Partei ${ }^{316}$. Ein Tiefpunkt wurde 1958 mit nur noch 13,4\% Jugendlichen erreicht. Ein Bericht des Sektors Befreundete Organisationen der SED von 1958 klagte jedoch über die erfolgreiche Werbung der DBD unter den Jugendlichen: Die DBD sei seit 1954 sehr um die ländliche Jugend bemüht gewesen. „Mithin ist der Anteil der Jungen in der DBD beachtlich hoch und ... [macht] fast das 3 fache aus wie in der Partei der Arbeiterklasse. “317 Der reale Rückgang von jugendlichen Mitgliedern in der DBD seit 1954 liege auch darin begründet, daß allein zwischen 1956 und 1958 die Mitgliedschaft von 1175 Jugendlichen während ihrer Dienstzeit bei Armee und Volkspolizei ruhe.

Dennoch bleibt festzuhalten, daß der Anteil der Jugendlichen im Laufe der Vollkollektivierung rapide sank und 1961 nur noch ein Zehntel betrug. Nachdem der DBD verboten worden war, unter Schülern und Studenten zu werben, sackte er 1963 auf 4,6\% ab ${ }^{318}$. Die DBD verlor Jugendliche an die SED oder durch Flucht in den Westen. Die relative Überalterung der Partei war zudem eingebettet in den anhaltenden Prozeß der Landflucht in der DDR ${ }^{319}$. Dennoch war die DBD im Juli 1962 im Vergleich die „jugendlichste“ Blockpartei. Während sie 9,6\% Mitglieder bis 25 Jahre zählte, lag dieser Anteil in der CDU bei $4 \%$, in der NDPD bei $3 \%$ und in der LDP sogar bei nur $2 \%{ }^{320}$. Bis zur Machtübernahme Honeckers 1971 waren Jugendliche in der DBD mit einem Anteil unter $2 \%$ marginalisiert. Erst ab 1972 stieg die Quote wieder an, erreichte jedoch bis 1982 nur 6,5\%.

316 ACDP VI-052-0529, Protokoll Sekretariat, 5. 2. 1955.

317 SAPMO DY 30 IV 2/15/53, Bericht „Über die Entwicklung und Lage in der Demokratischen Bauernpartei Deutschlands. (Zeitraum 1954-1958)“, 3. 5. 1958. Ebensolches notierte der Sektor BO in Suhl, SAPMO DY 30 IV 2/15/11, Bericht der SED über Entwicklung des BV Suhl der DBD 1954, Februar 1955.

318 SAPMO DY 30 IV 2/15/3, Zusammenstellung Sektor BO, 28. 7. 1962.

319 Statistisches Bundesamt, Sonderreihe, Heft 3, Bevölkerungsstatistische Übersichten 1946 bis 1989, S. 32-35, Bevölkerung nach Gemeindegrößenklassen, ein Anstieg in den GröBenklassen von ab 10000 Einwohner zeichnet sich allerdings erst von $1959 \mathrm{an}$ ab.

320 SAPMO DY 30 IV 2/15/3, Zusammenstellung Sektor BO, 28. 7. 1962. 